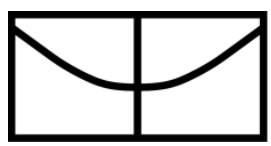

Universidade de Brasília

Instituto de Psicologia

Departamento de Psicologia Social e do Trabalho

Programa de Pós-graduação em Psicologia Social, do Trabalho e das Organizações

Sobrequalificação e Atitudes no Trabalho entre Servidores Públicos

João Moreira Gonçalves Neto

Brasília-DF

Março de 2017 
Sobrequalificação e Atitudes no Trabalho entre Servidores Públicos

João Moreira Gonçalves Neto

Dissertação de mestrado apresentada ao Programa de Pós-graduação em Psicologia Social, do Trabalho e das Organizações, da Universidade de Brasília (PSTO/UnB), como requisito parcial para obtenção do título de Mestre em Psicologia Social, do Trabalho e das Organizações.

Orientador: Jairo Eduardo Borges-Andrade

Brasília-DF

Março de 2017 


\title{
Sobrequalificação e Atitudes no Trabalho entre Servidores Públicos
}

\author{
João Moreira Gonçalves Neto
}

Dissertação de mestrado apresentada ao Programa de Pós-graduação em Psicologia Social, do Trabalho e das Organizações, da Universidade de Brasília (PSTO/UnB), como requisito parcial para obtenção do título de Mestre em Psicologia Social, do Trabalho e das Organizações.

\section{Banca examinadora}

Prof. Dr. Jairo Eduardo Borges-Andrade - Presidente

Universidade de Brasília (UnB)

Prof. ${ }^{a}$ Dr. ${ }^{a}$ Luciana Mourão Cerqueira e Silva - $1^{\circ}$ Membro

Universidade Salgado de Oliveira (UNIVERSO)

Prof. Dr. Mario César Ferreira - $2^{\circ}$ Membro

Universidade de Brasília (UnB)

Prof. ${ }^{a}$ Dr. ${ }^{a}$ Gardenia da Silva Abbad - Membro Suplente

Universidade de Brasília (UnB) 
À minha família, pelo suporte que me deram e continuam dando para que eu possa viver aventuras como esta...

Ao Professor Jairo, por ter me aceitado como orientando, dando-me a chance de cursar este mestrado...

À Professora Hilma Khoury, maior incentivadora de meu envolvimento em pesquisa científica...

A Victoria Mutran, Pedro Moreira, Naomi Shibata, Deyvison Talmo, Oscar De La Torre e Deniz Comez, que gastaram um pouco de seu tempo ajudando-me a preparar o principal instrumento utilizado neste trabalho...

Aos participantes, que dividiram comigo um pouco das suas percepções do trabalho, tornando possível esta pesquisa...

Minha sincera gratidão! 
[...] Ohne Arbeit wär das Leben öde, also sing ich müde meine kleine Ode an die Arbeit [...].

(Ode) An die Arbeit (Wir Sind Helden) 


\section{Resumo}

Sobrequalificação é a condição (objetiva ou percebida) na qual um trabalhador possui qualificação maior que a necessária ou exigida por seu cargo. Nesta dissertação foi apresentada a teoria da sobrequalificação (definição, constituição, teorias explicativas, classificações, mensuração e principais achados de pesquisa). Em seguida, foi verificado se no serviço público a sobrequalificação (objetiva e percebida) se relacionaria a atitudes no trabalho. Participaram 372 servidores públicos, respondendo a escalas de sobrequalificação percebida, comprometimento afetivo e calculativo, envolvimento com o trabalho, intenção de saída e um questionário sociodemográfico. Os escores médios foram comparados entre grupos de sobrequalificados e não-sobrequalificados objetivamente. Também foi testado um modelo das relações entre as variáveis investigadas, por meio de modelagem de equações estruturais. Encontrou-se a sobrequalificação percebida relacionada positivamente à objetiva e negativamente aos comprometimentos afetivo e calculativo. Discutiu-se que a sobrequalificação no serviço público não é algo a ser evitado, mas gerenciado.

Palavras-chaves: sobrequalificação; subemprego; atitudes no trabalho; serviço público. 


\begin{abstract}
Overqualification is the (objective or perceived) condition in which a worker has more qualifications than required by his/her job. In this master thesis the theory of overqualification (definition, constitution, explanatory theories, classifications, measurement, and main research results) was introduced. After that, it was verified whether in the public service the (objective and perceived) overqualification would relate to job attitudes. Three hundred seventy-two public servants participated, by answering scales of perceived overqualification, affective and continuance commitment, turnover intention, and sociodemographic questionnaire. Mean scores were compared among objectively overqualified and non-overqualified groups. A model about relations among investigated variables was also tested, by means of structural equation modeling. Perceived overqualification was found related positively to objective overqualification and negatively to affective and continuance commitments. It was discussed that overqualification in public service is not something to be avoided, but managed.
\end{abstract}

Keywords: overqualification; underemployment; job attitudes; public service. 


\section{Sumário}

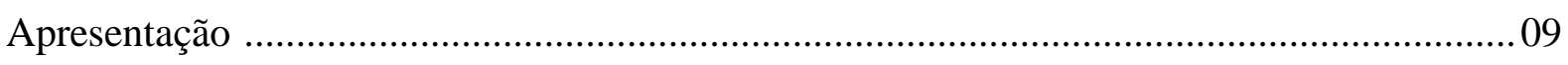

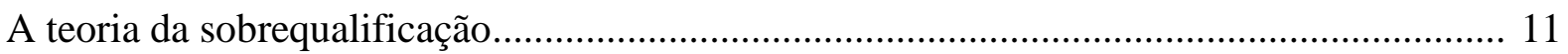

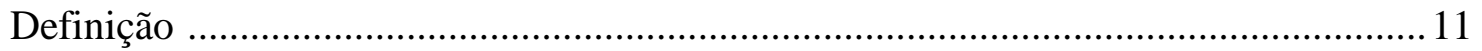

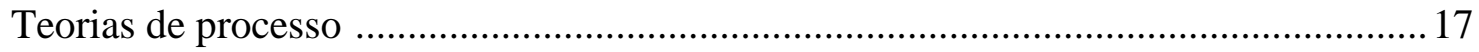

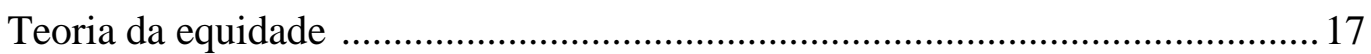

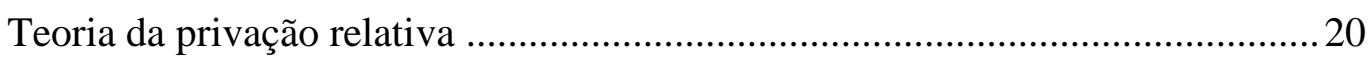

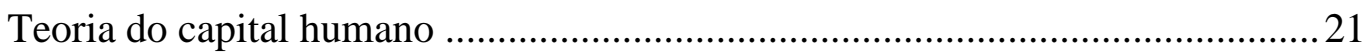

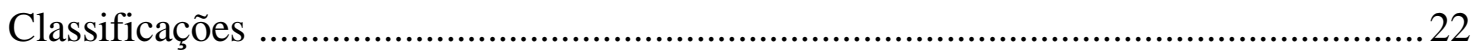

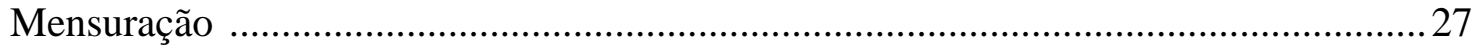

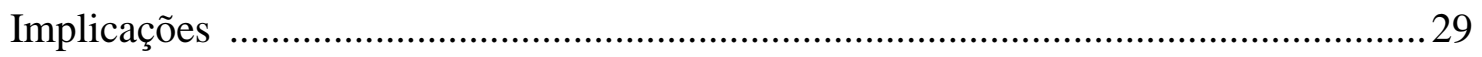

Revisão sistemática das pesquisas com amostras internacionais ................................33

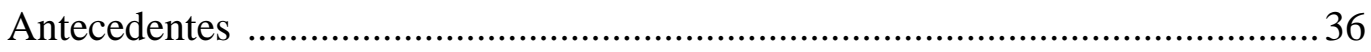

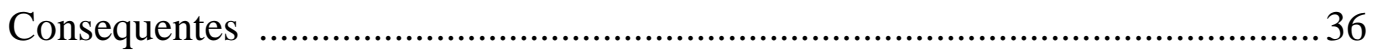

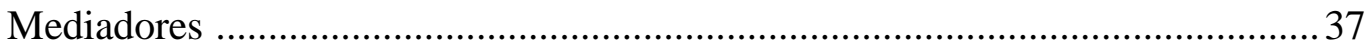

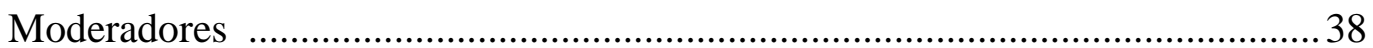

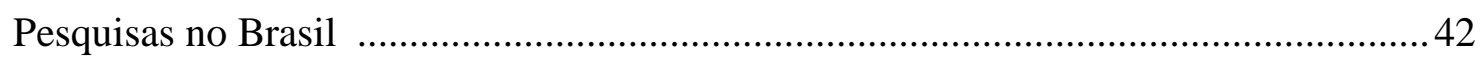

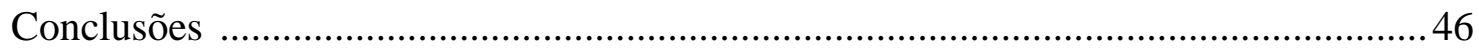

A sobrequalificação no serviço público ......................................................................... 49

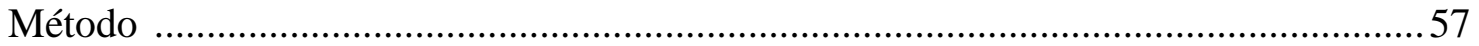

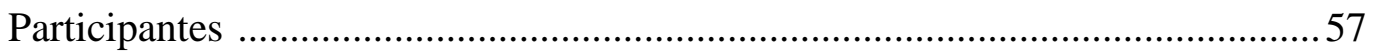

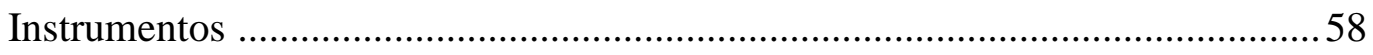

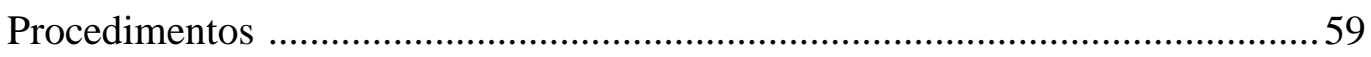

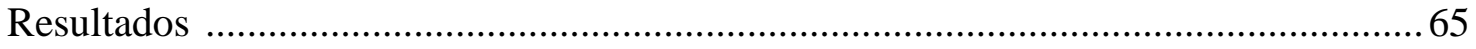




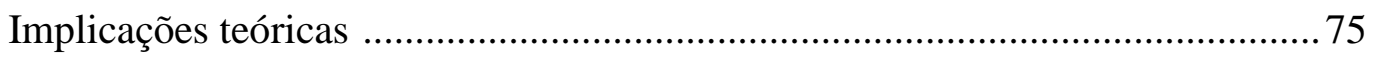

Limitações e sugestões para novos estudos ................................................... 77

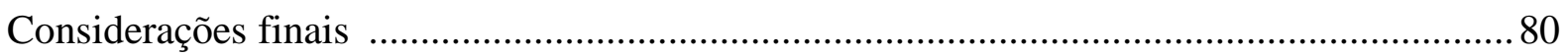

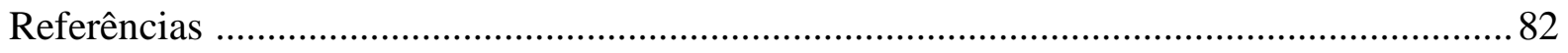

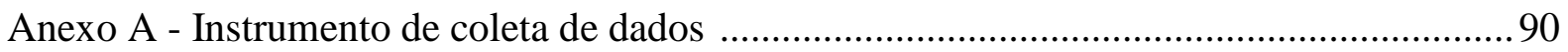

Anexo B - Comparação entre cargos públicos e famílias de ocupações da CBO ...................94

Anexo C - Matriz de variância-covariância da amostra ....................................................... 99

Anexo D - Tamanho da amostra por pares de variáveis ................................................ 101

Anexo E - Estatísticas descritivas das variáveis observáveis ........................................... 102

Anexo F - Matriz de variância-covariância do modelo ........................................................ 103

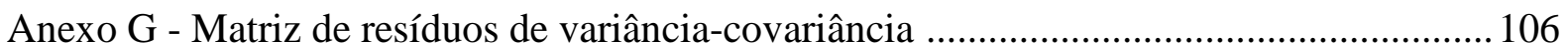

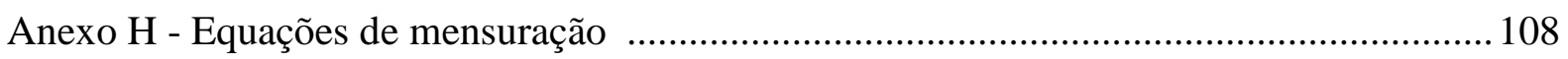

Anexo I - Equações estruturais do modelo estimado ...................................................... 109

Anexo J - Efeito total com valores dos parâmetros não-padronizados .................................. 110

Anexo K - Efeito total com valores dos parâmetros padronizados ...................................... 113

Anexo L - Efeito indireto com valores dos parâmetros não-padronizados ............................114

Anexo M - Efeito indireto com valores dos parâmetros padronizados ................................ 116

Anexo N - Solução padronizada para variáveis observáveis e latentes ...............................117 


\section{Apresentação}

Os avanços tecnológicos e a competição global por mercados têm exigido das organizações uma busca constante por atualização, nas últimas décadas, de modo a produzir mais, prestar mais serviços e com mais qualidade. As organizações repassaram tal tarefa para seus membros e potenciais membros, dando-lhes a responsabilidade de adquirir novas competências, no que foi denominado de empregabilidade.

Os sistemas de ensino ao redor do globo têm oferecido um leque enorme de opções para que as pessoas adquiram novas competências, a fim de se manterem qualificadas para satisfazer as necessidades organizacionais de atualização, ao menos até que novas necessidades surjam. Embora se saiba que as organizações necessitam estar atualizadas e que as pessoas necessitam estar qualificadas, há que saber: quais competências as pessoas devem adquirir hoje, a fim de oferecê-las quando as organizações precisarem? Quais novas competências as organizações necessitarão no futuro? Na Era da Informação o obstáculo não é a falta, mas o excesso de informações.

A ênfase no discurso da empregabilidade deixa implícita uma relação na qual, quanto mais qualificado o indivíduo for, maiores e melhores as recompensas organizacionais (como o crescimento na carreira). Mas, isso não é sempre verdadeiro. Há casos nos quais o indivíduo investe em qualificações que, provavelmente, nunca serão demandadas por sua organização ou o serão por pouco tempo, até serem substituídas por outras. Quando o indivíduo não vê retribuição ao seu investimento em qualificação, são estabelecidas as condições para a ocorrência do fenômeno chamado sobrequalificação. À ocorrência desse fenômeno têm sido atribuídas consequências negativas para o indivíduo e para a organização. Dentre essas consequências, destacam-se as atitudes negativas no trabalho.

No caso do serviço público, não é a busca por empregabilidade, mas a disputa acirrada 
por aprovação em concursos públicos que leva os indivíduos a investirem em qualificação, como obtenção de uma formação e preparação para realizar provas. Da mesma forma que o candidato à vaga no setor privado, a pessoa aprovada em concurso público ocupará um cargo que poderá não necessitar da qualificação que, para ser aprovada no concurso, precisou adquirir. Quais seriam as consequências disso?

Os objetivos deste estudo foram (1) apresentar a teoria da sobrequalificação e (2) investigar as possíveis relações entre sobrequalificação e atitudes no trabalho de servidores públicos. Para isso, o texto se dividiu em duas partes principais: uma revisão da literatura, integrando boa parte do conhecimento acumulado acerca da sobrequalificação em torno de uma teoria; e um estudo empírico, realizado com servidores públicos, a fim de investigar possíveis consequências negativas da sobrequalificação sobre as atitudes no trabalho no setor público. Apesar de realizado no contexto do serviço público, os resultados deste estudo têm implicações que o extrapolam e oferecem contribuições relevantes para o conhecimento na área. 


\section{A Teoria da Sobrequalificação}

O conceito de sobrequalificação é de certo modo intuitivo. Transmite rapidamente a ideia de uma situação na qual um trabalhador possui mais qualificação do que a necessária ou exigida em seu trabalho. Entretanto, é fundamental especificar o que se entende por qualificação ou o que vem a ser qualificação necessária para o trabalho e a relação entre elas. Dela advém os conceitos de sobre e sub-qualificação. Este último não é objeto de interesse na presente dissertação. É indispensável descrever o meio pelo qual a qualificação do indivíduo e a qualificação necessária/exigida em um trabalho poderiam ser mensuradas, já que a diferença entre ambas pressupõe uma relação quantitativa.

A sobrequalificação tem sido frequentemente confundida com subemprego e sobreeducação. A sobrequalificação tem sido descrita tanto como um tipo de subemprego (Liu, Luksyte, Zhou, Shi, \& Wang, 2015), quanto como parte dele (Fine \& Nevo, 2008) ou mesmo seu sinônimo (Johnson, Morrow, \& Johnson, 2002). Isso dificulta a interpretação e integração dos resultados das pesquisas (Liu \& Wang, 2012).

O objetivo desta primeira parte foi apresentar a teoria da sobrequalificação, sua definição, classificações, mensuração e implicações para indivíduos e organizações, bem como os principais achados das pesquisas acerca desse fenômeno. Para tal, foram tomados como base os trabalhos de Johnson et al. (2002) e de Maynard, Joseph e Maynard (2006), os quais se concentraram especificamente no estudo da sobrequalificação, definindo-a e desenvolvendo instrumentos para mensurá-la.

\section{Definição}

Sobrequalificação foi definida como a condição na qual um trabalhador supera a 
qualificação exigida para seu cargo ou tem oportunidades limitadas para adquirir ou utilizar novas habilidades relacionadas ao seu cargo (Johnson et al., 2002). Nessa definiçãa, a sobrequalificação é descrita como constituída por duas dimensões: incompatibilidade, que se referiria à qualificação maior que a exigida para o cargo; e não-crescimento, que se referiria à ausência de oportunidades para aquisição e uso de novas habilidades. A qualificação foi considerada como constituída por educação formal, experiência e habilidades profissionais. Essa definição se baseou nas dimensões do subemprego propostas por Feldman (1996). A sobrequalificação seria ainda sinônimo de subemprego (Johnson et al., 2002).

O subemprego tem sido basicamente estudado conforme duas abordagens, as econômicas e as comportamentais (Maynard \& Feldman, 2011), embora em ambas não haja consenso quanto a sua definição (Luksyte \& Spitzmueller, 2011). As econômicas são caracterizadas por analisar o nível macro, o mercado de trabalho, buscando compreender seu funcionamento e estimar o retorno (em termos de emprego e renda) do investimento em educação. São estudos geralmente descritivos baseados em dados secundários, provenientes de bancos de dados estatísticos de amostras nacionais e principalmente mantidos por órgãos governamentais (Wilkins \& Wooden, 2011). Por outro lado, as comportamentais investigam o nível micro (a relação entre indivíduo e organização), a fim de explicar teoricamente as causas e consequências do subemprego, para indivíduo e organização, principalmente analisando dados primários obtidos por meio de medidas de auto-relato (Luksyte \& Spitzmueller, 2011).

Nas abordagens econômicas, subemprego pode ser definido como uma condição de emprego contrária ao desejo e disponibilidade do indivíduo, bem como limitadora do uso de todo o seu potencial de trabalho (Wilkins \& Wooden, 2011). Assim, subemprego corresponderia, por exemplo, às situações nas quais: o indivíduo deseja um emprego de tempo integral, mas tem um emprego de meio período ou vice-versa; ganha salário inferior ao 
que poderia ganhar por sua qualificação; ou obtém nível de escolaridade superior, mas tem de aceitar emprego de nível de escolaridade médio.

Para as abordagens comportamentais, o subemprego pode ser definido como um tipo de incongruência entre características do indivíduo e do emprego (Luksyte \& Spitzmueller, 2011). Com base nessa definição, o subemprego ocorreria, por exemplo, quando o indivíduo possui mais habilidades ou maior nível de educação formal do que seria necessário para seu trabalho. Pode-se supor que as abordagens econômicas consideram o subemprego uma variável dicotômica e utilizam o desejo e disponibilidade do indivíduo como critério de definição, enquanto as abordagens comportamentais o consideram uma variável contínua e se baseiam na relação entre indivíduo e cargo para defini-la.

Uma das tentativas de integrar as abordagens econômicas e comportamentais, pretendendo organizar a teoria acerca do subemprego, foi empreendida por Feldman (1996). O subemprego seria caracterizado pela qualidade inferior de um emprego com relação a algum padrão de comparação. Cinco padrões referentes ao indivíduo foram propostos: seu nível de educação formal; suas habilidades e experiência profissional; sua área de formação profissional; o regime de trabalho que deseja; e a remuneração correspondente a sua qualificação profissional.

Da comparação do emprego aos padrões propostos, o subemprego seria constituído por cinco dimensões: maior educação formal do que a exigida pelo cargo; mais habilidades e mais experiência de trabalho do que as exigidas pelo cargo; aceitação involuntária (isto é, na ausência de opções melhores ou desejadas) de emprego em área diferente daquela para a qual recebeu formação; aceitação involuntária de emprego temporário, de meio-período ou sazonal; remuneração menor ou sub-remuneração (cerca de $20 \%$ ou mais) do que aquela recebida em empregos anteriores ou menor do que a de outros indivíduos com mesma formação (Feldman, 1996). 
A primeira e a segunda dimensões do modelo de subemprego de Feldman (1996) foram respectivamente denominadas sobre-educação e subutilização de habilidades/sobreexperiência (Fine \& Nevo, 2008). Seguindo essa terminologia, a terceira e quarta dimensões poderiam ser denominadas subatuação e sub-vinculação, respectivamente.

O modelo de subemprego proposto por Feldman (1996) também foi utilizado por Maynard et al. (2006). Mas a definição de sobrequalificação desses autores diferiu daquela de Johnson et al. (2002) em dois pontos. Em primeiro lugar, apenas a dimensão incompatibilidade seria constituinte da sobrequalificação, sendo ela a própria sobrequalificação. Em segundo lugar, a sobrequalificação seria um dos elementos constituintes do subemprego e não seu equivalente ou sinônimo. Assim, sobrequalificação foi definida como a condição na qual um trabalhador possui mais educação formal e mais habilidades e experiência profissional do que seu cargo exige (Maynard et al., 2006). Além de constituinte do subemprego, cada dimensão do subemprego seria um caso de incongruência pessoa-trabalho, segundos estes autores.

O modelo da congruência pessoa-trabalho foi descrito como relacionado ao ajustamento, equivalência, contingência ou influência conjunta entre indivíduo e trabalho, e a como isso interagiria com resultados individuais e organizacionais (Edwards, 1991). Para este autor, a congruência pessoa-trabalho pressupõe duas díades da relação entre indivíduo e trabalho: desejos-suprimentos e demandas-aptidões. A primeira díade, necessidadessuprimentos, seria constituída por: desejos do indivíduo, como necessidades psicológicas, metas, valores, interesses e preferências; e suprimentos disponibilizados pelo trabalho para satisfazer os desejos do indivíduo, que iriam desde características do trabalho a atributos específicos do cargo e da organização, como remuneração, participação nas decisões, clareza de papéis e enriquecimento de tarefas. A congruência necessidades-suprimentos seria preditora de satisfação no trabalho, estresse no trabalho, escolha profissional e motivação. 
A segunda díade, demandas-aptidões, seria composta por: demandas do trabalho, como carga de trabalho e requisitos para desempenho adequado; e aptidões do indivíduo, como atitudes, experiência e educação formal. A congruência demandas-aptidões seria preditora de desempenho e retenção e promoção. A sobrequalificação seria um tipo incongruência demandas-aptidões, para Maynard et al. (2006).

O modelo de congruência pessoa-trabalho seria um componente do modelo da congruência pessoa-ambiente, o qual incluiria a congruência entre indivíduo e vários elementos do ambiente organizacional, como grupo de trabalho, supervisor e organização (Kristof-Brown, Zimmerman, \& Johnson, 2005). A congruência pessoa-organização descrita por Kristof (1996) era semelhante ao modelo de congruência pessoa-trabalho apresentado por Edwards (1991), pelo fato de ambos utilizarem as mesmas díades (necessidades-suprimentos e demandas-aptidões).

Entretanto, Kristof (1996) diferenciou dois tipos de congruência: a suplementar, quando as características do indivíduo fossem similares às da organização e de seus demais membros; e a complementar, quando as características do indivíduo fossem diferentes, porém preenchessem lacunas na organização, somando-se às características desta e de seus demais integrantes. Assim, a perfeita congruência pessoa-organização se daria quando indivíduo e organização compartilhassem características fundamentais similares - congruência suplementar - e suprissem às necessidades um do outro - congruência complementar (Kristof, 1996).

A estrutura de um construto psicológico, isto é, sua definição constitutiva, é composta por três elementos: objetos, atributos e dimensões (Pasquali, 2010). Objeto é o foco de estudo, aquilo que se deseja investigar. Entretanto, objetos não podem ser mensurados; o que se mensura são os atributos, as características, dos objetos. Os atributos dos objetos podem ainda possuir mais de uma dimensão constituinte. 
Com base no modelo de subemprego (Feldman, 1996) e na teoria da congruência pessoa-trabalho (Edwards, 1991; Kristof, 1996), pode-se dizer que, constitutivamente, a sobrequalificação seria um dos atributos do subemprego e, em contrapartida, o subemprego seria o objeto da sobrequalificação. A sobrequalificação seria a incongruência entre características do indivíduo e características do cargo (Maynard et al., 2006), sendo constituída por três dimensões: maior educação formal do que a exigida pelo cargo (ou sobreeducação); mais habilidades do que as exigidas pelo cargo; e mais experiência profissional do que a exigida pelo cargo. Isso esclareceria a relação entre subemprego (objeto da sobrequalificação), sobrequalificação (atributo do subemprego) e sobre-educação (uma das dimensões da sobrequalificação). Finalmente, a sobrequalificação seria definida como a condição na qual o indivíduo possui qualificações (educação formal, habilidades e experiência profissional) maiores do que as exigidas por seu cargo.

Ainda que as dimensões da sobrequalificação, conforme o modelo aqui apresentado, se fundamentem no modelo de subemprego (Feldman, 1996), outras dimensões poderiam ser consideradas. Por exemplo, sobrequalificação foi definida como relacionada a conhecimentos, habilidades, aptidões e outras características necessárias (Lobene \& Meade, 2010). Essa definição permite incluir, como dimensões da sobrequalificação, outras características do indivíduo relacionadas à qualificação para o cargo, desde que relacionadas à congruência demandas-aptidões.

Dentre as possíveis dimensões não incluídas no modelo de subemprego de Feldman (1996) estão as aptidões cognitivas. Os indivíduos comparariam suas aptidões cognitivas (nível de inteligência, por exemplo) àquelas necessárias para o cargo, cuja incongruência resultante foi denominada sobrequalificação cognitiva percebida (Fine \& Nevo, 2008). Deste modo, além de educação formal, habilidades e experiência profissional, seria possível considerar as aptidões cognitivas como uma das dimensões da sobrequalificação. Nesse 
sentido, as aptidões cognitivas seriam a melhor medida de sobrequalificação objetiva, pois são características individuais estáveis para as quais existem instrumentos padronizados de mensuração, permitem comparação entre indivíduos, são preditoras de desempenho e independem do tipo de trabalho ou organização (Maltarich, Reilly, \& Nyberg, 2011).

\section{Teorias de processo}

O modelo de subemprego de Feldman (1996) e a congruência pessoa-trabalho de Edwards (1991) e Kristof (1996) são teorias estruturais da sobrequalificação. Propõem a definição constitutiva de sobrequalificação em termos dos elementos de um constructo psicológico mencionados por Pasquali (2010). Porém, não descrevem ou sugerem o processo por meio do qual a sobrequalificação e seus efeitos ocorrem. As principais teorias de processo, encontradas na literatura, são: a teoria da equidade (Adams, 1963); a teoria da privação relativa (Crosby, 1976); e a teoria do capital humano (Becker, 1994).

Teoria da equidade. A teoria da equidade é um caso de dissonância cognitiva, relacionada ao equilíbrio (de caráter psicológico e não necessariamente econômico) entre as contribuições do indivíduo e as recompensas organizacionais (Adams, 1963). Por contribuições do indivíduo, entendam-se atributos como: educação formal, inteligência, experiência, treinamento, habilidades, idade, sexo, bagagem étnica, status social e esforço. Por recompensas organizacionais, entendam-se retribuições como: pagamento, recompensas intrínsecas ao trabalho, benefícios por tempo de permanência na organização, status do trabalho, símbolos de status, etc. Destaque-se que a recompensa precisa possuir sentido psicológico ou utilidade para o indivíduo.

Contribuições e recompensas estão imperfeitamente relacionadas (Adams, 1963). Isso porque as expectativas normatizadas do indivíduo acerca dessa relação não se baseariam na 
realidade objetiva, mas em sua percepção dessa relação para outro indivíduo (familiar, amigo, colega de trabalho, vizinho, etc.) ou grupo de referência (grupo de trabalho, categoria profissional, área de atuação, setor de atuação, etc.). A referência do indivíduo poderia ainda ser ele mesmo, no passado (em um emprego anterior) ou no futuro (em um emprego desejado).

A expectativa normatizada prediz para o indivíduo quais contribuições espera oferecer à organização e em que quantidade, assim como quais recompensas espera receber da organização e em que quantidade. A percepção de injustiça ocorreria quando o sujeito percebe a violação de suas expectativas normatizadas, isto é, um desequilíbrio ou incongruência entre suas contribuições e as recompensas organizacionais.

Tanto as contribuições do indivíduo quanto as recompensas organizacionais teriam, como características, existência reconhecida e relevância. A existência do atributo deve ser reconhecida por indivíduo e organização para que este seja considerado uma contribuição (Adams, 1963). Se o indivíduo considera determinado atributo como contribuição, mas a organização não reconhece sua existência, ela não o recompensa e o indivíduo pode perceber injustiça. Se a organização oferece uma recompensa, cuja existência não é reconhecida pelo indivíduo, este perceberá sua contribuição não retribuída, podendo também levar à percepção de injustiça.

Um atributo também deve ser considerado relevante para ambos na relação de troca para ser uma contribuição (Adams, 1963). Por exemplo, se o indivíduo percebe o atributo como relevante para a relação de troca com a organização, então ele é uma contribuição, pela qual o indivíduo espera uma recompensa. Mas, se a organização não percebe o atributo como relevante para a relação de troca, então não é uma colaboração e, consequentemente, não o retribui, o que gera a percepção de injustiça. Se a retribuição oferecida pela organização não é relevante para o indivíduo, então não é uma recompensa; logo, o indivíduo perceberá 
injustiça por não ter sua contribuição recompensada.

A percepção de injustiça teria dois efeitos principais: geraria tensão no indivíduo que percebe a injustiça; e essa tensão o motivaria a tentar reduzir a injustiça percebida. Se o indivíduo percebe que suas recompensas são menores do que as do indivíduo ou grupo de referência, ele pode aumentar suas contribuições (aumentar seu esforço, adquirir mais conhecimentos e habilidades, aumentar seu nível de educação formal, etc.), a fim de obter as mesmas recompensas do indivíduo ou grupo de referência (que são maiores que as que ele recebe). O sujeito pode também reduzir suas contribuições, a fim de igualá-las às do indivíduo ou grupo de referência, caso recebam as mesmas recompensas que ele, mas por menor contribuição.

Assim, o esforço é a principal contribuição que o sujeito pode reduzir, pois nível de educação formal, experiência, habilidades, por exemplo, não podem ser reduzidas. Quando o indivíduo atribui a injustiça às suas colaborações, consideradas maiores que as recompensas recebidas, a principal consequência é o indivíduo reduzir seu esforço (produtividade, empenho, dedicação, etc.) no trabalho.

Outros meios, por meio dos quais o indivíduo tentaria reduzir a injustiça percebida seriam: abandonar o emprego, trocá-lo por outro ou faltar ao trabalho com frequência, chegar atrasado, etc. (absenteísmo); distorcer psicologicamente o valor de suas contribuições ou recompensas, aumentando ou diminuindo-as; distorcer as contribuições ou recompensas do indivíduo ou grupo de referência, por exemplo, convencendo-os a reduzir suas contribuições; ou mudar seu referencial. Em todo o caso, o modo como o indivíduo lida com a injustiça dependeria dos tipos de contribuições e recompensas, do contexto de trabalho, da organização ou do mercado, das características de personalidade, etc. (Adams, 1963).

Com base na teoria da equidade, a sobrequalificação seria um tipo de injustiça percebida pelo indivíduo entre suas contribuições oferecidas à organização - educação 
formal, conhecimentos e habilidades - e as recompensas organizacionais recebidas oportunidades para utilizar suas qualificações (Liu \& Wang, 2012). A injustiça surgiria quando o indivíduo compara a relação contribuições-recompensas, em vigor para ele, à relação contribuições-recompensas que ocorre para outros indivíduos (da mesma organização ou de outras).

A sobrequalificação surgiria quando a organização não reconhecesse nem considerasse relevantes determinadas qualificações do indivíduo (as quais ele reconhecesse e considerasse relevantes), não lhe dando oportunidades para utilizá-las em seu trabalho, levando-o à percepção de sobrequalificação (Liu \& Wang, 2012). Desse modo, essas qualificações não seriam consideradas como contribuições e, consequentemente, não seriam recompensadas, motivando o indivíduo a buscar o equilíbrio contribuições-recompensas. Isso levaria às consequências negativas da sobrequalificação, como, por exemplo, a redução do desempenho no trabalho, a fim que equipara-lo às recompensas recebidas.

Teoria da privação relativa. Em sentido amplo, privação relativa seria a situação na qual o indivíduo, ao se comparar a algum padrão de referência, sente-se privado de algo que o padrão de referência possui e ele não (Crosby, 1976). Além desse sentido, privação relativa seria a sensação ou sentimento de injustiça (agravo ou ressentimento) por não possuir algo que, por comparação ao padrão de referência, julga que deveria possuir. A privação relativa não é causada exclusivamente pela comparação a um padrão de referência, mas não ocorre sem essa comparação. A situação ou o sentimento de privação relativa não depende de uma condição real de injustiça, mas da percepção de tal condição, sendo um fenômeno subjetivo.

Os fatores determinantes da privação relativa, segundo Crosby (1976), seriam: traços de personalidade, história pessoal, ambiente imediato, normas sociais e necessidades biológicas. Inicialmente, para que a privação relativa ocorra seria necessário que a coisa desejada exista ou que o indivíduo acredite em sua existência. Assegurada a existência da 
coisa desejada, haveria cinco condições determinantes: o indivíduo precisa perceber que o padrão de referência (outro indivíduo ou grupo semelhantes a ele) possui a coisa desejada; o indivíduo precisa querer a coisa desejada; o indivíduo precisa se sentir merecedor de possuir a coisa desejada; o indivíduo precisa achar possível obter a coisa desejada; e o indivíduo não pode se sentir responsável por não possuir a coisa desejada.

As consequências da privação relativa dependeriam de variáveis mediadoras, como nível de controle pessoal do indivíduo e oportunidades para obtenção da coisa desejada. Essas consequências poderiam ser positivas, como auto-aperfeiçoamento do indivíduo, ou negativas, como estresse e violência. À medida que o tempo passa e o indivíduo não obtém a coisa desejada, seria possível que atribuísse essa não obtenção a si próprio, de modo que a privação relativa (condição e sensação) diminuiria até extinguir-se (Crosby, 1976).

Na sobrequalificação percebida, o indivíduo compararia seu emprego atual a um emprego por ele desejado ou preferido, estabelecido a partir da comparação entre seu emprego atual e um padrão de referência (emprego anterior, emprego de um familiar, amigo, colega de trabalho, etc.) (Liu \& Wang, 2012; Luksyte \& Spitzmueller, 2011). O indivíduo se perceberia privado de um emprego que um outro ou outros possuem e que ele deseja, sente-se merecedor de possuir, acha possível conseguir e não se culpa por ainda não possuí-lo. Essa incongruência entre o emprego atual e o desejado geraria frustração no indivíduo, a qual levaria às atitudes negativas no trabalho (Erdogan \& Bauer, 2009).

Teoria do capital humano. O sentido geral do termo capital se refere a algo que, aplicado ou investido em determinado contexto, gera lucro ou produtos úteis após certo período de tempo. Capital humano seria um tipo de capital caracterizado por ser inseparável do indivíduo que o possuí e cujo retorno do investimento nele seria e também não-monetário (Becker, 1994), sendo portanto algo que o indivíduo possui (e não algo que ele é). Por exemplo, a qualificação adquirida via educação formal seria um tipo de capital, pois geraria 
aumento de renda (quando investida no trabalho) ao indivíduo. Nesse sentido, despesas educacionais seriam investimentos em capital, pois produziriam conhecimento. Educação formal e treinamento (por meio dos quais se obtém conhecimentos, habilidades e métodos para resolução de problemas) seriam os mais importantes investimentos em capital humano, além da aquisição de experiência profissional (por meio da aprendizagem no ambiente de trabalho), cujos retornos esperados seriam maior renda para o indivíduo no futuro, segundo esse autor.

Para a teoria do capital humano, o indivíduo investiria em qualificação profissional (capital humano), na forma de educação formal, conhecimentos, habilidades e experiência, para obter maiores salário e perspectivas de carreira, segundo Luksyte e Spitzmueller (2011). Entretanto, a teoria do capital humano não explica o que ocorre quando o capital humano investido é superior ao retorno esperado, argumentaram esses dois autores. Ainda assim, ela explica o motivo da busca dos indivíduos por maior qualificação profissional, permitindo estabelecer seu objetivo. A partir da teoria do capital humano, é possível descrever a sobrequalificação percebida como a condição na qual o investimento do indivíduo é maior do que o retorno recebido ou o retorno recebido é menor do que o esperado.

Os fundamentos dessas três teorias são provavelmente construções sociais que variam entre indivíduos, grupos e culturas. Portanto, achados que as sustentem como explicativas da sobrequalificação precisam ser verificados, sob condições diversas relativas a crenças e valores a respeito do trabalho e dos vínculos que os indivíduos estabelecem com este e com as organizações com as quais estabelecem contratos (de natureza objetiva ou subjetiva).

\section{Classificações}

Existiriam dois tipos de subemprego, segundo Khan e Morrow (1991): um objetivo, 
quando, por exemplo, a educação formal do indivíduo é superior à exigida para o exercício do cargo; e um subjetivo ou percebido, quando o indivíduo sente ou percebe que suas aptidões não são completamente utilizadas no exercício de seu cargo. Isso indica a existência de dois tipos de sobrequalificação: uma objetiva, observada por meio de documentos e registros acerca da qualificação do indivíduo e da descrição do cargo; e uma percebida (ou subjetiva), observada por meio da percepção do ocupante do cargo. A diferenciação entre as sobrequalificações objetiva e percebida seria importante devido ao fato de que o indivíduo com qualificação compatível ao seu cargo poderia se perceber sobrequalificado, enquanto um indivíduo com qualificação superior aos requisitos de seu cargo poderia se perceber compatível a ele (Maynard et al., 2006).

As pesquisas têm dado maior ênfase à sobrequalificação percebida, sob a justificativa de que, se a incongruência é percebida pelo indivíduo, então ela existe, influenciando suas avaliações cognitivas e comportamento, independentemente da existência ou não de incongruência real (Johnson et al., 2002; Kristof, 1996). Atualmente, sugere-se que ambas as sobrequalificações deveriam ser consideradas, pois é provável que a sobrequalificação objetiva leve à percebida (Maltarich et al., 2011).

As sobrequalificações objetiva e percebida estão intimamente relacionadas ao cargo. Cargo pode ser definido como um conjunto de tarefas pré-determinadas, realizadas por meio de um conjunto de ações (Dul \& Weerdmeester, 2008), e os requisitos para ele exigidos descrevem o que se precisa conhecer e saber fazer para exercê-lo. Nessa definição, as tarefas correspondem àquilo que o indivíduo deve fazer, enquanto as ações correspondem àquilo que ele faz. Haveria uma incongruência entre tarefas e ações, quer dizer, entre o que o indivíduo deve fazer e o que ele realmente faz (Dejours, (1997). Aquilo que o cargo prescreve (as tarefas) não detalharia as ações que o indivíduo deveria realizar, de modo que as ações realizadas resultariam da interpretação e iniciativa do indivíduo ao realizar o trabalho. Às 
tarefas prescritas (o que se deve fazer) e às ações (o que se faz), aquele autor denominou de trabalho prescrito e trabalho real, respectivamente.

Os requisitos formais para o cargo, exigidos pela organização, dizem respeito às tarefas, partindo da premissa de que, se o indivíduo os atende, então é capaz de cumprir as tarefas do cargo (trabalho prescrito). Contudo, ao exercer o cargo, o indivíduo faz sua avaliação subjetiva sobre o que se precisa realmente conhecer e saber fazer (requisitos reais) para executar as ações necessárias (trabalho real) e cumprir as tarefas inerentes ao cargo (trabalho prescrito).

Desse modo, enquanto a sobrequalificação objetiva dependeria da relação entre os requisitos formalmente exigidos para o cargo e a qualificação do indivíduo, a sobrequalificação percebida dependeria da relação (avaliada subjetivamente) entre a qualificação do indivíduo e os requisitos reais exigidos pelo cargo. Dito de outra maneira, a sobrequalificação objetiva envolveria a relação entre o indivíduo e as exigências formais para o cargo, enquanto a sobrequalificação percebida envolveria a relação do indivíduo com as necessidades reais do cargo.

Em um cargo que exija formalmente o nível superior, é possível que apenas parte dos conhecimentos e habilidades, adquiridos pelo indivíduo ao longo da formação acadêmica, sejam realmente necessários para o desempenho do cargo. Assim, ainda que a qualificação do indivíduo fosse compatível com o requisito formal, a diferença entre requisito formal e necessidade real poderia levar à percepção de sobrequalificação. Desse modo, existiria a sobrequalificação percebida, mas não a objetiva. Por outro lado, se a formação do indivíduo excedesse o requisito formal exigido pelo cargo, mas fosse compatível com a necessidade real, seria possível que a percepção de sobrequalificação não ocorresse ou o fizesse em menor grau, existindo a sobrequalificação objetiva, mas não a percebida.

A relação entre exigência formal e necessidade real foi descrita por Green e Zhu 
(2010). À condição na qual a qualificação do indivíduo supera os requisitos formais para o cargo, mas não as necessidades reais, isto é, quando o indivíduo é sobrequalificado, mas utiliza a qualificação excedente em seu trabalho, aqueles autores denominaram sobrequalificação formal. Quando a qualificação do indivíduo superasse tanto os requisitos formais quanto as necessidades reais para o cargo, quer dizer, quando ele é sobrequalificado e não utiliza a qualificação excedente em seu trabalho, os mesmos autores denominaram sobrequalificação real. Essa classificação apontaria, então, para o uso de habilidades como dimensão do construto sobrequalificação, conforme sugerido por Johnson et al. (2002).

A divisão do cargo em exigências formais e necessidades reais também poderia ser estendida à qualificação do indivíduo. Isso pode ser inferido do um estudo que questionou as pesquisas que mensuraram a sobrequalificação (mais especificamente, sobre-educação) com base em anos de estudo. O tempo de duração dos estudos poderia ter dois efeitos: a certificação, o cumprimento do cronograma para obtenção do certificado de uma formação; ou a qualificação, a aprendizagem de conhecimentos e habilidades necessários para o exercício de uma atividade profissional (Brynin \& Longhi, 2009). Obter uma certificação não necessariamente corresponderia a adquirir uma qualificação.

Alguns indivíduos, por exemplo, necessitariam estudar mais tempo do que os outros para adquirir a mesma qualificação (Brynin \& Longhi, 2009). Por exemplo, um indivíduo ocupante de cargo que exigisse graduação, poderia necessitar cursar especialização para adquirir conhecimentos e habilidades que não adquiriu durante a graduação (ou, ao menos, não foram adquiridos no nível necessário para o exercício do cargo). Esse indivíduo utilizaria, em seu trabalho, os conhecimentos adquiridos durante a especialização, sendo formalmente, mas não realmente, sobrequalificado.

Então, não se trataria apenas de utilização (ou não) de qualificação excedente, mas também da relação entre a qualificação formal (certificada) e a qualificação real (aprendida) 
do indivíduo para o cargo. Pode-se supor que, se a qualificação excedente é utilizada no trabalho, então ela é necessária, de modo que a sobrequalificação não seria real, mas formal. Dessa maneira, utilizando os termos propostos por Green e Zhu (2010), a sobrequalificação formal ocorreria quando a qualificação formal fosse maior do que a exigência formal, mas a qualificação real fosse compatível à exigência formal. Por sua vez, a sobrequalificação real ocorreria quando ambas as qualificações formal e real excedessem a exigência formal para o cargo.

A diferenciação entre exigência formal e necessidades reais sugere que as organizações requereriam do indivíduo qualificação maior do que a necessária para o exercício do cargo, o que promoveria a sobrequalificação. Isso poderia ser fortuito, devido a uma descrição não-acurada do cargo (Liu \& Wang, 2012), mas, também poderia ser intencional. Em favor dessa segunda opção, argumentou-se que, frequentemente, as organizações exigem nível de educação formal superior ao necessário para o exercício do cargo (Feldman \& Maynard, 2011).

As organizações exigiriam maior nível de educação formal por três razões: o nível de escolaridade seria indicador de características desejáveis pela organização, como perseverança, consciência, etc.; o nível superior indicaria a maior probabilidade de os indivíduos se engajarem em comportamentos de cidadania organizacional e menor probabilidade de se engajarem em comportamentos contra-producentes; indivíduos com maior nível de escolaridade teriam custo de treinamento relativamente menor, apesar de apresentarem maior rotatividade (Feldman \& Maynard, 2011).

As organizações podem rejeitar os indivíduos com qualificações acima das exigidas para o cargo, condição denominada de sobrequalificação aparente (Erdogan, Bauer, Peiró, \& Truxillo, 2011a), e selecionar aqueles compatíveis com as necessidades reais do cargo. Entretanto, após ingressar na organização, os indivíduos selecionados podem adquirir maior 
qualificação ou, após exercer o cargo, passar a se perceberem sobrequalificados, condição denominada de sobrequalificação emergente (Erdogan et al., 2011a). Além disso, mesmo que a educação formal, habilidades e experiência profissional do indivíduo sejam compatíveis com o cargo, a incongruência demandas-aptidões pode ocorrer para outras características do indivíduo, como aptidões cognitivas (Fine \& Nevo, 2008).

\section{Mensuração}

Se a sobrequalificação corresponde à incongruência demandas-aptidões, mensurá-la significa mensurar essa incongruência. A incongruência demandas-aptidões poderia ser mensurada de forma direta, mensurando a incongruência propriamente dita, o que seria mais apropriado à mensuração da sobrequalificação percebida, ou indireta, mensurando separadamente a qualificação do indivíduo e a exigida para o cargo para, em seguida, compará-las e obter uma medida de sobrequalificação (Kristof, 1996). Tanto Johnson et al. (2002) quanto Maynard et al. (2006) desenvolveram instrumentos para mensuração direta da sobrequalificação percebida, respectivamente: Perceived Overqualification Scale (POQ) e Scale of Perceived Overqualification (SPOQ). Ambas as escalas mensuram a incongruência demandas-aptidões (educação formal, habilidades e experiência profissional), embora a POQ, mensure ainda uma dimensão não-crescimento.

A POQ é composta por dez itens igualmente distribuídos entre duas dimensões (incompatibilidade e não-crescimento), respondidos em escala de cinco pontos $(1=$ discordo fortemente; 5 = concordo fortemente). Originou-se de uma escala de subemprego, desenvolvida por Khan e Morrow (1991), os quais consideraram o subemprego composto por duas dimensões: sobrequalificação percebida (mais educação formal e habilidades do que exigidos pelo cargo); e não-crescimento percebido (percepção de subutilização de 
habilidades). Para esses autores, sobrequalificação percebida e não-crescimento percebido seriam construtos distintos e constituintes do subemprego.

A estrutura da escala de Khan e Morrow (1991) foi rearranjada por Johnson e Johnson (1996), renomeando sobrequalificação percebida como incongruência que, juntamente com não-crescimento percebido, foram consideradas constituintes da sobrequalificação. Posteriormente, dois itens do instrumento resultante desse rearranjo foram modificados, dando origem à POQ. Além da POQ, as escalas de Khan e Morrow (1991) e Johnson e Johnson (1996) também serviram de base para o Perceived Cognitive Overqualification Questionnaire (PCOQ), de Fine e Nevo (2008), composto por nove itens, também respondidos em escala de cinco pontos, para mensuração da sobrequalificação cognitiva percebida.

A estrutura da POQ não se ajusta ao modelo teórico aqui adotado. A sobrequalificação seria em si um caso de incongruência entre pessoa e trabalho, isto é, a incongruência não seria uma dimensão da sobrequalificação percebida, mas a própria sobrequalificação percebida (Maynard et al., 2006). Se a incongruência for a sobrequalificação percebida, então, o não-crescimento percebido deveria ser outra coisa. Contudo, a dimensão não-crescimento possuía dois componentes: a ausência de oportunidades para uso de habilidades; e a ausência de oportunidades para aquisição de habilidades. O primeiro componente deveria fazer parte do construto sobrequalificação. Isto porque, se o individuo tem habilidades não utilizadas, então, elas não são necessárias para o exercício do cargo e, consequentemente, ele tem mais habilidades do que as necessárias, o que poderia ser denominado sobre-habilidades.

Porém, o segundo componente da dimensão não-crescimento não parece fazer parte do construto sobrequalificação. A sobrequalificação se refere às habilidades que um indivíduo já possui e excedem aquelas necessárias para exercer seu cargo. A necessidade de 
oportunidades para aquisição de habilidades pode significar que o indivíduo não possui habilidades suficientes para exercer seu cargo, implicando em uma condição de subqualificação. Essa seria uma questão de necessidade de qualificação, não de seu excesso. No mais, ainda não haveria certeza se a dimensão não-crescimento seria parte do construto sobrequalificação (Johnson et al., 2002).

O instrumento mais ajustado ao modelo teórico adotado neste estudo foi a SPOQ. Este instrumento mensura diretamente a sobrequalificação percebida enquanto incongruência demandas-aptidões, considerando-se educação formal, experiência e habilidades como suas dimensões. A SPOQ é composta por nove itens, respondidos em escala de sete pontos $(1=$ discordo totalmente; $7=$ concordo totalmente). Os itens da SPOQ se referem às três dimensões da sobrequalificação: educação formal, experiência profissional e habilidades. Contudo, a SPOQ não fornece medidas independentes para essas dimensões, mas uma medida global de incongruência demandas-aptidões, que seria a própria sobrequalificação percebida (Maynard et al., 2006).

\section{Implicações}

Relacionar a sobrequalificação ao modelo de congruência pessoa-trabalho tem implicações não apenas para a definição da sobrequalificação, mas para predizer suas consequências. A premissa principal do modelo de congruência pessoa-trabalho é que, quanto maior a compatibilidade (ou congruência) entre as características do indivíduo e as características do cargo, melhores os resultados para indivíduo e organização. Por congruência, entenda-se um nível de qualificação ideal para o cargo, abaixo e acima do qual se supõe que o indivíduo não desempenhará o cargo satisfatoriamente. Isso porque o modelo de congruência pessoa-trabalho pressupõe uma relação curvilínea entre qualificação e 
desempenho (Fine \& Nevo, 2011).

Estudos encontraram a congruência pessoa-trabalho correlacionada positivamente à satisfação no trabalho e ao comprometimento organizacional, e negativamente à intenção de rotatividade (Kristof-Brown et al., 2005). Por essa razão, a literatura clássica acerca da sobrequalificação investigou essas mesmas atitudes no trabalho, tendo observado e reportado resultados semelhantes. A sobrequalificação percebida foi encontrada correlacionada negativamente à satisfação no trabalho e ao comprometimento organizacional afetivo, e positivamente à intenção de rotatividade (Liu \& Wang, 2012).

A relação negativa entre sobrequalificação e atitudes e comportamentos no trabalho fundamentou uma visão negativa da sobrequalificação, denominada perspectiva da sobrequalificação como risco (Kulkarni, Lengnick-Hall, \& Martinez, 2015). Consequentemente, tornou-se uma prática em seleção de pessoas rejeitar candidatos sobrequalificados (Erdogan et al., 2011a ; Fine, 2007). Porém, são os candidatos selecionados (os quais foram avaliados como compatíveis com o cargo) que, após ingressar na organização, se percebem sobrequalificados (sobrequalificação emergente). Em outras palavras, parece que ao rejeitar indivíduos sobrequalificados, as organizações acabam por admitir indivíduos sobrequalificados, o que foi chamado de paradoxo da sobrequalificação (Maynard, Taylor, \& Hakel, 2009, citados por Feldman \& Maynard, 2011).

Durante a seleção só é possível identificar, com alguma precisão, os candidatos objetivamente sobrequalificados. Mas, os resultados relatados na literatura anteriormente citada se referem à sobrequalificação percebida. Desse modo, a sobrequalificação percebida não seria aplicável em processos de recrutamento e seleção (Fine, 2007). Para que a rejeição de candidatos objetivamente sobrequalificados evitasse as consequências negativas relacionadas à sobrequalificação percebida, ambas as sobrequalificações deveriam estar interrelacionadas (Fine \& Nevo, 2011). Na ausência de tal relação, a rejeição seria inefetiva e 
deveriam ser encontrados outros preditores, como traços de personalidade (Fine, 2007).

A relação entre sobrequalificação objetiva e percebida ainda permanece um tema a ser investigado. Enquanto para alguns autores (Erdogan et al., 2011a; Fine \& Nevo, 2011; Maynard et al., 2006) não existe certeza acerca dessa relação, para outros (Lobene, Meade, \& Pond, 2015; Maltarich et al., 2011) ela seria óbvia. Estudo recente relatou correlação positiva moderada entre sobrequalificação percebida e sobrequalificação objetiva, esta mensurada como sobre-educação (Maynard, Brondolo, Connelly, \& Sauer, 2015). Em outro trabalho, encontrou-se a sobrequalificação percebida de um grupo de indivíduos objetivamente sobrequalificados (dimensão sobre-educação) significativamente maior do que a de um grupo de indivíduos não sobrequalificados objetivamente (Zhang, Law, \& Lin, 2016).

Sugeriu-se que a sobrequalificação objetiva levaria à sobrequalificação percebida (Maltarich et al., 2011). O indivíduo que possuísse mais qualificações que as exigidas por seu cargo ou possuídas por seus colegas de trabalho provavelmente seria capaz de perceber essa condição. Além disso, os efeitos negativos da sobrequalificação percebida sobre as atitudes no trabalho, descritos na literatura, poderiam ser efeitos da sobrequalificação objetiva mediados pela sobrequalificação percebida (Maltarich et al., 2011).

Contudo, a sobrequalificação percebida seria influenciada por outros fatores além da qualificação real (Maltarich et al., 2011). Alguns deles poderiam não ter relação com a qualificação ou o cargo, como as reações afetivas do indivíduo ao ambiente de trabalho. Dentre os fatores capazes de influenciar a sobrequalificação percebida estariam as características da instituição formadora. Por exemplo, indivíduos que estudaram em instituições de maior prestígio poderiam se perceber mais qualificados do que indivíduos que estudaram em instituições de menor prestígio (Erdogan et al., 2011a), embora ambos tenham recebido o mesmo título profissional.

Em oposição à perspectiva da sobrequalificação como risco, uma visão mais positiva 
pode ser encontrada na literatura. Segundo essa visão, denominada perspectiva da sobrequalificação como investimento (Kulkarni et al., 2015), as organizações poderiam obter vantagens com a admissão de indivíduos sobrequalificados. Essa perspectiva propõe que o indivíduo sobrequalificado possui um excedente (em relação aos requisitos do cargo) de conhecimentos, habilidades e aptidões que poderia ser aproveitado pela organização (Hu et al., 2015).

Argumenta-se que indivíduos sobrequalificados estariam mais aptos (dada sua maior qualificação) a assumir novas posições na organização, aprenderiam mais rápido, seriam mais facilmente treinados e ofereceriam novas competências à organização, aumentando sua vantagem competitiva (Erdogan et al., 2011a). Indivíduos sobrequalificados também apresentariam maior adaptabilidade à carreira, isto é, maior capacidade psicológica para enfrentamento de desafios na carreira (Yang, Guanb, Lai, She, \& Lockwood, 2015).

Ambas as perspectivas da sobrequalificação (risco e investimento) se baseiam nas consequências, o que indica a necessidade de estabelecer indicadores para determinar qual perspectiva assumir em determinada situação. Um provável indicador seria a voluntariedade do indivíduo à condição de sobrequalificado, chamada de incongruência voluntária (Maltarich et al., 2011). Essa voluntariedade poderia ser chamada também de sobrequalificação voluntária, se sobrequalificação for definida como a incongruência demandas-aptidões.

A literatura supõe que aceitar por escolha (voluntariamente) emprego para o qual se é sobrequalificado seria diferente de ser forçado a aceitar tal emprego. Por conseguinte, teria consequências diferentes e não necessariamente negativas (Erdogan, Bauer, Peiró, \& Truxillo, 2011b; Thompson, Shea, Sikora, Perrewé, \& Ferris, 2013). Nesse sentido, seria esperado que a condição de sobrequalificação voluntária tivesse consequências positivas ou não negativas, enquanto as consequências negativas se seguiriam à condição de 
sobrequalificação involuntária.

O indivíduo aceitaria voluntariamente a condição de sobrequalificação por várias razões. Aceitar um emprego para o qual se é sobrequalificado permitiria ao indivíduo aumentar seu capital social (as conexões interpessoais e redes que o indivíduo desenvolve e mantém por meio da interação no trabalho com colegas, supervisores, etc.), desde que essa condição fosse temporária (Feldman, \& Maynard, 2011).

Trabalhos de menor exigência de qualificação também reduziriam os conflitos trabalho-família, uma vez que trabalhos de menor responsabilidade ou duração permitiriam ao indivíduo se dedicar mais à família, e poderiam ser mais prazerosos e satisfatórios de realizar (Erdogan et al., 2011a). Estudantes de graduação, por exemplo, aceitariam empregos de menor demanda cognitiva para poderem se dedicar aos estudos (Erdogan et al., 2011b). Na ausência de motivos como esses, restaria ao indivíduo sobrequalificado mudar de emprego, havendo relatos de que indivíduos que mudaram de emprego se perceberam menos sobrequalificados no emprego seguinte do que no anterior (Maynard \& Parfyonova, 2013).

\section{Revisão Sistemática das Pesquisas com Amostras Internacionais}

Para descrever os resultados das pesquisas acerca da sobrequalificação, foram adotados três critérios de seleção, fundamentados no modelo teórico anteriormente apresentado e aqui adotado. Primeiramente, foram incluídos apenas estudos empíricos que definiram sua variável de estudo como sobrequalificação, sendo excluídos aqueles cuja variável investigada foi definida como sobre-educação ou subemprego. Em segundo lugar, para estudos que utilizaram o instrumento de Johnson e Johnson (1996) ou a POQ (Johnson et al., 2002), foram apresentados apenas os resultados referentes à dimensão incompatibilidade, considerando-se que somente essa dimensão daqueles instrumentos faz 
parte do construto sobrequalificação. Finalmente, foram incluídos apenas os estudos de abordagens comportamentais, os quais analisaram o nível micro, sugerindo variáveis para as quais seria possível intervir, a fim de reduzir ou evitar os efeitos negativos da sobrequalificação. Sob esses critérios, foram encontrados 19 relatos de pesquisa publicados fora do Brasil.

A definição de sobrequalificação nos textos analisados foi compatível com aquela adotada neste estudo. A sobrequalificação foi definida como a situação na qual o indivíduo:

- Possui mais educação formal, experiência ou habilidades do que as exigidas pelo trabalho, também chamada de subutilização de habilidades, subemprego ou ausência de oportunidades para crescimento e mudança (Johnson \& Johnson, 1996).

- Possui excesso de educação formal, experiência ou habilidades para seu trabalho ou tem oportunidades limitadas para adquirir e utilizar novas habilidades relacionadas a ele (Johnson et al., 2002).

- Possui excesso de educação formal, habilidades e experiência para seu trabalho (Erdogan et al., 2011a; Maynard et al., 2006).

- Possui maiores níveis de educação formal, experiência, habilidades e aptidão mental geral do que os realmente exigidos por seu trabalho, sendo parte do subemprego (Fine, 2007).

- Possui sobre-educação, sobre-experiência e sub-utilização de habilidades com relação ao que é exigido por determinado trabalho, correspondendo a uma parte do subemprego (Fine \& Nevo, 2008).

- Possui educação formal e habilidades que excedem os requisitos do trabalho (Erdogan \& Bauer, 2009); trabalha em um emprego que está abaixo de suas habilidades ou experiência, constituindo-se em uma forma de subemprego (Chen, Smith, \& Mustard, 2010). 
- Possui excesso de conhecimentos, habilidades, aptidões e outras características necessárias em comparação ao que é exigido pelo trabalho (Lobene \& Meade, 2010). Todos os estudos analisados utilizaram uma ou mais destas definições. O tipo de sobrequalificação mais investigado foi a sobrequalificação percebida, em 17 estudos (89\%), sendo o único tipo abordado por 14 deles (74\%). Dois estudos (Chen et al., 2010; Maynard et al., 2015) investigaram as sobrequalificações objetiva e percebida, um estudo (Fine \& Nevo, 2008) abordou as sobrequalificações percebida e cognitiva percebida e dois estudos (Fine, 2007; Lobene \& Meade, 2010) investigaram apenas a sobrequalificação cognitiva percebida. Para mensuração da sobrequalificação percebida, os instrumentos mais utilizados nos estudos analisados foram a SPOQ, utilizada em sete estudos (37\%), e o instrumento de Johnson e Johnson (1996), utilizado em seis estudos (32\%). Três estudos (Fine, 2007; Fine \& Nevo, 2008; Lobene \& Meade, 2010) utilizaram a PCOQ, de Fine e Nevo (2008). Um estudo (Chen et al., 2010) combinou medidas objetivas e subjetivas de habilidades, experiência e expectativas de emprego para obter uma medida de sobrequalificação. Outro estudo (Guerrero \& Hatala, 2015) utilizou o instrumento de Bolino e Feldman (2000), constituído de treze itens para mensuração de subemprego. Um único item com três opções de respostas, as quais classificavam o indivíduo como sub-qualificado, qualificado ou sobrequalificado, foi utilizado em outra pesquisa (Wu, Luksyte, \& Parker, 2015). A POQ foi utilizada apenas por seus autores. A sobrequalificação objetiva foi avaliada comparando-se o nível de escolaridade do participante àquele exigido pelo cargo e transformando-a em variável dicotômica, sobrequalificação versus não-sobrequalificação (Maynard et al., 2015).

Os trabalhos analisados investigaram a sobrequalificação tanto como variável antecedente, quanto como variável critério. As relações investigadas incluíram bem-estar, personalidade, atitudes e comportamentos no contexto do trabalho. Observou-se, nos estudos mais recentes, preocupação em identificar variáveis mediadoras e moderadoras das relações 
entre sobrequalificação e seus consequentes. O conhecimento de tais variáveis poderia orientar o planejamento de intervenções, a fim de eliminar ou reduzir os efeitos negativos da sobrequalificação, possibilitando seu gerenciamento (Fine \& Nevo, 2011). Os principais resultados encontrados pelos estudos analisados são descritos a seguir.

Antecedentes. O merecimento (uma das características da personalidade narcisista) foi preditor positivo da sobrequalificação percebida (Maynard et al., 2015), enquanto a troca líder-membros foi preditora negativa (Alfes, Shantz, \& Baalen, 2016). A abertura à experiência (uma das dimensões do Big Five) e a aptidão mental geral foram preditores positivos da sobrequalificação cognitiva percebida (Fine, 2007). A adaptabilidade na carreira se relacionou positivamente à sobrequalificação percebida, enquanto a delegação percebida foi seu preditor negativo e a ancoragem da carreira no desafio foi seu preditor positivo (Yang et al., 2015). Destacaram-se, como variáveis antecedentes investigadas, as que podem ser classificadas como disposicionais. Nesses casos, a variável critério nunca foi a sobrequalificação objetiva.

Consequentes. A sobrequalificação percebida se relacionou positivamente: à depressão e estresse (Johnson \& Johnson, 1996); à intenção de saída (Maynard et al., 2006) e à crença de auto-eficácia de extensão de papel (Zhang et al., 2016); a comportamentos contraproducentes (Luksyte et al., 2011); e a comportamentos de busca por novo emprego (Maynard \& Parfyonova, 2013); e à raiva quanto à situação de emprego (Liu et al., 2015). A sobrequalificação percebida foi preditora da insatisfação no trabalho (Maynard et al., 2006), de comportamentos contra-producentes (Liu et al., 2015) e de rotatividade voluntária (Maynard \& Parfyonova, 2013).

A sobrequalificação percebida se relacionou negativamente: à saúde mental (Chen et al., 2010); à auto-estima baseada na organização (Liu et al., 2015); à satisfação global no trabalho (Alfes et al., 2016; Fine \& Nevo, 2008) e, especificamente, à satisfação com a 
natureza do trabalho, salário e promoções (Johnson et al., 2002; Maynard et al., 2006), benefícios, comunicação, colegas, recompensas e supervisão (Maynard et al., 2006). A sobrequalificação percebida também se relacionou negativamente a comprometimento organizacional afetivo (Johnson et al., 2002; Maynard et al., 2006), contrato psicológico relacional e contrato psicológico equilibrado (Luksyte, Spitzmueller, \& Maynard, 2011).

A sobrequalificação cognitiva percebida foi encontrada relacionada: negativamente à satisfação global no trabalho (Fine \& Nevo, 2008; Lobene \& Meade, 2010) e aos comprometimentos afetivo, normativo e calculativo (Lobene \& Meade, 2010); e positivamente à intenção de saída (Lobene \& Meade, 2010) e a atitudes negativas no treinamento, como tédio e insatisfação (Fine, 2007).

Destacam-se, como variáveis consequentes investigadas, as que podem ser classificadas como atitudinais, enquanto a variável critério relatada nunca foi a sobrequalificação objetiva. Se positivas, as correlações com a sobrequalificação percebida são negativas; se negativas, as correlações são positivas. Apesar da predominância dos efeitos contraproducentes, têm sido relatados efeitos proveitosos. Por exemplo, a sobrequalificação cognitiva percebida se relacionou positivamente ao desempenho em treinamento, avaliado pelos pares e pelo supervisor (Fine, 2007) e avaliado objetivamente (Fine \& Nevo, 2008). A sobrequalificação percebida se relacionou positivamente ao desempenho no trabalho, autorelatado e avaliado pelo supervisor (Fine $\&$ Nevo, 2008) e ainda se relacionou positivamente ao desempenho avaliado objetivamente (Erdogan \& Bauer, 2009).

Mediadores. A satisfação no trabalho mediou: a relação positiva entre sobrequalificação cognitiva percebida e intenção de saída, sendo essa relação não significativa quando a satisfação no trabalho foi inserida no modelo (Lobene \& Meade, 2010); e a relação positiva entre sobrequalificação percebida e comportamento de busca por emprego, sendo mais fraca a relação, quanto maior a satisfação no trabalho (Maynard \& 
Parfyonova, 2013). O cinismo, uma dimensão da síndrome de burnout, mediou a relação entre sobrequalificação percebida e comportamentos contra-producentes, sendo mais forte a relação, quanto maior o cinismo (Luksyte et al., 2011).

A relação entre sobrequalificação e comportamentos contraproducentes (autorelatados) foi mediada pela raiva quanto à situação de emprego, sendo mais forte a relação quanto maior a raiva. Essa relação foi ainda mediada pela auto-estima baseada na organização, sendo mais forte a relação quanto menor a auto-estima (Liu et al., 2015). A relação entre adaptabilidade na carreira e sobrequalificação percebida foi mediada pela delegação percebida, sendo mais fraca a relação, quanto maior a delegação percebida. Essa relação foi também mediada pela ancoragem da carreira no desafio, sendo mais fraca a relação, quanto menor a ancoragem da carreira no desafio (Yang et al., 2015).

As variáveis mediadoras são do nível individual, especialmente disposicionais e de natureza afetiva medida por meio de indicadores cognitivos ou não. As variáveis critério relatadas geralmente foram efeitos proveitosos ou não proveitosos da sobrequalificação e, algumas vezes, esta foi a variável critério.

Moderadores. A pesquisa sobre moderação resultou em um conjunto bem mais substancial de achados que a pesquisa sobre mediação, embora as variáveis critério tenham sido aquelas já mencionadas na sessão anterior. Foram relatadas algumas variáveis moderadoras associadas às relações sociais nos postos de trabalho, mas a predominância continuou sendo de relatos sobre variáveis do nível individual, como aquelas citadas anteriormente. Esses achados serão sintetizados na presente sessão, inicialmente relativos a estas variáveis e depois os associados às que podem ser classificadas como típicas daquelas relações sociais (troca líder-membros, coesão da equipe e sobrequalificação dos colegas).

A sobrequalificação objetiva moderou a relação positiva entre merecimento narcisista e sobrequalificação percebida, sendo a relação não significativa na presença da 
sobrequalificação objetiva. Foi igualmente moderadora entre merecimento narcisista e estresse com a carreira, sendo a relação não significativa na presença da sobrequalificação objetiva (Maynard et al., 2015). Desse modo, há evidências de que existem relações de moderação entre as medidas objetiva e subjetiva de sobrequalificação.

A cultura nacional moderou a relação negativa (moderada pela autonomia do trabalho) entre sobrequalificação percebida e bem-estar no trabalho (Wu et al., 2015). Para cultura individualista, a relação entre sobrequalificação percebida e bem-estar no trabalho era negativa quando a autonomia era baixa e não-significativa quando a autonomia era alta. Para cultura coletivista, a relação negativa entre sobrequalificação percebida e bem-estar no trabalho era mais forte quanto a autonomia era alta e mais fraca quando a autonomia era baixa. Tais achados apoiam o argumento anteriormente apresentado no presente estudo, de que os princípios das teorias da equidade, privação relativa e capital humano não são aplicáveis a todas as culturas.

A necessidade financeira percebida moderou a relação entre intensidade da busca por emprego e sobrequalificação percebida, sendo positiva a relação quando a necessidade financeira era alta e não significativa quando a necessidade financeira era baixa (Guerrero \& Hatala, 2015). O tempo na organização moderou a relação negativa entre delegação percebida e sobrequalificação percebida, sendo mais forte a relação quando o tempo na organização era alto. O tempo na organização ainda moderou a relação positiva entre ancoragem da carreira no desafio e sobrequalificação percebida, sendo positiva a relação quando o tempo na organização era alto e não significativa quando o tempo na organização era baixo (Yang et al., 2015).

A vocação moderou a relação entre sobrequalificação percebida e comprometimento calculativo, sendo a relação negativa quando a vocação era baixa e positiva quando a vocação era alta. Essa vocação também moderou a relação entre sobrequalificação percebida e 
desempenho, sendo a relação negativa quando a vocação era alta e positiva quando a vocação era baixa (Lobene \& Meade, 2013).

Além dessas três variáveis individuais, um conjunto mais substancial de moderadores relatado nos estudos revisados é relativo a variáveis que muito provavelmente estão associadas a crenças e valores individuais, tais como empowerment, valores do trabalho, sensibilidade à justiça e orientação a metas. Esses achados são descritos nos próximos parágrafos.

O empowerment moderou a relação entre sobrequalificação percebida e: satisfação no trabalho, intenção de permanência e probabilidade de rotatividade (Erdogan \& Bauer, 2009). Foi observado que, quando o nível de empowerment era baixo, a sobrequalificação percebida se relacionava negativamente à satisfação no trabalho e intenção de permanência, e positivamente à probabilidade de rotatividade. Quando o nível de empowerment era alto, a sobrequalificação percebida não se relacionava significativamente à satisfação no trabalho, intenção de permanência e probabilidade de rotatividade.

Valores do trabalho (competência e crescimento) moderaram a relação negativa entre sobrequalificação percebida e comprometimento afetivo, sendo mais forte a relação, quando os valores eram altos. Ainda moderaram a relação positiva entre sobrequalificação percebida e comportamento de busca por novo emprego, sendo a relação não significativa quando os valores eram baixos (Maynard \& Parfyonova, 2013).

A sensibilidade à justiça moderou a relação positiva entre sobrequalificação percebida e raiva quanto à situação de emprego, sendo a relação mais fraca, quando a sensibilidade era alta (Liu et al., 2015). A sensibilidade à justiça moderou ainda a relação positiva (mediada negativamente pela auto-estima baseada na organização) entre sobrequalificação percebida e comportamentos contraproducentes (auto-relatado e relatado pelo supervisor), sendo a relação significativa quando a sensibilidade era alta e não significativa quando a sensibilidade 
era baixa. Essa sensibilidade também moderou positivamente a relação positiva (mediada positivamente pela raiva quanto à situação de emprego) entre sobrequalificação percebida e comportamentos contraproducentes (auto-relatado e relatado pelo supervisor), sendo a relação significativa quando a sensibilidade era alta e não significativa quando a sensibilidade era baixa (Liu et al., 2015).

A relação positiva entre sobrequalificação percebida e auto-eficácia de extensão de papel foi moderada pela orientação a metas de desempenho, sendo mais forte a relação, quando a orientação a metas de desempenho era alta. Foi igualmente moderada pela orientação a metas de aprendizagem, sendo mais forte a relação quando a orientação a metas de aprendizagem era baixa (Zhang et al., 2016). A orientação a metas de desempenho moderou ainda a relação (mediada pala auto-eficácia de extensão de papel) entre sobrequalificação percebida e comportamento proativo pró-organização, sendo mais forte a relação quando a orientação a metas de desempenho era alta. Essa orientação a metas também moderou a relação (mediada pala auto-eficácia de extensão de papel) entre sobrequalificação percebida e comportamento proativo pró-outros, sendo mais forte a relação, quando a orientação a metas de desempenho era alta (Zhang et al., 2016).

Por fim, há os achados relatados sobre variáveis moderadoras associadas às relações sociais nos postos de trabalho. A primeira delas é a troca líder-membros, que moderou a relação negativa entre sobrequalificação e satisfação no trabalho. Esta relação foi mais fraca quando a troca líder-membros era alta. Também foi moderada pela coesão da equipe, sendo mais fraca a relação quando a coesão era alta (Alfes et al., 2016). A sobrequalificação dos colegas moderou a relação entre sobrequalificação percebida e significado da tarefa, sendo a relação mais forte quando a sobrequalificação dos pares era alta. Também moderou a relação entre a sobrequalificação e a congruência indivíduo-grupo, sendo a relação mais forte quando a sobrequalificação dos colegas era alta (Hu et al., 2015). 
A sobrequalificação dos colegas também moderou a relação positiva (mediada pelo significado da tarefa) entre sobrequalificação e desempenho no cargo, sendo a relação mais forte quando a sobrequalificação dos colegas era alta. Ainda moderou a relação positiva (mediada pelo significado da tarefa) entre sobrequalificação e comportamentos de cidadania organizacional, sendo a relação mais forte quando a sobrequalificação dos colegas era alta. Finalmente, também moderou a relação positiva (mediada pela congruência indivíduo-grupo) entre sobrequalificação e comportamentos de cidadania organizacional, sendo a relação mais forte quando a sobrequalificação dos colegas era alta (Hu et al., 2015).

O conjunto de evidências sobre moderadores, anteriormente descrito, oferece importante suporte para a suposição de que crenças e valores sobre o trabalho, as organizações e os contratos psicológicos ou formais estabelecidos com eles podem afetar as relações encontradas entre antecedentes e consequentes da sobrequalificação. O mesmo pode ser afirmado sobre moderadores associados a relações sociais. Portanto, mostra-se relevante a investigar essas questões no contexto nacional, considerando-se que este pode incluir crenças, valores e relações sociais diferentes dos contextos nos quais os estudos anteriormente revisados foram realizados.

\section{Pesquisas no Brasil}

No Brasil, foram encontrados cinco estudos que investigaram a sobrequalificação, todos publicados no presente século, sugerindo que esse fenômeno só recentemente passou a ser objeto de interesse dos pesquisadores. No mais antigo desses estudos, foi analisado um banco de dados governamental, por Machado, Oliveira e Carvalho (2004), a fim de verificar se houve sobrequalificação na força de trabalho brasileira no período entre 1981 e 2001. Sobrequalificação foi definida como possuir educação formal (mensurada em anos de estudo) 
mais de um desvio-padrão acima da média dos indivíduos para determinado cargo.

Aquelas autoras utilizaram, como unidade de análise, uma taxa de incompatibilidade, que poderia ser considerada como uma taxa de sobrequalificação na força de trabalho. Relataram crescimento de $21 \%$ na taxa de incompatibilidade no período investigado, sendo que a partir de 1996 passou a diferir quanto ao sexo, sendo maior para as mulheres. Também observaram que a taxa de incompatibilidade diminuía conforme a idade. Com base em seus resultados, propuseram uma tipologia para a sobrequalificação de categorias ocupacionais. Taxas de incompatibilidade maiores que 50\% caracterizariam as categorias sobrequalificadas e taxas inferiores a esse valor caracterizariam as categorias compatíveis.

Em outro estudo, Boucinhas Filho (2008) desenvolveu uma tese na área do direito do trabalho relacionada à prática das organizações de não contratarem, não promoverem ou demitirem indivíduos sobrequalificados. Essa prática foi denominada de discriminação por sobrequalificação, definida como a situação na qual o indivíduo mais qualificado seria preterido, ao invés de valorizado, pelas organizações, sendo diferente de outros tipos de discriminação por não envolver estereotipia ou preconceito. Sobrequalificação foi definida como a condição na qual a formação do indivíduo supera a complexidade das tarefas de seu trabalho.

O efeito da sobrequalificação percebida sobre satisfação no trabalho, intenção de saída e comportamento de cooperação foi investigado por Maciel e Camargo (2013) em amostra de 331 trabalhadores. Para mensuração da sobrequalificação, foi utilizado um questionário baseado nos itens da POQ. Para mensurar satisfação no trabalho (global) e comportamento de cooperação, foram aplicados itens desenvolvidos pelos próprios autores. Ambas as dimensões da sobrequalificação percebida (incompatibilidade e não-crescimento) se relacionaram negativamente à intenção de saída; mas apenas a dimensão não-crescimento se relacionou negativamente à satisfação no trabalho (Maciel \& Camargo, 2013). As duas dimensões da 
sobrequalificação também se relacionaram ao comportamento de cooperação, sendo a relação positiva para a dimensão incongruência e negativa para a dimensão não-crescimento. Diferentemente do que a literatura apresenta, não foi encontrada relação entre a dimensão incongruência e a satisfação no trabalho. A dimensão incongruência se relacionou positivamente ao comportamento de cooperação. Essa seria, então, uma consequência positiva da sobrequalificação, não relatada nos trabalhos publicados com dados coletados fora do Brasil.

O estudo de Weymer, Maciel e Castor (2014) investigou os efeitos da aprendizagem organizacional (dos tipos exploitation e exploration) e da sobrequalificação sobre a satisfação no trabalho. A sobrequalificação foi mensurada por meio dos itens da dimensão incongruência, da POQ. Nos resultados, encontrou-se a sobrequalificação relacionada negativamente à satisfação no trabalho e os dois tipos de aprendizagem positivamente relacionados à satisfação no trabalho. A sobrequalificação não se relacionou a nenhum dos tipos de aprendizagem investigados.

Recentemente, Francisco (2015) investigou se, e o quanto, haveria conflitos entre a formação e a atuação de indivíduos sobrequalificados. Sobrequalificação foi definida com base no nível de educação formal, de modo que os participantes foram considerados sobrequalificados por possuírem nível de educação formal superior ao exigido pelo cargo que ocupavam. Por meio de entrevistas, foram coletados dados junto a doze técnicos de enfermagem (nível médio), que possuíam graduação e, em alguns casos, pós-graduação, também na área da saúde. Dentre os participantes, apenas dois já possuíam nível superior ao ingressar no hospital público no qual trabalhavam. Foi realizada análise de conteúdo com os dados coletados nas entrevistas. Os resultados sugeriram que os participantes buscaram obter o nível superior como meio para alcançar o reconhecimento profissional que não recebiam como profissionais de nível médio. Entretanto, conforme relataram, o nível superior não lhes 
trouxe o reconhecimento esperado e não puderam utilizar seus conhecimentos do nível superior, em suas atividades, o que lhes levou a reduzir sua produtividade no trabalho.

Em comparação à literatura internacional, a pesquisa de Machado et al. (2004) pode ser considerada de abordagem econômica, tendo analisado a sobrequalificação do ponto de vista macro, isto é, sua ocorrência na força de trabalho como um todo. Já as pesquisas de Maciel e Camargo (2013) e de Weymer et al. (2014) se enquadram nas abordagens comportamentais. O estudo de Francisco (2015), embora possa ser incluído nas abordagens comportamentais, diferiu da literatura internacional anteriormente revisada, por ter utilizado o método qualitativo. Também o trabalho de Boucinhas Filho (2008) diferiu dos estudos internacionais, tendo utilizado abordagem jurídica.

Quanto ao construto investigado, devido ao modo como definiram sobrequalificação, pode-se afirmar que Machado et al. (2004) e Francisco (2015) investigaram apenas uma dimensão da sobrequalificação, a sobre-educação. Enquanto isso, mais alinhados à literatura internacional, Maciel e Camargo (2013) definiram a sobrequalificação conforme Johnson et al. (2002) e Weymer et al. (2014) utilizaram a definição de subemprego, de Khan e Morrow (1991). A definição apresentada por Boucinhas Filho (2008), apesar de mais abrangente (não especifica o que é formação), está mais alinhada ao construto sobrequalificação como definido neste trabalho. Pode-se afirmar ainda que, enquanto Machado et al. (2004), Boucinhas Filho (2008) e Francisco (2015) se interessaram em estudar a sobrequalificação objetiva, Maciel e Camargo (2013) e Weymer et al. (2014) se interessaram pela sobrequalificação percebida.

Para mensuração da sobrequalificação, Maciel e Camargo (2013) e Weymer et al. (2014) utilizaram itens do instrumento da POQ (traduzidos para aplicação naqueles estudos), considerando a sobrequalificação multidimensional (incongruência e não-crescimento), embora Weymer et al. (2014) tenham utilizado apenas itens referentes à dimensão 
incongruência. Nos demais estudos, a sobrequalificação foi analisada como variável qualitativa, considerando a dicotomia sobrequalificado versus não-sobrequalificado.

De modo geral, nos estudos nacionais se observam os mesmos problemas teóricos que ocorrem na literatura internacional, os quais são a dificuldade na definição do construto sobrequalificação e sua relação com sobre-educação e subemprego. Porém, os estudos brasileiros apresentaram alternativas metodológicas (uso do método qualitativo e da abordagem jurídica) e investigaram relações não abordadas na literatura internacional revisada, tais como aprendizagem organizacional e comportamento de cooperação. Além disso, contribuíram para a literatura ao encontrarem a já conhecida relação negativa da sobrequalificação com satisfação no trabalho e intenção de saída em outra amostra, trabalhadores brasileiros, indicando que essa relação poderia independer da cultura.

Contudo, o conjunto dos achados das pesquisas nacionais está bastante distante de conseguir encontrar padrões que ofereçam suportes teórico ou prático para se confirmar a existência de um conhecimento autóctone a respeito da sobrequalificação no Brasil. É relevante fazê-lo, pois ocorreram importantes mudanças nos níveis educacionais brasileiros, nos últimos anos. Tais mudanças poderão aumentar a probabilidade de emergência do fenômeno sobrequalificação, no país.

\section{Conclusões}

Além das conclusões parciais já apresentadas, os textos analisados permitem definir sobrequalificação como a condição na qual um trabalhador possui mais educação formal, habilidades e experiência profissional que o necessário para o exercício de seu cargo. A sobrequalificação pode ser considerada um tipo de incongruência demandas-aptidões, consistindo em um dos atributos do subemprego, do qual ela é objeto (Figura 1). As 
demandas são entendidas como os requisitos do cargo referentes à educação formal, habilidades e experiência profissional. As aptidões são entendidas como educação formal, habilidades e experiência profissional do indivíduo. Consequentemente, incongruência corresponde à condição na qual as aptidões são maiores do que as demandas.

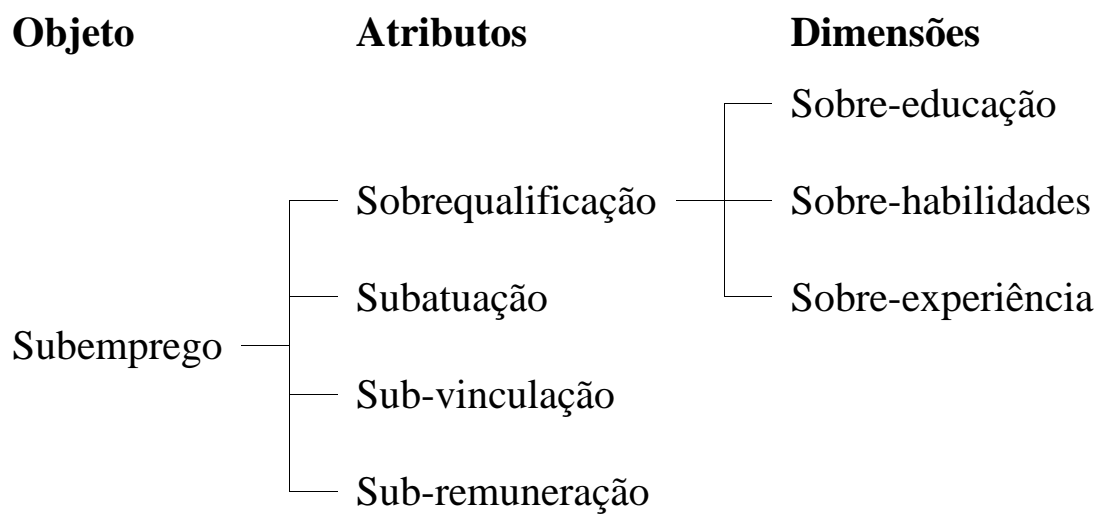

Figura 1. Modelo constitutivo do construto sobrequalificação, com base nas dimensões do modelo de subemprego (Feldman, 1996) e na definição de sobrequalificação (Maynard et al., 2006).

Quanto às teorias explicativas, a da equidade e a da privação relativa sugerem que a sobrequalificação resultaria de uma percepção de injustiça. Para a primeira teoria, a injustiça estaria na relação contribuições versus retribuições organizacionais. Para a segunda, a injustiça estaria na ausência de um emprego idealizado. A teoria do capital humano sugere que a sobrequalificação resultaria da insuficiência (ou ausência) do retorno ao investimento da qualificação na organização. Esse investimento geraria uma expectativa futura de retribuição.

$\mathrm{Na}$ relação indivíduo-organização, o indivíduo contribuiria com sua qualificação (investiria seu capital humano) em troca das retribuições organizacionais (o emprego, constituído por um cargo, com requisitos, tarefas, atividades e retribuições). A sobrequalificação ocorreria a partir da percepção de que a relação de troca (teoria da 
equidade) e o trabalho possuído (privação relativa) são injustos, havendo um investimento maior do que o retorno recebido ou esperado (teoria do capital humano).

A principal classificação da sobrequalificação é como objetiva ou percebida, conforme o meio de observá-la seja objetivo (comparando o desenho do cargo ao currículo profissional do indivíduo, etc.) ou subjetivo (perguntando ao próprio trabalhador quão qualificado se considera para seu cargo). Contudo, este último meio de observação foi o relatado em quase todos os estudos revisados, seus antecedentes são disposicionais e seus efeitos são principalmente os não proveitosos. A sobrequalificação também pode ser classificada quanto ao momento de ingresso do indivíduo na organização (aparente ou emergente), à aceitação dessa condição (voluntária ou involuntária) e quanto à relação entre qualificação e requisitos formais para o cargo (real ou formal). 


\section{A Sobrequalificação no Serviço Público}

Sob a perspectiva da sobrequalificação como investimento, admite-se que o indivíduo aceite um emprego inferior à sua qualificação (sobrequalificação voluntária) por razões consideradas positivas, como, por exemplo, para aumentar seu capital social. Entretanto, é igualmente possível que o aceite por motivos negativos. Em situações de escassez de emprego, o indivíduo aceita um emprego inferior apenas para garantir uma renda e evitar o desemprego (Erdogan et al., 2011a). A sobrequalificação se relaciona às condições macroeconômicas, à medida que estas afetam o mercado de trabalho (Erdogan et al., 2011b). Neste caso, torna-se válida a perspectiva da sobrequalificação como risco, pois, provavelmente, assim que o mercado de trabalho melhorar, o indivíduo buscará emprego compatível com sua qualificação.

A economia mundial passa por um período de enfraquecimento, estimando-se crescimento de 3,6\% para o ano de 2016, valor significativamente menor que o previsto em 2014, ao mesmo tempo em que se registra diminuição das vagas de emprego decente (caracterizado, dentre outras coisas, pela liberdade de escolha do trabalho e oportunidade de encontrar emprego com salário justo) e aumento das taxas de desemprego e de emprego vulnerável (trabalho por conta própria e trabalho familiar), segundo relatório da International Labour Organization (ILO, 2016). Assim, pode-se esperar que o atual contexto econômico favoreça o aumento da ocorrência da sobrequalificação, à medida que o reduzido número de postos de trabalho motive os indivíduos (dispensados de seus empregos compatíveis) a aceitarem cargos de menor qualificação.

As motivações para se submeter à condição de sobrequalificação poderão não impedir que ela seja percebida como tal, por razões apontadas na literatura internacional, como maior aptidão mental geral, crença de merecimento, abertura à mudança, adaptabilidade na carreira 
e ancoragem desta no desafio, baixas trocas líder-membros e delegação percebida. Os efeitos desse processo no comportamento humano nas organizações são geralmente não proveitosos, como anteriormente discutido.

No Brasil, a crise econômica (caracterizada pela queda no nível de atividade econômica e aumento da inflação) afetou significativamente o mercado de trabalho. Foi observada piora nos principais indicadores do comportamento do mercado de trabalho, como, por exemplo, a taxa de desemprego, que apresentou aumento de $8,1 \%$, no primeiro trimestre de 2015, para 11,1\%, no mesmo período de 2016, segundo dados do Instituto de Pesquisa Econômica Aplicada (IPEA, 2016). Assim, como sugerido anteriormente, pode ser esperado que indivíduos dispensados aceitem empregos inferiores ao anterior, implicando no aumento do percentual de indivíduos sobrequalificados no Brasil. Dois dados corroboram essa afirmação: no primeiro trimestre de 2016, os indivíduos dispensados e recontratados (em novo emprego) receberam salários até $15,0 \%$ menores que o anteriormente recebido; e o aumento da taxa de desemprego foi maior para indivíduos com nível de escolaridade fundamental completo ou médio incompleto, indo de $10,7 \%$, no primeiro trimestre de 2015 , para 15,4\%, no primeiro trimestre de 2016 (IPEA, 2016). Pode-se supor, então, que indivíduos de menor escolaridade (fundamental completo/médio incompleto) foram mais atingidos pelo desemprego, por terem sido substituídos por indivíduos de maior escolaridade (ensino médio completo ou acima), que perderam seu emprego e aceitaram emprego de menor exigência de escolaridade e de menor remuneração, caracterizando a condição de sobrequalificação.

Em termos de salário, entre o primeiro trimestre de 2015 e o primeiro trimestre de 2016, o rendimento mensal médio sofreu perda de 3,8\%, estabilizando-se em R $\$ 1.934,51$, seguindo uma tendência nacional de queda iniciada no terceiro trimestre de 2013 (IPEA, 2016). Considerando-se o tipo de vínculo empregatício, no período entre janeiro de 2014 e 
outubro de 2016, o rendimento mensal médio foi de $\mathrm{R} \$ 1.961,33$ para trabalhadores com carteira assinada, de $\mathrm{R} \$ 1.191,00$ para trabalhadores sem carteira assinada e de $\mathrm{R} \$ 1.570,67$ para trabalhadores por conta própria. Porém, nem todos enfrentaram perda; nesse mesmo período, o rendimento mensal médio de empregados do setor público foi de $\mathrm{R} \$ 3.142,67$. Enquanto os trabalhadores com carteira assinada e os por conta própria experimentaram variações negativas em seus rendimentos médios reais $(-0,8 \%$ e $-4,9 \%$, respectivamente), para os trabalhadores sem carteira assinada a variação foi de $0,3 \%$ e, para o setor público, foi de $1,1 \%$, de acordo com dados da Secretaria de Planejamento e Assuntos Econômicos, do Ministério do Planejamento (SEPLAN, 2016). Em outras palavras, no setor público o rendimento médio não apenas foi maior, como sofreu aumento naquele período.

O melhor exemplo do setor público é o público federal, o qual funciona como modelo seguido pelos governos de estados e municípios (Cardoso Junior \& Nogueira, 2011; Moura \& Souza, 2016). No poder executivo (que agrega quase $60,0 \%$ do total de servidores públicos federais), metade dos servidores tem remunerações acima de $\mathrm{R} \$ 5.500,00$, segundo dados de outubro de 2016, do Ministério do Planejamento, Desenvolvimento e Gestão (MPDG, 2016). Deste modo, o setor público brasileiro oferece os melhores salários (em comparação com o setor privado) e, na maioria dos casos, não é afetado por crises econômicas. Além disso, está geralmente imune a uma das piores consequências da crise econômica para o trabalhador, a demissão, devido à sua característica mais marcante: a estabilidade no cargo.

O serviço público tornou-se uma alternativa às incertezas do mercado de trabalho privado, no Brasil. Em comparação com o setor privado, vulnerável a variações nos mercados com reflexo direto sobre o mercado de trabalho, o serviço público é marcado pela estabilidade financeira e de emprego, e pela maior remuneração. Essas vantagens têm atraído muitas pessoas para o serviço público em todas as esferas (federal, estadual e municipal). Porém, essas vantagens parecem ser as únicas motivações para o ingresso, 
independentemente das atividades inerentes ao cargo a ser ocupado (Albrecht \& Krawulski, 2011; Mendes, 2011; Morici \& Barbosa, 2013; Santos, Brandão, \& Maia, 2015). Portanto, é um contexto no qual mais provavelmente seria observado o fenômeno da sobrequalificação, objeto de pesquisa da presente dissertação.

Enquanto no setor privado ocorreu aumento do desemprego, o serviço público federal (civil) admitiu 155 mil servidores, entre 2003 e 2010, e mais de 117 mil, entre 2012 e 2016, via concursos públicos (Cardoso Junior \& Nogueira, 2011; MPDG, 2016). Contudo, esse aumento correspondeu ao preenchimento de vagas deixadas por servidores que deixaram o serviço público, que passaram para a inatividade ou que eram terceirizados. A partir de 1995, o serviço público federal passou por um período de redução do quadro de pessoal, por meio da criação de entidades públicas de regime celetista, de planos de demissão voluntária, do aumento das aposentadorias e da redução do número de concursos públicos, o que se repetiu nos estados e municípios (Cardoso Junior \& Nogueira, 2011).

A legislação em vigor estabelece que o ingresso no serviço público ocorra mediante aprovação em concurso público (de provas ou provas e provas de títulos) e que a estabilidade no cargo seja adquirida mediante aprovação em estágio probatório de três anos (Constituição da República Federativa do Brasil, 1988/2013). O concurso público foi o meio encontrado, segundo a ideologia republicana, para pôr fim ao poder de nomeação exercido pelos gestores públicos (característico do período monárquico), pois este seria antidemocrático e feriria o ideal de igualdade republicano (Fontainha et al., 2014). Por meio do concurso público, o servidor seria escolhido com base em sua capacidade técnico-profissional (conforme a ideologia burocrática) e, como indicador dessa capacidade, adotou-se o mérito escolar/acadêmico, constituindo-se uma ideologia meritocrática (Fontainha, Geraldo, Veronese, \& Alves, 2015).

Duas outras ideologias fundamentam o concurso público: a acadêmica e a 
profissional (Fontainha et al., 2015). Segundo a ideologia acadêmica, o concurso público selecionaria os melhores egressos das escolas e universidades, com base no conhecimento (escolar/acadêmico) avaliado por representantes dessas instituições. De acordo com a ideologia profissional, o concurso público selecionaria os indivíduos mais competentes e habilidosos, por meio de provas práticas semelhantes às rotinas do trabalho a ser executado, sob avaliação de profissionais que exercem tais trabalhos.

Contudo, a seleção por concurso público tem sido questionada por não selecionar os melhores candidatos, como pregado pelas ideologias acadêmica e profissional (Fontainha et al., 2015; Mendes, 2011; Morici \& Barbosa, 2013). Os concursos públicos tendem a selecionar os candidatos que apresentam as maiores notas nas provas e que (quando aplicável) possuem os maiores títulos acadêmicos (Fontainha et al., 2015), não avaliando as habilidades e aptidões dos candidatos às atividades inerentes ao cargo a ser preenchido (Mendes, 2011; Morici \& Barbosa, 2013). Além disso, haveria desperdício da formação quando, por exemplo, engenheiros agrônomos ingressam no Ministério da Justiça e advogados tornam-se fiscais sanitários (Mendes, 2011). Esses problemas da seleção via concurso podem, em parte, ser atribuídos a sua falta de alinhamento a um planejamento estratégico nas organizações públicas (Fontainha et al., 2015; Mendes, 2011; Moura \& Souza, 2016).

Apesar das deficiências da seleção por concurso público, este ainda parece ser a melhor opção. O processo de recrutamento e seleção praticado no setor privado não garante isenção (Morici \& Barbosa, 2013). Assim, caso fosse praticado no setor público, a prática de nepotismo e o apadrinhamento político, que não são incomuns (embora ilegais), poderiam se acentuar ainda mais.

Devido às ideologias que fundamentam o concurso público, os requisitos para o cargo se constituem somente em exigências mínimas para seu exercício, isto é, em limites inferiores 
de qualificação. Por exemplo, para cargos de nível médio, exige-se ao menos o ensino médio completo; para cargos de nível superior, exige-se ao menos graduação completa. Todavia, raramente os candidatos aprovados para cargos de nível médio possuem apenas esse nível ou os aprovados para cargos de nível superior possuem apenas graduação. Há relato de situação na qual 39,0\% dos candidatos com nível superior declarou que prestaria concurso para cargos de nível médio (Albrecht \& Krawulski, 2011). No caso dos cargos de nível superior, a prova de títulos favorece a aprovação de candidatos que possuem mais do que graduação. Pode-se afirmar, então, que esse tipo de processo de seleção favorece a sobrequalificação objetiva no serviço público brasileiro.

A literatura relata que a sobrequalificação geralmente tem consequências não proveitosas para pessoas e organizações, de modo que estas evitam a admissão de indivíduos sobrequalificados. Restaria saber, então, se essas consequências negativas também ocorreriam no serviço público, considerando-se as diferenças entre esse contexto e aqueles nos quais foram realizados os estudos internacionais anteriormente revisados. Assim, o objetivo desta segunda parte da dissertação foi investigar as possíveis relações entre sobrequalificação (objetiva e percebida) e atitudes no trabalho de servidores públicos, especificamente comprometimentos organizacionais afetivo e calculativo, envolvimento com o trabalho e intenção de saída.

Atitudes são conjuntos de crenças, cognições e afetos relacionados a um objeto social (pessoas, instituições, normas, etc.), os quais predispõem o indivíduo a se comportar de determinada maneira com relação ao objeto (Rodrigues, Assmar, \& Jablonski, 2013). Dentre as atitudes no contexto do trabalho estão: comprometimento (afetivo e calculativo), envolvimento e intenção de saída.

O comprometimento afetivo corresponde a um vínculo emocional do indivíduo para com a organização, quando ele se identifica com ela e deseja nela permanecer, enquanto o 
comprometimento calculativo corresponde à conscientização, por parte do indivíduo, dos custos relacionados a deixar a organização, levando-o a nela permanecer por necessidade (Meyer \& Allen, 1991). Envolvimento no trabalho pode ser definido como o quanto o desempenho do indivíduo no trabalho afeta sua auto-estima (Lodahl \& Keyner, 1965). A intenção de saída (ou intenção de rotatividade) corresponde à intenção de deixar a organização na qua se trabalha (Mowday, Porter, \& Steers, 1982).

Comprometimento (afetivo e calculativo), envolvimento e intenção de saída foram as atitudes no trabalho selecionadas para esta pesquisa por serem variáveis clássicas no estudo da sobrequalificação ainda não investigadas em amostras nacionais, a exceção da intenção de saída, abordada em estudo antes mencionado (Maciel \& Camargo, 2013). As hipóteses específicas acerca da relação entre essas atitudes e a sobrequalificação foram formuladas com base nas teorias de processo apresentadas anteriormente. Não foram elaboradas hipóteses referentes a relações de mediação ou moderação, pois sequer existe conhecimento estabelecido sobre a predição dessas atitudes.

Assume-se que ser objetivamente sobrequalificado favorece a aprovação em concurso público, considerando-se que segundo a ideologia meritocrática, essa condição seria utilizada para admitir candidatos, não eliminá-los. Com base na teoria do capital humano (Becker, 1994), supõe-se que o indivíduo poderia perceber a aprovação no concurso como retribuição ao seu investimento em qualificação (formação, preparo para aprovação no concurso, etc.), de modo que não se perceberia sobrequalificado (embora objetivamente o fosse). Disso, propôsse a hipótese $\left(H_{1}\right)$ de que, entre servidores públicos, a sobrequalificação objetiva não se relacionaria à sobrequalificação percebida.

A aprovação no concurso público, enquanto recompensa, pode ser decomposta em duas partes: a remuneração e a estabilidade. Além disso, a aprovação teria um alto custo para o indivíduo (tempo de estudo, investimento financeiro, etc.), o que torna elevado o custo de 
deixar o serviço público (Santos et al., 2015). Assumindo-se que o ingresso no serviço público seja motivado pela remuneração e pela estabilidade, e que o custo de saída seja alto, pode-se supor que a permanência do servidor na organização pública se deva ao temor da perda desses benefícios e aos custos da saída, constituindo-se em comprometimento calculativo. Contudo, o indivíduo sobrequalificado se julga merecedor e capaz de obter emprego melhor do que aquele que possui (Crosby, 1976), de modo que não temeria a perda do cargo atual. Assim, propôs-se a hipótese $\left(H_{2}\right)$ de que a sobrequalificação percebida se relacionaria negativamente ao comprometimento calculativo.

Considerando-se que o concurso público não avalia as habilidades e aptidões dos candidatos (Mendes, 2011; Morici \& Barbosa, 2013), é possível que, ao ser aprovado e exercer o cargo, o indivíduo se perceba possuidor de mais aptidões e habilidades que seus colegas de mesmo cargo. De acordo com a teoria da privação relativa (Crosby, 1976), esse indivíduo poderia se perceber merecedor e privado de um cargo melhor, o qual se acharia capaz de possuir, mas se culparia por não possuí-lo. Isso corresponderia à sobrequalificação percebida e geraria atitudes negativas no trabalho (Erdogan \& Bauer, 2009). Assim, propuseram-se as hipóteses de que a sobrequalificação percebida se relacionaria $\left(H_{3}\right)$ negativamente ao comprometimento afetivo e $\left(H_{4}\right)$ ao envolvimento com o trabalho, e $\left(H_{5}\right)$ positivamente à intenção de saída.

Se as atitudes no trabalho se relacionam negativamente à sobrequalificação percebida e esta não se relaciona à sobrequalificação objetiva, propuseram-se as hipóteses de que a sobrequalificação objetiva não se relacionaria $\left(H_{6}\right)$ ao comprometimento calculativo, $\left(H_{7}\right)$ ao comprometimento afetivo, $\left(H_{8}\right)$ ao envolvimento com o trabalho e $\left(H_{9}\right)$ à intenção de saída. Considerando-se que comprometimento afetivo, comprometimento calculativo e envolvimento com o trabalho se relacionam negativamente à intenção de saída (Siqueira \& Gomide Junior, 2014), as hipóteses propostas neste estudo podem ser representadas pela 
Figura 2.

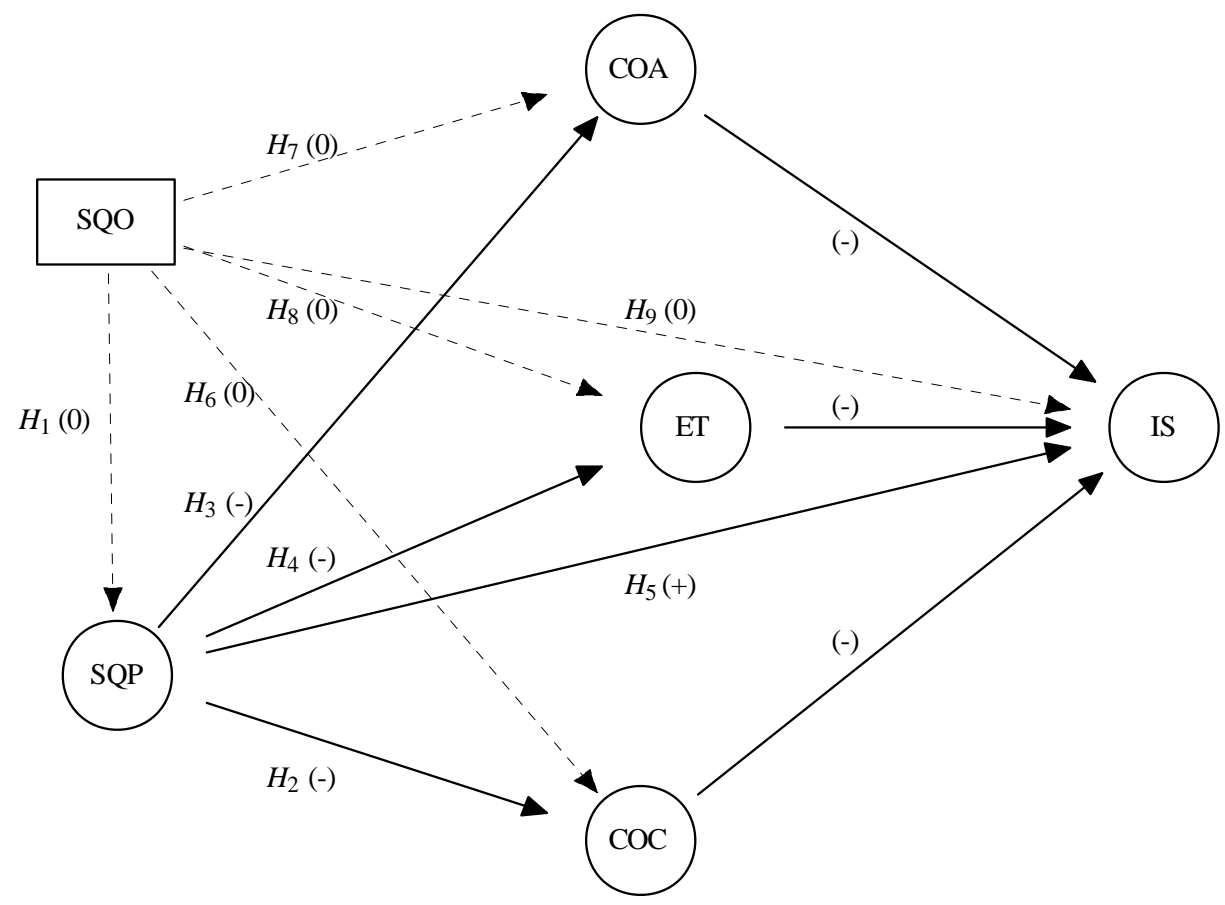

Figura 2. Relações propostas entre sobrequalificações objetiva (SQO) e percebida (SQP), comprometimentos afetivo (COA) e calculativo (COC), envolvimento com o trabalho (ET) e intenção de saída (IS). As setas contínuas indicam relações positivas (+) ou negativas (-). As setas pontilhadas indicam ausência de relação (0).

\section{Método}

Participantes. Obteve-se a participação voluntária de 372 servidores públicos (170 homens; 197 mulheres; cinco não informados), com média de idade de 39,29 anos (DP = 10,81), e trabalhando, em média, havia 9,04 anos $(D P=9,41)$ no serviço público, sendo que $67 \%$ possuíam vínculo efetivo. Eles foram recrutados em uma escola de governança de um estado brasileiro, dentre os participantes de cursos de qualificação no momento da coleta de dados. Ocupavam cargos de nível fundamental (11\%), médio (49\%), graduação (35\%), pósgraduação (5\%). Para dois participantes esse nível não foi informado. Quanto ao nível de escolaridade possuído, os dados são: $2 \%$ fundamental; $31 \%$ médio; $35 \%$ graduação; e 32\% pós-graduação. Um caso não informado. 
Instrumentos. Os participantes responderam a um instrumento (Anexo A) composto por um questionário sociodemográfico (QSD) e escalas para mensuração de sobrequalificação percebida, comprometimentos afetivo e calculativo com as organizações de trabalho, envolvimento com o trabalho e intenção de saída. O QSD obteve informações quanto a: idade, sexo, nível de escolaridade, título do cargo ocupado, vínculo, nível escolaridade do cargo ocupado e tempo de serviço no cargo atual.

A Escala de Sobrequalificação Percebida (ESQP; Gonçalves Neto, 2016) é uma versão da SPOQ (Maynard et al., 2006) adaptada ao português brasileiro, que apresenta sete opções de respostas $(1=$ discordo totalmente $; 7=$ concordo totalmente $)$ a nove assertivas. A ESQP fornece uma medida global de sobrequalificação percebida (SQP-Global), formada por duas medidas específicas: percepção de sobrequalificação quanto às necessidades do cargo (SQP-Necessidade), com quatro itens, e percepção de sobrequalificação quanto às exigências do cargo (SQP-Exigência), com cinco itens.

O envolvimento com o trabalho foi mensurado por meio da Escala de Envolvimento com o Trabalho (EET; Siqueira, 1995), com cinco itens respondidos e cinco opções de resposta $(1=$ discordo totalmente $; 5=$ concordo totalmente $)$. A intenção de saída foi mensurada por meio da Escala de Intenção de Rotatividade (EIR; Siqueira, 1995), composta por três itens respondidos em escala de cinco pontos $(1=$ nunca $; 5=$ sempre $)$.

Para mensuração do comprometimento afetivo organizacional foram utilizadas:

- A versão reduzida (cinco assertivas) da Escala de Comprometimento Organizacional Afetivo (ECOA; Siqueira, 1995), respondida em escala de cinco pontos $(1=$ nada $; 5=$ extremamente).

- A Escala de Comprometimento Organizacional Calculativo (ECOC; Siqueira, 1995), composta por 15 itens respondidos em escala de cinco pontos $(1=$ discordo totalmente; 5 = concordo totalmente), avaliando quatro dimensões: perdas sociais (perda da 
estabilidade e do prestígio do emprego, dos colegas de trabalho, etc.), perdas de investimentos feitos na organização (perda do tempo dedicado à, e posições alcançadas dentro da, organização), perdas de retribuições organizacionais (perda da remuneração e dos benefícios oferecidos pela organização) e perdas profissionais (perda do status alcançado na carreira, custos de adaptar-se a novo emprego e a aprender novas tarefas).

Procedimentos. Inicialmente, foi solicitada autorização aos responsáveis pela instituição para realização da coleta de dados em suas dependências. Uma vez concedida, as turmas foram visitadas pelo pesquisador no intervalo das aulas, explicando brevemente a pesquisa e convidando a participar. Aos que aceitaram, foi entregue o instrumento de pesquisa, cujo preenchimento durava cerca de 20 minutos, após os quais o pesquisador os recolhia. Não houve recusa de participação dentre os convidados.

Para a análise de validade dos instrumentos, foram excluídos os casos com dados ausentes, nos quais ao menos uma das escalas estava em branco, e com respostas invariadas para todos os itens em uma mesma escala. O número de casos válidos restantes para análise de cada instrumento é apresentado na Tabela 1

Tabela 1

Casos Válidos para Análise das Escalas após Exclusão de Casos com Respostas Invariadas e Respostas Ausentes

\begin{tabular}{|c|c|c|c|c|c|c|c|c|c|}
\hline \multirow[t]{2}{*}{ Escalas } & \multirow[t]{2}{*}{$n$} & \multicolumn{2}{|c|}{$\begin{array}{l}\text { Respostas } \\
\text { invariadas }\end{array}$} & \multicolumn{2}{|c|}{$\begin{array}{c}\text { Respostas } \\
\text { ausentes }\end{array}$} & \multicolumn{2}{|c|}{$\begin{array}{c}\text { Casos } \\
\text { excluídos }\end{array}$} & \multicolumn{2}{|c|}{ Casos válidos } \\
\hline & & $F$ & $F \%$ & $F$ & $F \%$ & $F$ & $F \%$ & $F$ & $F \%$ \\
\hline ESQP & 372 & 24 & 6,5 & 8 & 2,2 & 32 & 8,6 & 340 & 991,4 \\
\hline ECOA & 372 & 86 & 23,1 & - & - & 86 & 23,1 & 286 & 76,9 \\
\hline $\mathrm{ECOC}$ & 372 & 12 & 3,2 & 6 & 1,6 & 18 & 4,8 & 354 & 95,2 \\
\hline EET & 372 & 5 & 1,3 & 2 & 0,5 & 7 & 1,9 & 365 & 98,1 \\
\hline EIR & 372 & 196 & 52,7 & - & - & 196 & 52,7 & 176 & 47,3 \\
\hline
\end{tabular}


A verificação de evidências de validade dos instrumentos foi realizada por meio de análise fatorial confirmatória (AFC) com estimação por máxima verossimilhança robusta, utilizando o qui-quadrado de Satorra-Bentler ( $\left.\mathrm{SB} \chi^{2}\right)$, devido aos dados dos instrumentos não apresentarem normalidade multivariada (Brown, 2015), conforme resultados do teste de normalidade multivariada de Doornik-Hansen e do teste de assimetria e curtose multivariadas de Mardia. A AFC encontrou ajustamento perfeito para a EIR, ajustamento satisfatório para ESQP, ECOA e ECOC, e ajustamento pobre para a EET (Tabela 3). Este último instrumento foi excluído das análises posteriores.

Como critérios de ajustamento ao modelo na $\mathrm{AFC}$, foram considerados: $\mathrm{SB} \chi^{2}$ relativo $\left(\mathrm{SB} \chi^{2} / g l\right)$ menor ou igual a 2,00, RMSEA menor ou igual a 0,08 e CFI maior ou igual a 0,90 (Schmacker \& Lomax, 2010); consistência interna ( $\alpha$ de Cronbach) maior ou igual a 0,70 (Pasquali, 2012). À exceção das dimensões SQP-Necessidade (ESQP) e perdas sociais (ECOC), que apresentaram valores marginais, todos os instrumentos apresentaram índices adequados de consistência interna (Tabela 2).

Os participantes foram categorizados quanto à sobrequalificação objetiva, com base em duas dimensões: educação formal e experiência profissional. Quanto à educação formal, foram considerados sobrequalificados objetivamente aqueles cujo nível de escolaridade estivesse acima do mínimo exigido por seu cargo. Quanto à experiência profissional, tomouse o tempo de serviço como seu indicador. Uma vez que tempo de serviço não é requisito para o ingresso no serviço público, os cargos dos participantes foram comparados aos seus equivalentes do setor privado (Anexo B), com base nas famílias de ocupações descritas na Classificação Brasileira de Ocupações (CBO), disponível no site: <www.mtecbo.gov.br/>.

Foram considerados sobrequalificados objetivamente aqueles cujo tempo de serviço fosse superior ao mínimo exigido para cargo equivalente no setor privado. Consideraram-se não-sobrequalificação, as condições nas quais: o nível de educação formal fosse igual ou 
inferior ao exigido pelo cargo; o tempo de serviço fosse igual ou inferior ao exigido por cargo semelhante no setor privado; o cargo não exigisse nível mínimo de escolaridade; e o cargo não exigisse tempo de serviço mínimo.

Tabela 2

Resultados das Análises Fatoriais Confirmatórias das Escalas

\begin{tabular}{|c|c|c|c|c|c|}
\hline Escalas & $\mathrm{SB} \chi^{2}$ & RMSEA & CFI & Dimensões & $\begin{array}{c}\alpha \text { de } \\
\text { Cronbach }\end{array}$ \\
\hline \multirow[t]{3}{*}{ ESQP } & 3,07 & $0,08[0,06,0,10]$ & 0,94 & SQP-Global & 0,82 \\
\hline & & & & SQP-Necessidade & 0,65 \\
\hline & & & & SQP-Exigência & 0,78 \\
\hline $\mathrm{ECOA}^{\mathrm{a}}$ & 2,61 & $0,08[0,03,013]$ & 0,99 & - & 0,87 \\
\hline \multirow[t]{4}{*}{ ECOC } & 2,64 & $0,07[0,06,0,08]$ & 0,94 & Perdas sociais & 0,67 \\
\hline & & & & Perdas de investimento & 0,80 \\
\hline & & & & Perdas de retribuições & 0,76 \\
\hline & & & & Perdas profissionais & 0,84 \\
\hline $\mathrm{EET}^{\mathrm{a}}$ & 9,58 & $0,15[0,12,0,19]$ & 0,88 & - & 0,73 \\
\hline $\mathrm{EIR}^{\mathrm{b}}$ & - & - & - & - & 0,78 \\
\hline
\end{tabular}

Nota: Intervalo de confiança (95\%) para o RMSEA entre colchetes.

${ }^{\text {a }}$ Escala unidimensional.

${ }^{\mathrm{b}}$ Modelo saturado, com SB $\chi^{2}=0,00(p=1,00)$.

Após categorização, os participantes foram distribuídos, conforme o número de casos válidos para cada instrumento (Tabela 3), entre quatro grupos: sobrequalificação objetiva por educação formal e experiência (SET); sobrequalificação objetiva por educação formal (SE); sobrequalificação objetiva por experiência (ST); e não-sobrequalificação objetiva (NS). Cento e quarenta e três casos não foram incluídos em qualquer grupo por ausência de dados (nível do cargo, nível de escolaridade, tempo de serviço ou cargo equivalente na CBO) para categorizá-los quanto à sobrequalificação objetiva. 
Tabela 3

Número de Casos Válidos por Escala para Comparação entre Grupo de Sobrequalificação Objetiva

\begin{tabular}{lrrrrrr}
\hline \multirow{2}{*}{ Instrumentos } & Casos & \multicolumn{5}{c}{$n$ por Grupo } \\
\cline { 3 - 6 } & válidos & $\mathrm{SET}^{\mathrm{a}}$ & $\mathrm{SE}^{\mathrm{b}}$ & $\mathrm{ST}^{\mathrm{c}}$ & $\mathrm{NS}^{\mathrm{d}}$ & n Total \\
\hline ESQP & 340 & 71 & 57 & 37 & 43 & 208 \\
ECOA & 286 & 62 & 40 & 34 & 41 & 177 \\
ECOC & 354 & 74 & 54 & 41 & 47 & 216 \\
EIR & 176 & 35 & 22 & 22 & 30 & 109 \\
\hline
\end{tabular}

${ }^{\text {a }}$ Sobrequalificação objetiva por educação formal e experiência;

${ }^{\mathrm{b}}$ Sobrequalificação objetiva por educação formal;

${ }^{\mathrm{c}}$ Sobrequalificação objetiva por experiência;

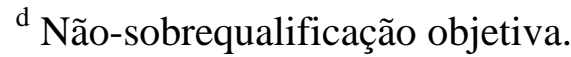

O teste das hipóteses referentes à sobrequalificação objetiva $\left(H_{1}, H_{6}, H_{7}\right.$ e $\left.H_{8}\right)$ ocorreu pela comparação dos escores médios entre grupos (SET, SE, ST e NS). Por meio do teste de Kolmogorov-Smirnov, observou-se que os escores apresentavam distribuição não-normal, de modo que as diferenças entre os grupos foram analisadas pelo teste não-paramétrico de Kruskal-Wallis e reportadas as medianas (incluindo erros-padrão e intervalos de confiança de 95\%, calculados por meio do método de reamostragem bootstrap).

Para teste das hipóteses referentes à sobrequalificação percebida $\left(H_{2}, H_{3}, H_{4}\right.$ e $\left.H_{5}\right)$ foi utilizada a modelagem de equações estruturais (structural equation modeling, SEM, por meio do programa EQS 6.3), conforme procedimentos descritos por Bentler (2006), especificandose um modelo (Figura 3) a partir das hipóteses representadas na Figura 2.

Os itens das escalas foram utilizados para constituição dos construtos a serem analisados. Os itens da ESQP constituíram as variáveis latentes sobrequalificação percebida por necessidade (SQPN) e por exigência (SQPE), as quais constituíram a sobrequalificação percebida (SQP). Os itens da ECOA constituíram o comprometimento organizacional afetivo 
(COA); os da ECOC os comprometimentos organizacionais calculativos relacionados às perdas sociais (COCS), de investimento (COCI), de retribuições (COCR) e profissionais (COCP); e os itens da EIR a intenção de saída (IS).

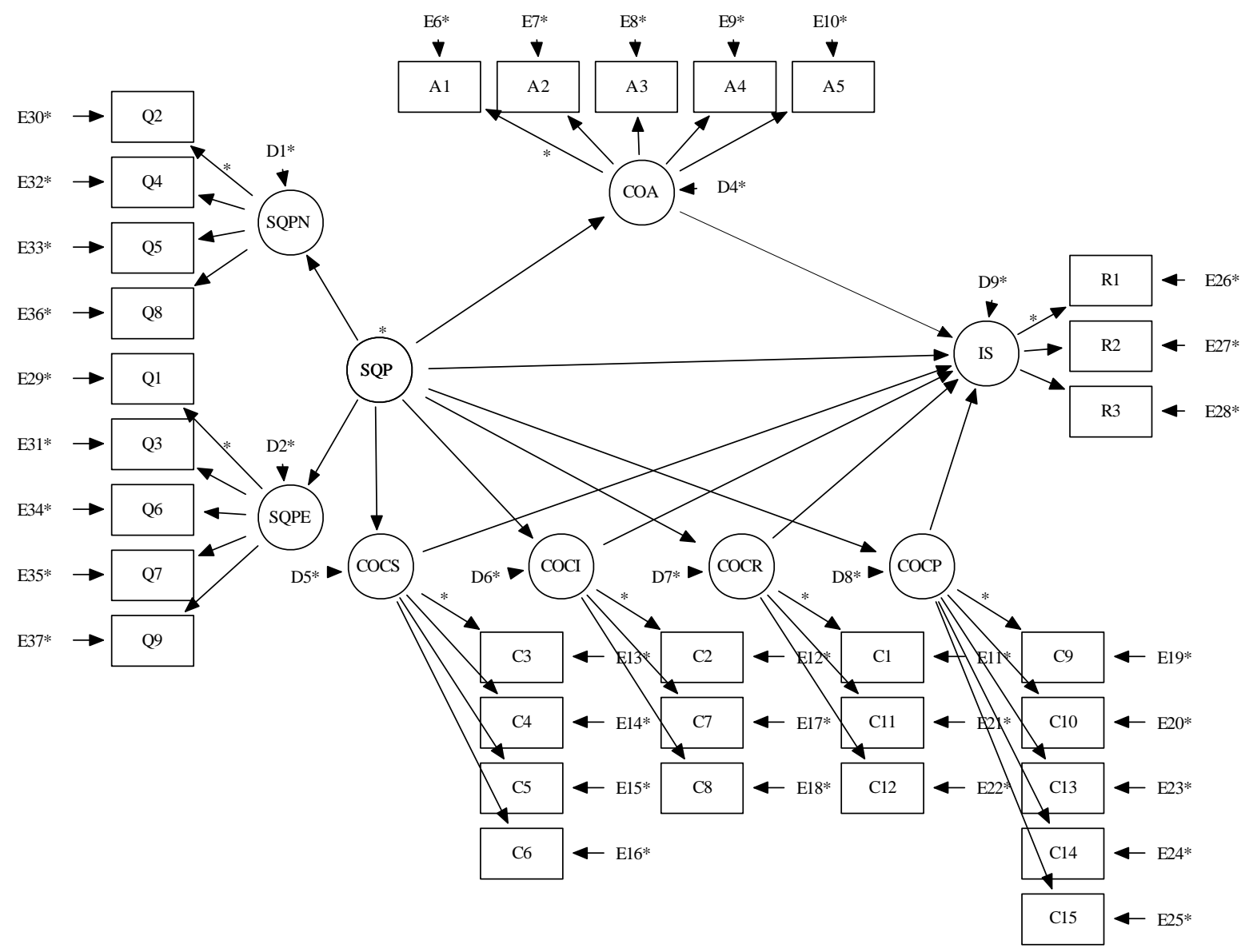

Figura 3. Modelo especificado (de mensuração e estrutural), com base nas hipóteses propostas (referentes à sobrequalificação percebida) e na literatura. Os parâmetros fixos estão marcados com asteriscos $(*)$.

A matriz de variância-covariância da amostra (Matriz S; Anexo C) apresentou 528 valores distintos e foram identificados 77 parâmetros livres a serem estimados (além de 49 parâmetros fixos: as variâncias dos erros de mensuração e dos erros de predição), resultando em 451 graus de liberdade. Desse modo, o modelo foi sobre-identificado e satisfez a condição de ordem (Schmacker \& Lomax, 2010). A Matriz S apresentou determinante $\left(1,43 \times 10^{3}\right)$ 
maior que zero, sugerindo ausência de multicolinearidade (Tabachnik \& Fidell, 2010) e satisfazendo a condição do posto (Schmacker \& Lomax, 2010).

Devido à ausência de normalidade multivariada dos dados, o modelo foi estimado por meio de máxima verossimilhança robusta, utilizando o SB $\chi^{2}$ (Brown, 2015; Tabachnik \& Fidell, 2010). Análise dos dados ausentes indicou serem completamente aleatórios (missing completely at random, MCAR), conforme resultado da análise da matriz de correlações de variáveis dicotomizadas (Bentler, 2006). Neste caso, os dados ausentes foram tratados com eliminação por pares (Anexo D), evitando redução drástica no tamanho da amostra (a qual inviabilizaria o uso de SEM). Foram necessárias 17 iterações para convergência a um conjunto ótimo de parâmetros estimados, ocorrendo mudança absoluta de 7,33 x $10^{-4}$ nas médias dos parâmetros após a última iteração.

$\mathrm{O}$ modelo estimado apresentou bom ajustamento com: $\mathrm{SB} \chi^{2}$ relativo $=1,79 ; \mathrm{CFI}=$ 0,90; e RMSEA $=0,05$, IC 95\% [0,04, 0,05]. Tanto a média de resíduos padronizados absolutos de variância quanto a média de resíduos padronizados absolutos de covariância, apresentaram valores iguais a 0,06 , indicando que menos de $1 \%$ da variância e covariância não foram explicadas pelo modelo, o que também sugeriu bom ajustamento (Ullman, 2006). Em anexo, encontram-se as tabelas com: estatísticas descritivas das variáveis de mensuração (Anexo E); as matrizes de variância-covariância do modelo (matriz $\Sigma$; Anexo F) e de resíduos (Anexo $\mathrm{G})$; equações de mensuração (Anexo $\mathrm{H}$ ) e estruturais (Anexo I); efeito total nãopadronizado (Anexo J) e padronizado (Anexo K); efeito indireto não-padronizado (Anexo L) e padronizado (Anexo M); e solução padronizada e variância explicada (Anexo N).

As variáveis latentes constituintes do modelo (SQP, SQPN, SQPE, COA, COCS, COCI, COCR, COCP e IS), apesar de relacionadas aos itens dos instrumentos utilizados (ESQP, ECOA, ECOC e EIR), não representam seus escores, mas construtos interpretados a partir de seus itens. Variáveis latentes ou construtos são abstrações das variáveis observáveis 
mensuradas (Thompson, 2004). Essa observação é especialmente importante para a variável SQP. Na ESQP, a dimensão SQP-Global é constituída por duas dimensões (SQP-Necessidade e SQP-Exigência), as quais são constituídas pelos itens do instrumento. Esses itens foram desenvolvidos para mensuração direta da sobrequalificação percebida. Isso significa que, quanto maior o valor da resposta a eles (por meio da escala de respostas do instrumento), maior o escore na dimensão correspondente e, consequentemente, maior o escore SQPGlobal. Assim, em decorrência dessa relação com os itens, a dimensão SQP-Global é considerada uma medida direta da sobrequalificação.

No modelo estimado neste estudo, a variável latente SQP apresentou relação negativa com as variáveis latentes SQPN e SQPE, as quais se relacionaram positivamente aos itens da ESQP, as variáveis observáveis. Isso significa que a variável SQP também se relacionou negativamente aos itens. Por isso, a variável SQP necessitou de interpretação diferente daquela da dimensão SQP-Global. Mais especificamente, a SQP correspondeu à nãosobrequalificação, isto é, quanto maior a variância dos itens da ESQP, menor a variância do construto SQP ou menor a não-sobrequalificação. Portanto, para efeito do teste das hipóteses desta pesquisa, considerou-se que quanto maior o valor da variável SQP, menor a sobrequalificação percebida.

\section{Resultados}

Das nove hipóteses propostas nesta pesquisa, duas não foram testadas por problemas metodológicos, duas não foram apoiadas e cinco encontraram apoio nos dados empíricos. Devido à ausência de evidências de validade da EET, optou-se por não testar as hipóteses referentes ao envolvimento no trabalho $\left(H_{4}\right.$ e $\left.H_{8}\right)$, evitando imprecisão nos resultados e conclusões. Serão, então, descritos os resultados referentes às sete hipóteses restantes. 
A primeira hipótese $\left(H_{1}\right)$ desta pesquisa propôs que a sobrequalificação objetiva não se relacionaria à sobrequalificação percebida. Os escores médios de SQP-Global diferiram entre os grupos, com $H(3)=16,95(p<0,01)$. A comparação por pares indicou que a diferença ocorreu entre os grupos SET e NS $(U=43,33 ; p<0,01 ; r=0,25)$ e SE e NS $(U=$ 41,44; $p<0,01 ; r=0,24)$, sendo o escore médio menor para o grupo NS do que para os grupos SET e SE (Tabela 4).

Tabela 4

Estatísticas Descritivas dos Escores de SQP-Global e SQP-Exigência para os Grupos de Sobrequalificação Objetiva

\begin{tabular}{lcccc}
\hline \multirow{2}{*}{ Escores } & \multirow{2}{*}{ Grupos } & Mdn & \multicolumn{2}{c}{ Bootstrap } \\
\cline { 3 - 5 } & & & $E P$ & IC95\% \\
\hline SQP-Global & SET $^{\mathrm{a}}$ & 4,56 & 0,28 & {$[4,00,5,06]$} \\
& $\mathrm{SE}^{\mathrm{b}}$ & 4,33 & 0,22 & {$[3,67,4,89]$} \\
& $\mathrm{ST}^{\mathrm{c}}$ & 3,56 & 0,34 & {$[3,11,4,22]$} \\
& $\mathrm{NS}^{\mathrm{d}}$ & 3,00 & 0,31 & {$[2,61,3,67]$} \\
SQP-Necessidade & $\mathrm{SET}^{\mathrm{a}}$ & 3,75 & 0,24 & {$[3,25,4,00]$} \\
& $\mathrm{SE}^{\mathrm{b}}$ & 4,25 & 0,28 & {$[3,38,4,50]$} \\
& $\mathrm{ST}^{\mathrm{c}}$ & 3,25 & 0,34 & {$[2,50,4,00]$} \\
& $\mathrm{NS}^{\mathrm{d}}$ & 2,75 & 0,25 & {$[2,25,3,38]$} \\
SQP-Exigência & $\mathrm{SET}^{\mathrm{a}}$ & 5,20 & 0,31 & {$[4,60,5,80]$} \\
& $\mathrm{SE}^{\mathrm{b}}$ & 4,60 & 0,29 & {$[4,00,5,40]$} \\
& $\mathrm{ST}^{\mathrm{c}}$ & 4,00 & 0,35 & {$[3,00,4,40]$} \\
& $\mathrm{NS}^{\mathrm{d}}$ & 3,40 & 0,32 & {$[2,80,4,10]$}
\end{tabular}

\footnotetext{
${ }^{a}$ Sobrequalificação objetiva por educação formal e experiência;

${ }^{\mathrm{b}}$ Sobrequalificação objetiva por educação formal;

${ }^{c}$ Sobrequalificação objetiva por experiência;

d Não-sobrequalificação objetiva.
}

Os escores médios de SQP-Necessidade também diferiram entre os grupos, com $H(3)$ 
$=10,11(p<0,05)$. A comparação por pares encontrou diferença apenas entre os grupos SE e NS $(U=36,24 ; p<0,05 ; r=0,21)$, sendo o escore médio do grupo NS menor do que o do grupo SE (Tabela 4). Os escores de SQP-Exigência diferiram significativamente entre os grupos, com $H(3)=18,17(p<0,001)$. A comparação por pares encontrou diferença apenas entre os grupos SET e NS $(U=46,42 ; p<0,001 ; r=0,26)$ e SE e NS $(U=36,94 ; p<0,05 ; r$ $=0,21$ ), sendo o escore do grupo NS menor que os dos grupos SET e SE (Tabela 4). Esses resultados não apoiaram a hipótese $H_{1}$.

A Figura 4 apresenta o modelo estimado por meio do qual foram testadas as hipóteses referentes à sobrequalificação percebida. São apresentados os valores padronizados para todos os parâmetros. No modelo de mensuração, todos os coeficientes estruturais das variáveis de mensuração (itens dos instrumentos) se relacionaram positiva e significativamente aos seus respectivos construtos (Anexo 8). Somente coeficientes entre as variáveis SQP e SQPN e variáveis SQP e SQPE apresentaram coeficientes negativos. As significâncias dos parâmetros foram testadas por meio do teste- $z$, cujo valor crítico é 1,96, para nível de significância de 5\%.

A hipótese $H_{2}$ propôs que a sobrequalificação percebida se relacionaria negativamente ao comprometimento calculativo. A variável SQP se relacionou positivamente às variáveis $\operatorname{COCS}\left(\gamma=0,96 ; R^{2}=0,93\right), \operatorname{COCI}\left(\gamma=0,86 ; R^{2}=0,75\right), \operatorname{COCR}\left(\gamma=0,87 ; R^{2}=0,76\right)$ e COCP $\left(\gamma=0,95 ; R^{2}=0,91\right)$. Considerando-se que a SQP representou a não-sobrequalificação, esse resultado ofereceu apoio à hipótese $H_{2}$. A hipótese $H_{3}$ propôs que a sobrequalificação percebida se relacionaria negativamente ao comprometimento afetivo. A SQP se relacionou positivamente ao construto COA, com coeficiente estrutural $\gamma=0,35\left(R^{2}=0,12\right)$, apoiando a hipótese $H_{3}$. A hipótese $H_{5}$ propôs que a sobrequalificação percebida se relacionaria positivamente à intenção de saída. Não foi encontrada relação significativa entre SQP e IS, não tendo sido apoiada a hipótese $H_{5}$. O efeito indireto da SQP sobre a IS (mediado por 
COA, COCS, COCI, COCR e COCP), também não foi significativo.

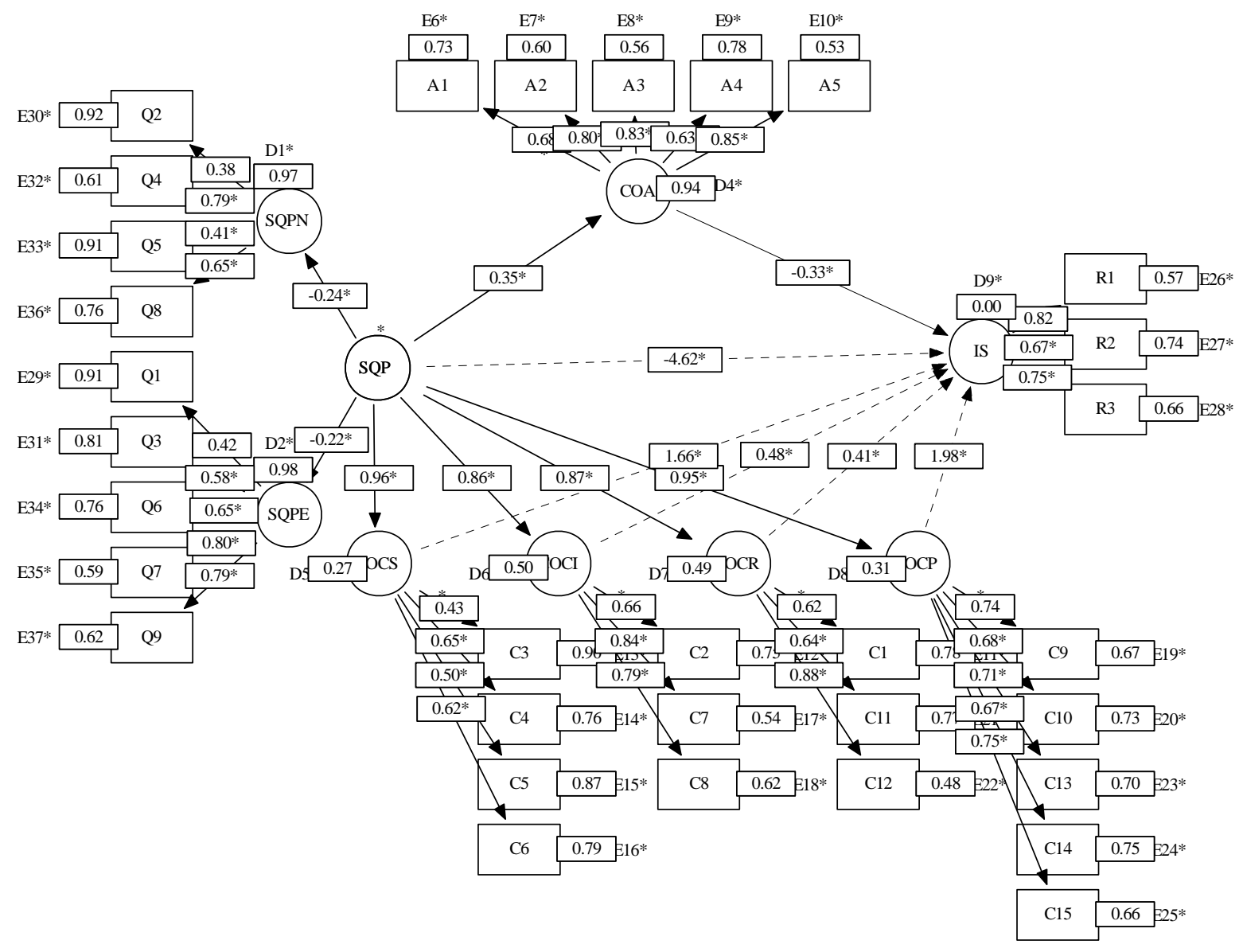

Figura 4. Modelo estimado com valores padronizados para os parâmetros. As linhas pontilhadas indicam relações não-significativas entre as variáveis $(p>0,05)$. Os parâmetros cujos valores estão marcados com asteriscos estavam livres durante a estimação do modelo.

A hipótese $H_{6}$ propôs que a sobrequalificação objetiva não se relacionaria ao comprometimento calculativo. O teste de Kruskal-Wallis não encontrou diferença significa entre os grupos quantos aos escores das quatro dimensões da ECOC, o que apoiou a hipótese $H_{6}$. A hipótese $H_{7}$ propôs que a sobrequalificação objetiva não se relacionaria ao comprometimento afetivo. Novamente, não foi encontrada diferença significativa entre os escores dos grupos para a ECOA, apoiando a hipótese $H_{7}$. A hipótese $H_{9}$ propôs que a sobrequalificação objetiva não se relacionaria à intenção de saída, porém, não foi encontrada 
diferença significativa entre os escores dos grupos para a EIR, dando apoio à hipótese $H_{9}$.

Finalmente, embora não fossem hipóteses formais, esperava-se que as variáveis COA, COCS, COCI, COCR e COCP se relacionassem negativamente à IS, conforme descrito na literatura (Siqueira \& Gomide Junior, 2014), o que complementaria o modelo proposto. O construto COA se relacionou negativamente à variável IS $(\gamma=-0,33)$, mas COCS, COCI, COCR e COCP não apresentaram relação significativa com IS.

\section{Discussão}

O modelo proposto e testado por meio das hipóteses deste estudo foi parcialmente apoiado. Mesmo as relações das atitudes no trabalho entre si, descritas na literatura (Siqueira \& Gomide Junior, 2014), não foram totalmente observadas. Os resultados empíricos, aliados à literatura da sobrequalificação apresentada, sugeriram outra estrutura para a relação entre sobrequalificação e atitudes no trabalho.

Diferente do que propôs a primeira hipótese $\left(H_{1}\right)$, a sobrequalificação objetiva se associou positivamente à sobrequalificação percebida. Participantes que possuíam nível de educação formal e experiência profissional superiores aos exigidos por seus cargos se perceberam mais sobrequalificados do que seus pares que possuíam nível de educação formal e experiência profissional equivalentes ou inferiores aos exigidos. Isso sugeriu que a aprovação em concurso público não foi percebida como retorno ao investimento dos participantes em educação ou talvez tenha sido percebida com retorno insuficiente, levando à percepção de sobrequalificação. É provável que os participantes vislumbrassem retorno ao seu investimento em educação que ia além da aprovação no concurso público.

A relação entre as sobrequalificações objetiva e percebida permite ainda supor que os servidores tinham conhecimento de sua condição de sobrequalificados, como sugerido na 
literatura (Maltarich et al., 2011). Essa seria uma das razões de seus níveis de educação formal e de experiência profissional (tempo de serviço) terem influenciado suas percepções de sobrequalificação.

A sobrequalificação percebida se relacionou negativamente às quatro dimensões do comprometimento calculativo, conforme proposto pela hipótese $H_{2}$. Quanto mais sobrequalificados os servidores públicos se perceberam, menores os custos percebidos (perdas sociais, de investimentos, de retribuições e profissionais) de um pedido de exoneração. Porém, o baixo custo desta possível saída não exerceu efeito sobre a intenção de saída, pois não foi encontrada relação significativa entre comprometimento calculativo e intenção de saída. Se o comprometimento calculativo representa a perda de retribuições como estabilidade e remuneração e este não se relacionou à intenção de saída, então se pode supor que estabilidade e remuneração não seriam os principais motivadores da permanência dos participantes no serviço público, embora possam ter sido para o ingresso, como sugere a literatura (Albrecht \& Krawulski, 2011; Mendes, 2010; Morici \& Barbosa, 2013; Santos et al., 2015).

A relação negativa entre sobrequalificação percebida e comprometimento calculativo permitiu também inferências quanto à vocação dos participantes para seus cargos. Pode-se supor que apresentavam baixa vocação para seu trabalho, uma vez que a relação negativa entre sobrequalificação percebida e comprometimento calculativo ocorreria quando a vocação é baixa (Lobene \& Meade, 2013). Isso corroborou a afirmação de que as pessoas que ingressam no serviço público não consideram as atividades inerentes ao cargo (sua vocação para tal) no momento do ingresso (Albrecht \& Krawulski, 2011; Mendes, 2011; Morici \& Barbosa, 2013; Santos et al., 2015).

A sobrequalificação percebida foi encontrada negativamente relacionada ao comprometimento afetivo, conforme proposto na hipótese $H_{3}$. Essa relação corresponde a um 
efeito não-proveitoso da sobrequalificação sobre as atitudes no trabalho dos servidores, como relatado em outras pesquisas (Liu \& Wang, 2012; Maynard \& Parfyonova, 2013).

Devido à experiência no setor público, é possível supor que os participantes desejassem que seu investimento em capital humano fosse retribuído (Becker, 1994), mas não esperassem tal retribuição pela organização. Neste caso, os servidores reconheceriam a existência de sua qualificação excedente e a perceberiam como uma contribuição relevante não retribuída pela organização, conforme propõe a teoria da equidade (Adams, 1963). Ainda assim, esses servidores desejariam essa retribuição (em termos de promoções, remuneração, benefícios, etc.), que considerariam possível obter (pela sua qualificação adquirida) e da qual se julgariam merecedores (pelo seu esforço), não se culpando por não recebê-la (pois dependeria da organização), como sugere a teoria da privação relativa (Crosby, 1976). A incongruência entre investimento e retorno seria então percebida como injusta, afetando negativamente o vínculo afetivo com a organização (Erdogan \& Bauer, 2009).

A sobrequalificação percebida, diferente dos resultados descritos na literatura (Liu \& Wang, 2012), não se relacionou à intenção de saída, como proposto pela hipótese $H_{5}$. Isso sugere que perceber-se sobrequalificado ou não foi irrelevante para que os servidores desejassem deixar os órgãos nos quais trabalhavam. A única variável relacionada à intenção de saída foi o comprometimento afetivo. De acordo com esse resultado, a permanência dos participantes poderia ser atribuída ao desejo de permanecerem nos seus cargos e à congruência entre seus valores e os das instituições; quanto maior esses desejo e congruência, menor a intenção de pedir exoneração.

Apesar de ter se associado positivamente à sobrequalificação percebida, a sobrequalificação objetiva não se associou a qualquer das atitudes no trabalho que puderam ser testadas neste estudo, corroborando as hipóteses $H_{6}, H_{7}$ e $H_{9}$. Isso sugere que, no caso dos servidores públicos investigados, possuir maior nível de educação formal ou mais experiência 
profissional (em termos de tempo de serviço) não influenciou seus comprometimentos (de bases afetiva e cognitiva), nem suas intenções de deixar seus cargos.

Os resultados deste estudo sugeriram que a relação entre sobrequalificação e atitudes no trabalho poderia ocorrer em cadeia. A sobrequalificação objetiva se relacionaria positivamente a sobrequalificação percebida, que manteria relação negativa com os comprometimentos afetivo e calculativo. O comprometimento afetivo, por sua vez, se relacionaria negativamente à intenção de saída. Em termos de comportamentos no trabalho, o comprometimento afetivo estaria ainda positivamente relacionado ao desempenho no trabalho e negativamente à rotatividade (Siqueira \& Gomide Junior, 2014). Essas relações sugerem que o comprometimento afetivo seria mediador da relação entre sobrequalificação percebida e intenção de saída.

Assim, quanto maior o nível de educação formal e a experiência profissional dos servidores, maior sua percepção de sobrequalificação; quanto maior a percepção de sobrequalificação, menores os custos percebidos quanto de saída percebidos e menor o vínculo afetivo com a instituição; quanto menor esse vínculo, menor o desempenho e maior a intenção de exoneração voluntária. Essa foi a relação entre sobrequalificação e atitudes no trabalho observada para os servidores públicos participantes deste estudo.

No início deste trabalho questionou-se se as consequências negativas da sobrequalificação (para pessoas e organizações), observadas no setor privado, também ocorreriam no serviço público. Os dados empíricos permitiram responder que sim, a sobrequalificação percebida ocorre e tem consequências negativas também no serviço público. Contudo, a solução para evitar essas consequências negativas no serviço público não seria a mesma empregada no setor privado.

Nas organizações privadas, durante o processo de recrutamento e seleção, indivíduos sobrequalificados podem ser excluídos do processo, seguindo a perspectiva da 
sobrequalificação como risco (Kulkarni et al., 2015). Essa medida é ineficaz, pois apenas evita a sobrequalificação aparente e adia a ocorrência da sobrequalificação emergente, culminando no paradoxo da sobrequalificação (Maynard et al., 2009, citados por Feldman \& Maynard, 2011). Entretanto, embora essa medida seja comum no setor privado (Erdogan et al., 2001a; Fine, 2007) pode ser considerada uma prática discriminatória (Boucinhas Filho, 2008).

No caso do serviço público, considerando-se o modelo em cadeia inferido dos resultados aqui encontrados, evitar o ingresso de indivíduos sobrequalificados seria intervir no primeiro elo da cadeia. Isso exigiria intervir no processo de seleção por concurso público, como defendido por alguns autores (Fontainha et al., 2015; Mendes, 2011; Morici \& Barbosa, 2013). Substituir o concurso público pelo processo de recrutamento e seleção do setor privado poderia agravar o favorecimento político e o nepotismo no serviço público, por não garantir isenção (Morici \& Barbosa, 2013). A discussão sobre modificações na seleção por concurso público fugiria dos objetivos deste estudo, além de poder envolver práticas consideradas discriminatórias.

Nesta pesquisa foi adotada a perspectiva da sobrequalificação como investimento (Kulkarni et al., 2015), assumindo-se que a sobrequalificação não é algo a ser evitado, mas gerenciado (Fine \& Nevo, 2011). Sugere-se que o elo da cadeia sobre o qual se deve intervir é na sobrequalificação percebida. O concurso público favorece o ingresso de servidores sobrequalificados. Contudo, deve-se considerar que os indivíduos sobrequalificados que ingressam no serviço público o fazem voluntariamente; essas pessoas sabem que possuem qualificações acima das exigidas para o cargo. Esse conhecimento da condição de sobrequalificação seria uma das explicações para a relação positiva encontrada entre as sobrequalificações objetiva e percebida dos participantes desta pesquisa. Essa sobrequalificação voluntária não teria obrigatoriamente consequências negativas para 
indivíduo e organização (Erdogan et al., 2011b; Maltarich et al., 2011; Thompson et al., 2013).

A qualificação excedente dos servidores sobrequalificados poderia ser aproveitada pelas organizações públicas, como sugerido para o setor privado (Hu et al., 2015). Se devidamente gerenciadas, essas competências excedentes poderiam ser convertidas em serviços de melhor qualidade à população. O que faltaria ao serviço público seria a gestão adequada da sobrequalificação de seu pessoal. Isso envolveria, por exemplo, a definição de critérios para a distribuição do pessoal, evitando o desperdício da formação profissional dos servidores (Mendes, 2011). Isso evitaria, por exemplo, que um agente administrativo (nível médio) graduado em contabilidade trabalhasse em um setor jurídico, enquanto um agente administrativo graduado em direito trabalhasse no setor de contabilidade do mesmo órgão público.

A gestão da sobrequalificação no serviço público não é apenas uma questão de controle das atitudes e comportamentos dos servidores públicos no trabalho. Gerenciar adequadamente a sobrequalificação é cuidar do bem-estar dos servidores. A sobrequalificação percebida pode se relacionar positivamente a estresse e depressão (Johnson \& Johnson, 1996) e negativamente à saúde mental (Chen et al., 2010), enquanto reação emocional à injustiça (Adams, 1963; Liu \& Wang, 2012) e à privação (Crosby, 1976; Luksyte \& Spitzmueller, 2011). A gestão da sobrequalificação seria, provavelmente, a maneira mais adequada de lidar com esse fenômeno no contexto do serviço público.

A gestão da sobrequalificação no serviço público deveria envolver ainda o plano de carreiras. A ocupação de funções de gestão, por exemplo, poderia ser condicionada a qualificação profissional, independentemente do nível do cargo. Assim, servidores de nível médio possuidores de graduação (ou pós-graduação) poderiam ser promovidos a funções de gestão. Uma medida mais complexa envolveria planos de carreira que permitissem, aos 
servidores, migrar de cargos (de nível médio para superior, por exemplo), à medida que adquirissem maior qualificação, por meio de algum tipo de concurso interno. Obviamente, para que medidas como essas sejam possíveis, são necessárias mudanças na legislação que regulamenta o serviço público brasileiro.

Implicações Teóricas. Um dos objetivos deste estudo foi investigar os possíveis efeitos da sobrequalificação (objetiva e percebida) sobre as atitudes no trabalho de servidores públicos. Nesse objetivo estariam incluídas três implicações teóricas. Em primeiro lugar, a sobrequalificação e suas relações com atitudes no trabalho é um tema pouco estudado no Brasil, apesar da extensa literatura internacional. Esta foi, portanto, uma das primeiras investigações sobre esse fenômeno entre trabalhadores brasileiros. Em segundo lugar a sobrequalificação provavelmente ocorre no serviço público brasileiro há bastante tempo e, embora possa ser intuitivamente reconhecida, ainda não foi suficientemente investigada. Consequentemente, esta seria uma das primeiras pesquisas sobre esse fenômeno no serviço público brasileiro. Em terceiro lugar, a realização deste estudo em amostra brasileira permitiu, até certo ponto, levantar suposições sobre processos culturais. As relações da sobrequalificação com os comprometimentos afetivo e calculativo, encontradas em amostras de outros países, foram observadas também no Brasil, sugerindo que esse fenômeno ocorre de modo semelhante em culturas supostamente diferentes.

Os resultados aqui encontrados também contribuem para a teoria acerca das dimensões da sobrequalificação. A associação entre sobrequalificação percebida e sobrequalificação objetiva, observada nos resultados, corroborou a educação formal e a experiência profissional não apenas como dimensões da sobrequalificação, conforme o modelo da sobrequalificação (Edwards, 1991; Feldman, 1996; Kristof, 1991; Maynard et al., 2006), mas como medidas de sobrequalificação. Foram avaliadas duas dimensões da sobrequalificação, a educação formal e a experiência profissional, considerando-se que 
indivíduos com maior nível de educação formal e mais experiência profissional seriam mais sobrequalificados objetivamente do que indivíduos com somente maior nível de educação formal ou somente mais experiência profissional. Por sua vez, estes seriam mais objetivamente sobrequalificados do que indivíduos com nível de educação formal e experiência profissional equivalentes ou inferiores aos exigidos por seus cargos.

Os participantes para os quais as dimensões avaliadas (educação formal e experiência profissional) estavam acima das exigidas pelo cargo apresentaram maior sobrequalificação percebida do que os servidores para os quais essas dimensões eram equivalentes ou inferiores às exigências de seus cargos (diferença estatisticamente significativa). Quando a sobrequalificação percebida se referia às necessidades do cargo, aqueles que possuíam somente maior nível de educação formal se perceberam mais sobrequalificados do que aqueles que possuíam somente mais experiência profissional, sendo observada relação inversa quando a sobrequalificação percebida se referia às exigências do cargo (diferenças não significativas estatisticamente).

$\mathrm{Na}$ literatura não há consenso acerca da relação entre sobrequalificação objetiva e sobrequalificação percebida. Alguns autores a consideraram incerta (Erdogan et al, 2011a; Fine \& Nevo, 2011; Maynard et al., 2006), enquanto outros sugeriram a existência de relação positiva (Maltarich et., 2011; Maynard et al., 2015; Zhang et al., 2016). Os resultados desta pesquisa contribuíram para a literatura ao encontrar apoio para a existência dessa relação, dada a associação entre as sobrequalificações objetiva e percebida aqui relatada. Também não foi encontrado, na literatura revisada, relato de relação entre sobrequalificação percebida e comprometimento calculativo, exceto aquela moderada pela vocação (Lobene \& Meade, 2013). Este estudo contribuiu para a literatura ao relatar tal relação.

Apesar de o estudo da sobrequalificação objetiva ser defendido por alguns autores (Maltarich et al., 2011), a ideia de que o foco nela é menos relevante que o foco na 
sobrequalificação percebida (Johnson et al., 2002; Kristof, 1996) foi apoiada neste estudo. Enquanto a sobrequalificação percebida se relacionou aos comprometimentos afetivo e calculativo, a sobrequalificação objetiva não se relacionou a qualquer das atitudes no trabalho investigadas. Sabendo-se, então, que a sobrequalificação objetiva se relaciona positivamente à sobrequalificação percebida, na prática, o estudo desta última seria mais relevante.

Outra contribuição importante para a literatura foi a possibilidade de investigar indivíduos objetivamente sobrequalificados. As pesquisas acerca da sobrequalificação investigaram amostras de trabalhadores que já ocupavam seus cargos havia algum tempo e, apesar de apresentarem sobrequalificação percebida, muito provavelmente ingressaram nas organizações por não terem sido considerados objetivamente sobrequalificados durante o processo de recrutamento e seleção. Nessas amostras, provavelmente a sobrequalificação seria do tipo emergente. Os participantes investigados neste estudo, por outro lado, foram em sua maioria selecionados para seus cargos com base em critério oposto, sendo favorecido o ingresso de indivíduos objetivamente sobrequalificados. É muito provável que boa parte deles já apresentasse nível de educação formal, experiência profissional e habilidades acima dos exigidos no concurso público do qual participaram (no caso dos servidores de vínculo efetivo) e no qual foram aprovados. Assim, foi possível investigar as atitudes de indivíduos que haviam ingressado objetivamente sobrequalificados na organização. Talvez esta seja uma das razões desta pesquisa ter encontrado relação positiva entre sobrequalificação objetiva e sobrequalificação percebida. Novo estudo, coletando informações acerca da condição do servidor antes de ingressar no órgão (se objetivamente sobrequalificado ou compatível ao cargo), poderia testar essa hipótese.

Limitações e sugestões para novos estudos. Esta pesquisa foi realizada em um único estado brasileiro, mas incluiu servidores das três esferas do serviço público (federal, estadual e municipal), tanto civis quanto militares. Infelizmente, a fim de garantir o anonimato dos 
participantes, não foram solicitadas informações quanto à esfera a qual estavam vinculados. Isso representa perda de informações relevantes, pois há diferenças significativas entre as esferas, quanto a plano de carreira e remunerações, por exemplo. Estudo futuro poderia incluir essa variável para análise. Além disto, aproximadamente um terço dos participantes da amostra possuía vínculo não-efetivo e, portanto, muitos não foram admitidos via concurso público. Outros ingressaram mediante concurso, mas não possuíam vínculo efetivo, como os militares das Forças Armadas. Seria interessante a realização de estudo avaliando apenas servidores efetivos ingressantes por concurso ou comparando efetivos e não-efetivos a fim de investigar possíveis diferenças entre vínculos.

Chamou a atenção o grande número de casos excluídos, a maioria por respostas invariadas. Apesar de nenhum dos servidores convidados ter se recusado a participar da pesquisa, as respostas invariadas poderiam ser um tipo de recusa velada a responder questões sobre determinado assunto (abordado em determinada escala). Não se sabe até que ponto as respostas invariadas a uma escala poderiam ter influenciado as respostas às demais escalas. Ainda assim, casos com respostas invariadas a apenas uma das escalas foram mantidos, a fim de garantir número suficiente de casos para análise.

Apesar das dimensões da sobrequalificação percebida (SQP-Necessidade e SQPExigência) estarem presentes no modelo, suas relações com as atitudes no trabalho não foram analisadas, devido a problemas técnicos. Estudo futuro poderia incluir também essas dimensões como variáveis preditoras, a fim de determinar o efeito individual de cada uma delas. Também foram abordadas apenas duas dimensões da sobrequalificação objetiva (educação formal e experiência profissional). Seria relevante investigar também a dimensão habilidades, completando o modelo constitutivo da sobrequalificação. Tendo sido investigadas as atitudes no trabalho, como variáveis critério, estudos futuros poderiam investigar a relação entre sobrequalificação e comportamentos no trabalho (como rotatividade 
e absenteísmo). Essas foram as principais limitações deste estudo e as sugestões dele decorrentes para novas pesquisas. 


\section{Considerações Finais}

Esta dissertação visou dois objetivos. O primeiro foi apresentar a teoria acerca da sobrequalificação, sua definição, estrutura, classificação, teorias explicativas, mensuração, implicações e os resultados dos principais estudos sobre esse fenômeno. O segundo foi realizar um estudo empírico, em amostra diferente da relatada em estudos internacionais quanto a duas características: brasileiros e servidores públicos. Ambos os objetivos foram alcançados.

A literatura revisada e apresentada nesta dissertação não esgotou a literatura sobre o tema. Entretanto, a maior parte do conteúdo teórico (definições, conceitos, classificações, etc.) foi seguramente contemplada. Também foram abordados os trabalhos clássicos da área e os instrumentos de medida mais utilizados nas pesquisas. Esse conteúdo teórico fundamentou uma estrutura para o construto sobrequalificação. Deste modo, este trabalho se constitui em fonte inicial de consulta para aqueles que pretendam investigar esse fenômeno.

O estudo empírico se constituiu em um dos primeiros a respeito da sobrequalificação no Brasil. Apesar de existirem outras pesquisas nacionais sobre o tema (também descritas na literatura revisada), este foi o mais fundamentado teoricamente, em termos de definição e mensuração da sobrequalificação (objetiva e percebida). As variáveis critério abordadas (atitudes no trabalho) foram escolhidas justamente por terem sido abordadas nos estudos clássicos acerca da sobrequalificação. Isso se justifica pelo fato de que, para acompanhar o estado da arte das pesquisas sobre o fenômeno sobrequalificação, é necessário assegurar-se de que, no Brasil, sua ocorrência se assemelha a de amostras de outros países. Assim, garante-se que os pressupostos apresentados na literatura internacional também são válidos para amostras brasileiras, podendo fundamentar o estudo da sobrequalificação em amostras nacionais. 
Muito embora a teoria aqui apresentada e os achados empíricos aqui descritos sejam relevantes e possam ter implicações para os setores público e privado, as decisões sobre como lidar com a sobrequalificação dependem, antes de qualquer coisa, de interesses econômicos e de decisões políticas. Isso limita a coleta de dados (receio das organizações em revelar suas práticas de recrutamento e seleção) e o desenho de intervenções (devido aos custos, no setor privado, e prováveis restrições legais, no setor público). Ainda assim, o estudo da sobrequalificação, especialmente a descrição e compreensão de suas causas e consequências, é uma fonte promissora de ações para a melhoria das relações entre indivíduos, organizações e trabalho. 


\section{Referências}

Adams, J. S. (1963). Toward an understanding of inequity. Journal of Abnormal and Social Psychology, 67(5), 422-436.

Albrecht, P. A. T. \& Krawulski, E. (2011). Concurseiros e a busca por um emprego estável: Reflexões sobre os motivos de ingresso no serviço público. Cadernos de Psicologia Social do Trabalho, 14(2), 211-226.

Alfes, K., Shantz, A., \& Baalen, S. (2016). Reducing perceptions of overqualification and its impact on job satisfaction: The dual roles of interpersonal relationships at work. Human Resource Management Journal, 26(1), 84-101.

Becker, G. S. (1994). Human capital: A theoretical and empirical analysis, with special reference to education (3rd Ed.). Chicago: The University of Chicago Press.

Bentler, P. M. (2006). EQS 6 structural equations program manual. Encino, CA: Multivariate Software, Inc.

Bolino, M. C. \& Feldman, C. D. (2000). The antecedents and consequentes of underemployment among expatriates. Journal of Organizational Behavior, 21, 889911.

Boucinhas Filho, J. C. (2008). Discriminação por sobrequalificação (Dissertação de mestrado). Retirado de http://www.teses.usp.br/teses/

Brown, T. A. (2015). Confirmatory factor analysis for applied research (2nd Ed.). New York: The Guilford Press.

Brynin, M. \& Longhi, S. (2009). Overqualification: Major or minor mismatch? Economics of Education Review, 28, 114-121.

Cardoso Junior, J. C. \& Nogueira, R. P. (2011). Ocupação no setor público brasileiro: Tendências recentes e questões em aberto. Revista do Serviço Público, 62(3), 237-260. 
Chen, C., Smith, P., \& Mustard, C. (2010). The prevalence of over-qualification and its association with health status among occupationally active new immigrants to Canada. Ethnicity \& Health, 15(6), 601-619.

Constituição da República Federativa do Brasil de 1988 (2013). [Organização de Alexandre de Moraes]. (37 Ed.). São Paulo: Atlas.

Crosby, F. (1976). A model of egoistical relative deprivation. Psychological Review, 83(2), 85-113.

Dejours, C. (1997). O fator humano. Rio de Janeiro: FGV.

Dul, J. \& Weerdmeester, B. (2008). Ergonomics for beginners: A quick reference guide $\left(3^{\text {rd }}\right.$ Ed). New York: CRC Press.

Edwards, J. R. (1991). Person-job fit: A conceptual integration, literature review, and methodological critique. In: C. L. Cooper \& I. T. Robertson (Orgs.). International review of industrial and organizational psychology (Vol. 6, pp. 283-357). Chichester: John Wiley \& Sons.

Erdogan, B. \& Bauer, T. N. (2009). Perceived overqualification and its outcomes: The moderating role of empowerment. Journal of Applied Psychology, 94(2), 557-565.

Erdogan, B., Bauer, T. N., Peiró, J. M., \& Truxillo, D. M. (2011a). Overqualified employees: Making the best of a potentially bad situation for individuals and organizations. Industrial and Organizational Psychology, 4, 215-232.

Erdogan, B., Bauer, T. N., Peiró, J. M., \& Truxillo, D. M. (2011b). Overqualification theory, research, and practice: Things that matter. Industrial and Organizational Psychology, 4, $260-267$.

Feldman, D. C. \& Maynard, D. C. (2011). A labor economic perspective on overqualification. Industrial and Organizational Psychology, 4, 233-235.

Feldman, D. C. (1996). The nature, antecedents and consequences of underemployment. 
Journal of Management, 22(3), 385-407.

Fine, S. \& Nevo, B. (2008). Too smart for their own good? A study of perceived cognitive overqualification in the workforce. The International Journal of Human Resource Management, 19(2), 346-355.

Fine, S. \& Nevo, B. (2011). Overqualified job applicants: We still need predictive models. Industrial and Organizational Psychology, 4, 240-242.

Fine, S. (2007). Overqualification and selection in leadership training. Journal of Leadership \& Organizational Studies, 14(1), 61-68.

Fontainha, F. C., Geraldo, P. H. B., Veronese, A., \& Alves, C. A. (2015). O concurso público brasileiro e a ideologia concurseira. Revista Jurídica da Presidência, 16(110), 671-702.

Fontainha, F. C., Geraldo, P. H. B., Veronese, A., Alves, C. A., Figueiredo, B. H., \& Waldburger, J. (2014). Processos seletivos para a contratação de servidores públicos: Brasil, o país dos concursos? Rio de Janeiro: Direito Rio.

Francisco, D. S. (2015). Gestão do trabalho e valorização profissional: A questão da sobrequalificação para o trabalhador técnico do SUS (Dissertação de mestrado). Retirado de http://www.posgraduacao.epsjv.fiocruz.br/

Gonçalves Neto, J. M. (2016). Adaptação e análise de validade de uma escala de sobrequalificação percebida. Relatório de pesquisa não-publicado.

Green, F., \& Zhu, Y. (2010). Overqualification, job dissatisfaction, and increasing dispersion in the returns to graduate education. Oxford Economic Papers, 62(4), 740-763.

Guerrero, L. \& Hatala, J. P. (2015). Antecedents of perceived overqualification: A threewave study. Career Development International, 20(4), 409-423.

Hu, J., Erdogan, B., Bauer, T. N., Jiang, K., Liu, S., \& Li, Y. (2015). There are lots of big fish in this pond: The role of peer overqualification on task significance, perceived fit, and performance for overqualified employees. Journal of Applied Psychology, 100(4), 
$1228-1238$.

Instituto de Pesquisa Econômica Aplicada (2016). Análise do mercado de trabalho. Mercado de Trabalho: Conjuntura e Análise, 22(61), 9-20.

International Labour Organization (2016). World employment and social outlook: Trends 2016. Recuperado de http://www.ilo.org/global/research/globalreports/weso/2016/WCMS_443480/lang--en/index.htm

Johnson, G. J. \& Johnson, W. R. (1996). Perceived overqualification and psychological wellbeing. The Journal of Social Psychology, 136(4), 435-445.

Johnson, W. R., Morrow, P. C. \& Johnson, G. J. (2002). An evaluation of a perceived overqualification scale across work settings. The Journal of Psychology, 136(4), 425441.

Khan, L. J. \& Morrow, P. C. (1991). Objective and subjective underemployment relationships to job satisfaction. Journal of Business Research, 22, 211-218.

Kristof, A. L. (1996). Pearson-organization fit: An integrative review of its conceptualizations, measurement, and implications. Personnel Psychology, 49, 1-49.

Kristof-Brown, A. L., Zimmerman, R. D., \& Johnson, E. C. (2005). Consequences of individuals' fit at work: A meta-analysis of person-job, person-organization, persongroup, and person-supervisor fit. Personnel Psychology, 58, 281-342.

Kulkarni, M., Lengnick-Hall, M. L., \& Martinez, P. G. (2015). Overqualification, mismatched qualification, and hiring decisions: Perceptions of employers. Personnel Review, 44(4), 529-549.

Liu, S. \& Wang, M. (2012). Perceived overqualification: A review and recommendations for research and practice. In: Perrewé, P. L., Halbesleben, J. R. B., \& Rosen, C. C. (Orgs.). Research in occupational stress and well being: The role of the economic crisis on occupational stress and well being (pp. 1-42). Bingley/UK: Emerald. 
Liu, S., Luksyte, A., Zhou, L., Shi, J., \& Wang, M. (2015). Overqualification and counterproductive work behaviors: Examining a moderated mediation model. Journal of Organizational Behavior, 36, 250-271.

Lobene, E. V., \& Meade, A. W. (2013). The effects of career calling and perceived overqualification on work outcomes for primary and secondary school teachers. Journal of Career Development, 40(6), 508-530.

Lobene, E. V., Meade, A. W., \& Pond, S. B. (2015). Perceived overqualification: A multisource investigation of psychological predisposition and contextual triggers. The Journal of Psychology, 149(7), 684-710.

Lobene, E., \& Meade, A. W. (2010, April). Perceived overqualification: An exploration of outcomes. Paper presented at the 25th Annual Meeting of the Society for Industrial and Organizational Psychology, Atlanta, GA.

Lodahl, T. M. \& Keyner, M. (1965). The definition and measurement of job involvement. Journal of Applied Psychology, 49(1), 24-33.

Luksyte, A. \& Spitzmueller, C. (2011). Behavioral science approaches to studying underemployment. In: D. C. Maynard \& D. C. Feldman (Eds.). Underemployment: Psychological, economic, and social challenges (pp. 35-56). New York: Springer.

Luksyte, A., Spitzmueller, C., \& Maynard, D. C. (2011). Why do overqualified incumbents deviate? Examining multiple mediators. Journal of Occupational Health Psychology, 16(3), 279-296.

Machado, A. F., Oliveira, A. M. H. C., \& Carvalho, N. F. (2004). Tipologia de qualificação da força de trabalho: Uma proposta com base na noção de incompatibilidade entre ocupação e escolaridade. Nova Economia, 14(2), 11-33.

Maciel, C. O. \& Camargo, C. (2013). Sobrequalificação no trabalho e sua influência sobre atitudes e comportamentos. Revista de Administração Contemporânea, 17(2), 218-238. 
Maltarich, M. A., Reilly, G., \& Nyberg, A. J. (2011). Objective and Subjective Overqualification: Distinctions, Relationships, and a Place for Each in the Literature. Industrial and Organizational Psychology, 4, 236-239.

Maynard, D. C, Joseph, T. A., \& Maynard, A. M. (2006). Underemployment, job attitudes, and turnover intentions. Journal of Organizational Behaviour, 27, 509-536.

Maynard, D. C. \& Feldman, D. C. (2011). Underemployment: Psychological, economic, and social challenges. New York: Springer.

Maynard, D. C. \& Parfyonova, N. M. (2013). Perceived overqualification and withdrawal behaviors: Examining the roles of job attitudes and work values. Journal of Occupational and Organizational Psychology, 86, 435-455.

Maynard, D. C., Brondolo, E. M., Connelly, C. E., \& Sauer, C. E. (2015). I'm too good for this job: Narcissism's role in the experience of overqualification. Applied Psychology: An International Review, 64(1), 208-232.

Mendes, M. (2011). Política de pessoal do governo federal: Diretrizes para maior produtividade, qualidade, economicidade e igualdade. In: F. B. Meneguin (Org.). Agenda legislativa para o desenvolvimento nacional (pp. 357-384). Brasília/DF: Senado Federal/Subsecretaria de Edições Técnicas.

Meyer, J. P. \& Allen, N. J. (1991). A three-component conceptualization of organizational commitment. Human Resource Management Review, 1(1), 61-89.

Ministério do Planejamento, Desenvolvimento e Gestão (2016). Boletim Estatístico de Pessoal e Informações Organizacionais, 21(246). Brasília-DF: MP.

Morici, M. C. \& Barbosa, A. C. Q. (2013). A gestão de recursos humanos em hospitais do Sistema Único de Saúde (SUS) e sua relação ao modelo de assistência: Um estudo em hospitais de Belo Horizonte, Minas Gerais. Revista de Administração Pública, 47(1), 205-225. 
Moura, A. L. N. \& Souza, B. C. (2016). Gestão estratégica de pessoas na administração indireta do setor público federal: Na prática, ainda um discurso. Revista do Serviço Público, 64(4), 575-602.

Mowday, R. T., Porter, L. W., \& Steers, R. M. (1982). Employee-organization linkages: The psychology of commitment, absenteeism, and turnover. New York: Academic Press.

Pasquali, L. (2010). Testes referentes a construto: Teoria e modelo de construção. In: L. Pasquali (Org.). Instrumentação psicológica: fundamentos e práticas (pp. 166-198). Porto Alegre: Artmed.

Pasquali, L. (2012). Análise fatorial para pesquisadores. Brasília: LabPAM.

Rodrigues, A., Assmar, E. M. L., \& Jablonski, B. (2010). Psicologia social (30 ${ }^{\text {a }}$ Ed.). Petrópolis/RJ: Vozes.

Santos, M. S., Brandão, L. E. T., \& Maia, V. M. (2015). Decisão de escolha de carreira no Brasil: Uma abordagem por opções reais. Revista de Administração, 50(2), 141-152.

Schumacker, R. E. \& Lomax, R. G. (2010). A beginner's guide to structural equation modeling (3th Ed.). London: Routledge.

Secretaria de Planejamento e Assuntos Econômicos, Ministério do Planejamento, Desenvolvimento e Gestão (2016). Panorama macroeconômico. Recuperado de http://www.planejamento.gov.br/publicacoes/estudos-economicos

Siqueira, M. M. M. \& Gomide Junior, S. (2014). Vínculos do indivíduo com o trabalho e com a organização. In: J. C. Zanelli, J. E. Borges-Andrade, \& A. V. B. Bastos (Orgs.). Psicologia, organizações e trabalho no Brasil (2ª Ed.) (pp. 316-348). Porto Alegre: Artmed.

Siqueira, M. M. M. (1995). Antecedentes comportamentais de cidadania organizacional: Análise de um modelo pós-cognitivo (Tese de doutorado). Universidade de Brasília, Brasília. 
Tabachnick, B. G. \& Fidell, L. S. (2010). Using multivariate statistics (6th Ed.). Boston: Pearson.

Thompson, B. (2004). Exploratory and confirmatory factor analysis: Understanding concepts and applications. Washington/DC: American Psychological Association.

Thompson, K. W., Shea, T. H., Sikora, D. M., Perrewé, P. L., \& Ferris, G. R. (2013). Rethinking underemployment and overqualification in organizations: The not so ugly truth. Business Horizons 56, 113-121.

Ullman, J. B. (2006). Structural equation modeling: Reviewing the basics and moving forward. Journal of Personality and Assessment, 87(1), 35-50.

Weymer, A. S. Q., Maciel, C. O., \& Castor, B. V. J. (2014). A influência da sobrequalificação e da aprendizagem sobre a satisfação do indivíduo no trabalho. Revista Brasileira de Gestão de Negócios, 16(50), 96-109.

Wilkins, R. \& Wooden, M. (2011). Economic approaches to studying underemployment. In: D. C. Maynard \& D. C. Feldman (Eds.). Underemployment: Psychological, economic, and social challenges (pp. 13-34). New York: Springer.

Wu, C. H., Luksyte, A., \& Parker, S. K. (2015). Overqualification and subjective well-being at work: The moderating role of job autonomy and culture. Social Indic. Research, 121, 917-937.

Yang, W., Guanb, Y., Lai, X., She, Z., \& Lockwood, A. J. (2015). Career adaptability and perceived overqualification: Testing a dual-path model among Chinese human resource management professionals. Journal of Vocational Behavior, 90, 154-162.

Zhang, M. J., Law, K. S., \& Lin, B. (2016). You think you are big fish in a small pond? Perceived overqualification, goal orientations, and proactivity at work. Journal of Organizational Behavior, 37, 61-84. 


\author{
Anexo A \\ Instrumento de Coleta de Dados
}

Você está sendo convidado(a) a participar de um estudo sobre o que os servidores públicos percebem e sentem nas instituições onde trabalham. A sua participação consiste em responder às perguntas deste questionário, o que levará aproximadamente 20 (vinte) minutos. Este questionário não é nenhum tipo de teste, busca apenas saber o que você percebe e sente trabalhando na instituição pública onde você trabalha. Não há respostas certas ou erradas, existem apenas as suas respostas. Desde já, muito obrigado por participar!

A seguir serão apresentadas cinco frases referentes ao seu trabalho atual. Indique o quanto você concorda ou discorda de cada uma delas. Dê suas respostas anotando nos parênteses que antecedem cada frase aquele número (de 1 a 7 ) que melhor representa sua resposta.

$$
\begin{aligned}
& 1 \text { - Discordo totalmente } \\
& 2 \text { - Discordo moderadamente } \\
& 3 \text { - Discordo levemente } \\
& 4 \text { - Nem concordo nem discordo } \\
& 5 \text { - Concordo levemente } \\
& 6 \text { - Concordo moderadamente } \\
& 7 \text { - Concordo totalmente }
\end{aligned}
$$

( ) As maiores satisfações da minha vida vêm de meu trabalho.

( ) As horas que passo trabalhando são as melhores horas de meu dia.

( ) As coisas mais importantes que acontecem em minha vida envolvem o meu trabalho.

( ) Eu como, vivo e respeito o meu trabalho.

( ) Eu estou pessoalmente muito ligado ao meu trabalho.

Abaixo estão listados vários sentimentos que alguém poderia ter em relação à instituição onde trabalha. Gostaríamos de saber o quanto você sente estes sentimentos. Dê suas respostas anotando, nos parênteses que antecedem cada frase, aquele número (de 1 a 5 ) que melhor representa sua resposta.

$$
\begin{aligned}
& 1 \text { - Nada } \\
& 2 \text { - Pouco } \\
& 3 \text { - Mais ou menos } \\
& 4 \text { - Muito } \\
& 5 \text { - Extremamente }
\end{aligned}
$$

A instituição onde trabalho faz-me sentir...

\begin{tabular}{|ll|}
( & ) Orgulhoso dela. \\
( & ) Contente com ela. \\
( & ) Entusiasmado com ela. \\
( & Interessado por ela. \\
\hline
\end{tabular}


As frases abaixo falam de algumas perdas e dificuldades que você teria se pedisse exoneração da instituição pública onde você está trabalhando e fosse trabalhar em outra organização. Gostaríamos de saber o quanto você concorda ou discorda de cada frase. Dê suas respostas anotando, nos parênteses que antecedem cada frase, aquele número (de 1 a 5) que melhor representa sua resposta.

$$
\begin{aligned}
& 1 \text { - Discordo totalmente } \\
& 2 \text { - Discordo } \\
& 3 \text { - Nem concordo nem discordo } \\
& 4 \text { - Concordo } \\
& 5 \text { - Concordo totalmente }
\end{aligned}
$$

Pedir exoneração da instituição onde trabalho e ir trabalhar em outra organização não valeria a pena porque...

( ) Eu teria dificuldades para ganhar um salário tão bom quanto o que eu tenho hoje.

( ) Eu jogaria fora todos os esforços que fiz para chegar onde cheguei dentro da instituição onde trabalho.

( ) Eu perderia a estabilidade no emprego que tenho hoje na instituição onde trabalho (garantias de não ser demitido).

( ) Eu teria dificuldade para conseguir outro cargo que me desse o mesmo prestígio que tenho com o meu cargo atual.

( ) Eu demoraria a encontrar em outra organização pessoas tão amigas quanto as que eu tenho hoje entre meus colegas de trabalho dentro da instituição onde trabalho.

( ) Eu perderia a liberdade que tenho de realizar meu trabalho dentro da instituição onde trabalho.

( ) Eu estaria desperdiçando todo o tempo que já me dediquei à instituição onde trabalho.

( ) Eu deixaria para trás tudo o que já investi na instituição onde trabalho.

) Eu estaria prejudicando minha vida profissional.

( ) Eu demoraria a conseguir ser tão respeitado em outra organização como sou hoje dentro da instituição onde trabalho.

( ) Eu deixaria de receber vários benefícios que a instituição onde trabalho oferece aos seus servidores (vale-transporte, convênios médicos, vale-refeição, etc.).

) Eu teria mais coisas a perder do que a ganhar com este pedido de exoneração.

( ) Eu perderia o prestígio que tenho hoje por ser servidor na instituição onde trabalho.

( ) Eu levaria muito tempo para me acostumar a um novo trabalho.

( ) Eu estaria jogando fora todo o esforço que fiz para aprender as tarefas do meu cargo atual.

A seguir estão três frases que podem representar alguns pensamentos seus. Dê suas respostas anotando, nos parênteses que antecedem cada frase, aquele número (de 1 a 5 ) que melhor representa sua resposta.

\begin{tabular}{|c|c|c|c|c|}
\hline 1 & 2 & 3 & 4 & 5 \\
Nunca & Raramente & Às vezes & Frequentemente & $\begin{array}{c}5 \\
\text { Sempre }\end{array}$ \\
\hline
\end{tabular}

) Penso em sair da instituição onde trabalho.

) Planejo sair da instituição onde trabalho.

( ) Tenho vontade de sair da instituição onde trabalho. 
A seguir, serão apresentadas afirmações comparando a sua qualificação ao seu cargo atual. O objetivo é saber o quanto você se considera qualificado(a) para seu cargo atual. Leia cuidadosamente cada afirmação e indique o quanto você discorda dela ou concorda com ela, marcando um número entre 1 e 7 . O número 1 significa que você discorda totalmente da afirmação e o número 7 significa que você concorda totalmente com a afirmação. Não há respostas certas ou erradas.

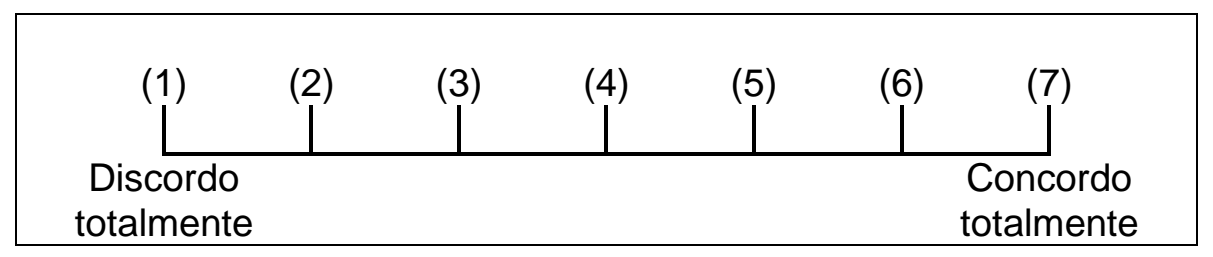

Meu cargo exige menos educação formal do que eu possuo. (1) (2) (3) (4) (5) (6) (7)

A experiência profissional que eu tenho não é necessária para ter sucesso neste cargo.

(1) (2) (3) (4) (5) (6) (7)

Eu possuo habilidades profissionais que não são exigidas neste trabalho.

(1) (2) (3) (4) (5) (6) (7)

Alguém com menos formação que eu poderia ter um bom desempenho no meu cargo.

(1) (2) (3) (4) (5) (6) (7)

Meu treinamento anterior não está sendo totalmente utilizado neste cargo.

(1) (2) (3) (4) (5) (6) (7)

Eu tenho muitos conhecimentos que eu não preciso para desempenhar o meu cargo.

(1) (2) (3) (4) (5) (6) (7)

Meu nível educacional é superior ao exigido pelo meu cargo. (1) (2) (3) (4) (5) (6) (7)

Alguém com menos experiência profissional do que eu poderia desempenhar o meu cargo tão bem quanto eu.

(1) (2) (3) (4) (5) (6) (7)

Eu possuo mais capacidades do que eu preciso para desempenhar o meu cargo.

(1) (2) (3) (4) (5) (6) (7) 
Idade:

anos.

Sexo:

( ) Masculino

( ) Feminino

Vínculo:

( ) Efetivo

( ) Não-efetivo

Qual o seu cargo?

Há quanto tempo está nesse cargo? anos e meses.

Qual o nível de educação formal do cargo que você ocupa?
( ) Fundamental
( ) Médio/Técnico
( ) Superior
( ) Especialização
( ) Mestrado
( ) Doutorado

Qual o nível de educação formal que você possui atualmente?

( ) Ensino Fundamental completo

( ) Ensino Médio/Técnico incompleto

( ) Ensino Médio/Técnico completo

( ) Graduação incompleta

( ) Graduação completa

( ) Especialização incompleta

( ) Especialização completa

( ) Mestrado incompleto

( ) Mestrado completo

( ) Doutorado incompleto

( ) Doutorado completo

Muito obrigado por sua participação! 


\section{Anexo B}

Comparação entre Cargos Públicos e Famílias de Ocupações da CBO

\begin{tabular}{|c|c|c|c|}
\hline Cargo público & Família de ocupações da CBO & $\begin{array}{c}\text { Educação } \\
\text { formal } \\
\text { exigida }\end{array}$ & $\begin{array}{c}\text { Experiência } \\
\text { exigida (em } \\
\text { anos) }\end{array}$ \\
\hline Administrador & Administradores & Superior & $*$ \\
\hline Agente administrativo & Agentes, assistentes e auxiliares administrativos & Médio & 2 \\
\hline Agente de combate às endemias & Trabalhadores em serviços de promoção e apoio à saúde & Fundamental & * \\
\hline Agente de portaria & Porteiros, vigias e afins & Médio & * \\
\hline Agente de serviços urbanos & $\begin{array}{l}\text { Trabalhadores nos serviços de coleta de resíduos, de limpeza } \\
\text { e conservação de áreas públicas }\end{array}$ & Fundamental & 2 \\
\hline Agente de vigilância sanitária e ambiental & Agentes da saúde e do meio ambiente & Superior & * \\
\hline Agente prisional administrativo & Agentes, assistentes e auxiliares administrativos & Médio & 2 \\
\hline Ajudante da gestora da caixa de economia & Auxiliares de contabilidade & Médio & $*$ \\
\hline Analista administrativo & Administradores & Superior & * \\
\hline Analista ambiental & Agentes da saúde e do meio ambiente & Superior & * \\
\hline Analista de sistemas & Analistas de tecnologia da informação & Superior & 2 \\
\hline Analista jurídico & Advogados & Superior & $*$ \\
\hline Apoio administrativo & Agentes, assistentes e auxiliares administrativos & Médio & 2 \\
\hline Arquivista & $\begin{array}{l}\text { Auxiliares de serviços de documentação, informação e } \\
\text { pesquisa }\end{array}$ & Médio & 2 \\
\hline Assessor de imprensa & Profissionais do jornalismo & Superior & * \\
\hline Assessor jurídico & Advogados & Superior & $*$ \\
\hline Assessor pedagógico & Programadores, avaliadores e orientadores de ensino & Superior & 4 \\
\hline Assessora de comunicação & Profissionais do jornalismo & Superior & $*$ \\
\hline Assistente administrativo & Agentes, assistentes e auxiliares administrativos & Médio & 2 \\
\hline Assistente da coordenação administrativa & Agentes, assistentes e auxiliares administrativos & Médio & 2 \\
\hline Assistente de administração & Agentes, assistentes e auxiliares administrativos & Médio & 2 \\
\hline Assistente de programa - pedagogo & Programadores, avaliadores e orientadores de ensino & Superior & 4 \\
\hline Assistente em administração & Agentes, assistentes e auxiliares administrativos & Médio & 2 \\
\hline Assistente social & Assistentes sociais e economistas domésticos & Superior & $*$ \\
\hline Atendente de consultório dentário & Recepcionistas & Médio & 2 \\
\hline Auxiliar administrativo & Agentes, assistentes e auxiliares administrativos & Médio & 2 \\
\hline Auxiliar da assessoria jurídica & Serventuários da justiça e afins & Fundamental & $*$ \\
\hline Auxiliar de administração & Agentes, assistentes e auxiliares administrativos & Médio & 2 \\
\hline
\end{tabular}




\section{Anexo B}

Comparação entre Cargos Públicos e Famílias de Ocupações da CBO (continuação)

\begin{tabular}{|c|c|c|c|}
\hline Cargo público & Família de ocupações da CBO & $\begin{array}{c}\text { Educação } \\
\text { formal } \\
\text { exigida }\end{array}$ & $\begin{array}{c}\text { Experiência } \\
\text { exigida (em } \\
\text { anos) }\end{array}$ \\
\hline Auxiliar de contabilidade & Auxiliares de contabilidade & Médio & $*$ \\
\hline Auxiliar de departamento de pessoal & Agentes, assistentes e auxiliares administrativos & Médio & 2 \\
\hline Auxiliar de escritório & Agentes, assistentes e auxiliares administrativos & Médio & 2 \\
\hline Auxiliar de pagamento & Auxiliares de contabilidade & Médio & $*$ \\
\hline Auxiliar de pessoal & Agentes, assistentes e auxiliares administrativos & Médio & 2 \\
\hline Auxiliar de produção II & Alimentadores de linhas de produção & Fundamental & 1 \\
\hline Auxiliar de secretaria - arquivista/protocolista & $\begin{array}{l}\text { Auxiliares de serviços de documentação, informação e } \\
\text { pesquisa }\end{array}$ & Médio & 2 \\
\hline Auxiliar de serviços urbanos & $\begin{array}{l}\text { Trabalhadores nos serviços de coleta de resíduos, de limpeza } \\
\text { e conservação de áreas públicas }\end{array}$ & Fundamental & 2 \\
\hline Auxiliar judiciário & Agentes, assistentes e auxiliares administrativos & Médio & 2 \\
\hline Auxiliar pedagógico & Programadores, avaliadores e orientadores de ensino & Superior & 4 \\
\hline Auxiliar técnico em máquinas - motorista & Motoristas de veículos de pequeno e médio porte & Fundamental & 2 \\
\hline Bibliotecário & Profissionais da informação & Superior & $*$ \\
\hline Chefe da seção de contabilidade de custos & Contadores e afins & Superior & 4 \\
\hline Chefe do almoxarifado & Gerentes de suprimentos e afins & Superior & 5 \\
\hline Chefe do setor de documentação técnica & Profissionais da informação & Superior & $*$ \\
\hline Chefia de gabinete & Secretários executivos e afins & Superior & 3 \\
\hline Condutor de veículos & Motoristas de veículos de pequeno e médio porte & Fundamental & 2 \\
\hline Contador & Contadores e afins & Superior & 4 \\
\hline Contador da área de $\mathrm{RH}$ & Contadores e afins & Superior & 4 \\
\hline Coordenador de apoio administrativo & Supervisores administrativos & Médio & 4 \\
\hline Coordenador de material e patrimônio & Administradores & Superior & $*$ \\
\hline Coordenador pedagógico & Programadores, avaliadores e orientadores de ensino & Superior & 4 \\
\hline Coordenadora administrativa & Supervisores administrativos & Médio & 4 \\
\hline Coordenadora operacional & Supervisores administrativos & Médio & 4 \\
\hline Copeiro & $\begin{array}{l}\text { Trabalhadores no atendimento em estabelecimentos de } \\
\text { serviços de alimentação, bebidas e hotelaria }\end{array}$ & Fundamental & 1 \\
\hline Datilógrafo & $\begin{array}{l}\text { Operadores de equipamentos de entrada e transmissão de } \\
\text { dados }\end{array}$ & Médio & 1 \\
\hline
\end{tabular}




\section{Anexo B}

Comparação entre Cargos Públicos e Famílias de Ocupações da CBO (continuação)

\begin{tabular}{|c|c|c|c|}
\hline Cargo público & Família de ocupações da CBO & $\begin{array}{c}\text { Educação } \\
\text { formal } \\
\text { exigida }\end{array}$ & $\begin{array}{c}\text { Experiência } \\
\text { exigida (em } \\
\text { anos) }\end{array}$ \\
\hline Diretora administrativa e financeira & Diretores administrativos e financeiros & Superior & 5 \\
\hline Economista & Economistas & Superior & 2 \\
\hline Educador - recepcionista & Recepcionistas & Médio & 2 \\
\hline Educador social & $\begin{array}{l}\text { Trabalhadores de atenção, defesa e proteção a pessoas em } \\
\text { situação de risco e adolescentes em conflito com a lei }\end{array}$ & - & $*$ \\
\hline Engenharia civil & Engenheiros civis e afins & Pós-graduação & 5 \\
\hline Engenheiro agrônomo & Engenheiros agrossilvipecuários & Pós-graduação & $*$ \\
\hline Engenheiro civil & Engenheiros civis e afins & Pós-graduação & 5 \\
\hline Escrivão da polícia civil & Serventuários da justiça e afins & Médio & $*$ \\
\hline Especialista em educação & Programadores, avaliadores e orientadores de ensino & Superior & 4 \\
\hline Gerente administrativo e financeiro & Diretores administrativos e financeiros & Superior & 5 \\
\hline Gerente contábil & Contadores e afins & Superior & 4 \\
\hline Gerente de compras & Gerentes de suprimentos e afins & Superior & 5 \\
\hline Gerente de controle pedagógico & Programadores, avaliadores e orientadores de ensino & Superior & 4 \\
\hline Gerente de turismo de pesca esportiva & $\begin{array}{l}\text { Gerentes de operações de serviços em empresa de turismo, } \\
\text { de alojamento e alimentação }\end{array}$ & Médio & 2 \\
\hline $\begin{array}{l}\text { Gestor em recursos humanos - assessoria de projetos e } \\
\text { convênios }\end{array}$ & Gerentes de recursos humanos e de relações do trabalho & Superior & 5 \\
\hline Motorista & Motoristas de veículos de pequeno e médio porte & Fundamental & 2 \\
\hline Nutricionista & Nutricionistas & Superior & * \\
\hline Operador de máquinas pesadas & $\begin{array}{l}\text { Preparadores e operadores de máquinas-ferramenta } \\
\text { convencionais }\end{array}$ & Fundamental & 2 \\
\hline Operador de teleprocessamento & Operadores de rede de teleprocessamento e afins & Médio & $*$ \\
\hline Orientação educacional - coordenador pedagógico & Programadores, avaliadores e orientadores de ensino & Superior & 4 \\
\hline Pedagogo & Programadores, avaliadores e orientadores de ensino & Superior & 4 \\
\hline Pregoeiro & Leiloeiros e avaliadores & - & $*$ \\
\hline Professora - vice-diretora & Diretores e gerentes de instituição de serviços educacionais & Superior & 5 \\
\hline Programador & Técnicos de desenvolvimento de sistemas e aplicações & Superior & 4 \\
\hline Psicólogo & Psicólogos e psicanalistas & Superior & 4 \\
\hline Recepção - operacional & Recepcionistas & Médio & 2 \\
\hline
\end{tabular}




\section{Anexo B}

Comparação entre Cargos Públicos e Famílias de Ocupações da CBO (continuação)

\begin{tabular}{|c|c|c|c|}
\hline Cargo público & Família de ocupações da CBO & $\begin{array}{c}\text { Educação } \\
\text { formal } \\
\text { exigida } \\
\end{array}$ & $\begin{array}{c}\text { Experiência } \\
\text { exigida (em } \\
\text { anos) }\end{array}$ \\
\hline Secretária & Recepcionistas & Médio & 2 \\
\hline Secretário de coordenação & Recepcionistas & Médio & 2 \\
\hline Secretário de gabinete - setor de logística & Secretários executivos e afins & Superior & 3 \\
\hline Secretário executivo & Secretários executivos e afins & Superior & 3 \\
\hline Servente - supervisor da merenda escolar & $\begin{array}{l}\text { Trabalhadores no atendimento em estabelecimentos de } \\
\text { serviços de alimentação, bebidas e hotelaria }\end{array}$ & Fundamental & 1 \\
\hline Superintendente de patrimônio imobiliário & Administradores & Superior & $*$ \\
\hline Técnico em contabilidade & Técnicos em contabilidade & Médio & 4 \\
\hline $\begin{array}{l}\text { Técnico em gestão de meio ambiente - engenharia de } \\
\text { produção }\end{array}$ & Engenheiros de produção, qualidade, segurança e afins & Pós-graduação & 4 \\
\hline Técnico administrativo & Agentes, assistentes e auxiliares administrativos & Médio & 2 \\
\hline Técnico bancário & Técnicos em operações e serviços bancários & Médio & 2 \\
\hline Técnico de enfermagem & Técnicos e auxiliares de enfermagem & Médio & $*$ \\
\hline Técnico de qualidade & Agentes fiscais metrológicos e de qualidade & Médio & $*$ \\
\hline Técnico em administração e finanças - biblioteconomia & Profissionais da informação & Superior & $*$ \\
\hline Técnico em administração e finanças - psicologia & Psicólogos e psicanalistas & Superior & 4 \\
\hline Técnico em agrimensura & Técnicos em geomática & Médio & 2 \\
\hline Técnico em assuntos educacionais - assessor pedagógico & Programadores, avaliadores e orientadores de ensino & Superior & 4 \\
\hline Técnico em contabilidade & Técnicos em contabilidade & Médio & 4 \\
\hline Técnico em edificações & Técnicos em construção civil (edificações) & Médio & 1 \\
\hline Técnico em educação & Programadores, avaliadores e orientadores de ensino & Superior & 4 \\
\hline Técnico em gestão - administrador & Administradores & Superior & $*$ \\
\hline Técnico em gestão agropecuária - engenharia agronômica & Engenheiros agrossilvipecuários & Pós-graduação & $*$ \\
\hline Técnico em gestão do meio ambiente - engenheiro florestal & Engenheiros agrossilvipecuários & Pós-graduação & $*$ \\
\hline Técnico em gestão pública - administrador & Administradores & Superior & $*$ \\
\hline Técnico em gestão pública - antropólogo & $\begin{array}{l}\text { Profissionais em pesquisa e análise antropológica } \\
\text { sociológica }\end{array}$ & Superior & $*$ \\
\hline Técnico em gestão pública - contador & Contadores e afins & Superior & 4 \\
\hline Técnico em gestão, ciência e tecnologia - economista & Economistas & Superior & 2 \\
\hline Técnico em informática & Técnicos em eletrônica & Médio & 5 \\
\hline
\end{tabular}




\section{Anexo B}

Comparação entre Cargos Públicos e Famílias de Ocupações da CBO (continuação)

\begin{tabular}{|c|c|c|c|}
\hline Cargo público & Família de ocupações da CBO & $\begin{array}{c}\text { Educação } \\
\text { formal } \\
\text { exigida }\end{array}$ & $\begin{array}{c}\text { Experiência } \\
\text { exigida (em } \\
\text { anos) }\end{array}$ \\
\hline Técnico em infra-estrutura & Técnicos em construção civil (obras de infra-estrutura) & Médio & 2 \\
\hline Técnico em mecânica & Técnicos em mecânica veicular & Médio & 1 \\
\hline Técnico em redes de computadores & Administradores de tecnologia da informação & Superior & 2 \\
\hline Técnico em saneamento & Técnicos em construção civil (obras de infra-estrutura) & Médio & 2 \\
\hline
\end{tabular}

* Nenhuma experiência exigida para o cargo, segundo a CBO. 


\section{Anexo C}

Matriz de Variância-Covariância da Amostra - Matriz S

\begin{tabular}{|c|c|c|c|c|c|c|c|c|c|c|c|c|c|c|c|c|}
\hline & $\mathrm{A} 1$ & $\mathrm{~A} 2$ & $\mathrm{~A} 3$ & $\mathrm{~A} 4$ & A5 & $\mathrm{C} 1$ & $\mathrm{C} 2$ & $\mathrm{C} 3$ & $\mathrm{C} 4$ & C5 & C6 & $\mathrm{C} 7$ & $\mathrm{C} 8$ & C9 & $\mathrm{C} 10$ & $\mathrm{C} 11$ \\
\hline A1 & 1,39 & & & & & & & & & & & & & & & \\
\hline A2 & 0,66 & 0,93 & & & & & & & & & & & & & & \\
\hline A3 & 0,71 & 0,71 & 1,16 & & & & & & & & & & & & & \\
\hline A4 & 0,43 & 0,44 & 0,60 & 1,11 & & & & & & & & & & & & \\
\hline A5 & 0,75 & 0,71 & 0,82 & 0,68 & 1,21 & & & & & & & & & & & \\
\hline $\mathrm{C} 1$ & 0,27 & 0,29 & 0,25 & 0,20 & 0,29 & 1,79 & & & & & & & & & & \\
\hline $\mathrm{C} 2$ & 0,26 & 0,32 & 0,24 & 0,16 & 0,23 & 0,70 & 1,79 & & & & & & & & & \\
\hline $\mathrm{C} 3$ & $-0,07$ & 0,07 & 0,07 & 0,07 & 0,11 & 0,41 & 0,73 & 1,58 & & & & & & & & \\
\hline $\mathrm{C} 4$ & 0,12 & 0,20 & 0,20 & 0,14 & 0,25 & 0,85 & 0,68 & 0,45 & 1,46 & & & & & & & \\
\hline C5 & 0,10 & 0,14 & 0,19 & 0,16 & 0,31 & 0,40 & 0,39 & 0,23 & 0,42 & 1,55 & & & & & & \\
\hline C6 & 0,16 & 0,21 & 0,20 & 0,23 & 0,30 & 0,44 & 0,55 & 0,37 & 0,55 & 0,63 & 1,38 & & & & & \\
\hline C7 & 0,14 & 0,21 & 0,20 & 0,29 & 0,28 & 0,52 & 0,90 & 0,47 & 0,69 & 0,55 & 0,75 & 1,71 & & & & \\
\hline $\mathrm{C} 8$ & 0,24 & 0,27 & 0,19 & 0,16 & 0,36 & 0,54 & 0,86 & 0,35 & 0,62 & 0,47 & 0,64 & 1,09 & 1,46 & & & \\
\hline C9 & 0,30 & 0,31 & 0,27 & 0,18 & 0,32 & 0,60 & 0,73 & 0,53 & 0,63 & 0,55 & 0,54 & 0,83 & 0,74 & 1,37 & & \\
\hline $\mathrm{C} 10$ & 0,26 & 0,27 & 0,22 & 0,16 & 0,25 & 0,48 & 0,62 & 0,28 & 0,59 & 0,51 & 0,57 & 0,66 & 0,57 & 0,67 & 1,31 & \\
\hline C11 & 0,25 & 0,27 & 0,28 & 0,10 & 0,32 & 0,75 & 0,51 & 0,50 & 0,61 & 0,38 & 0,45 & 0,62 & 0,42 & 0,66 & 0,54 & 1,74 \\
\hline $\mathrm{C} 12$ & 0,23 & 0,30 & 0,25 & 0,25 & 0,28 & 0,94 & 0,88 & 0,71 & 0,76 & 0,50 & 0,63 & 0,98 & 0,67 & 0,85 & 0,68 & 0,96 \\
\hline $\mathrm{C} 13$ & 0,24 & 0,19 & 0,18 & 0,14 & 0,24 & 0,69 & 0,69 & 0,53 & 0,70 & 0,53 & 0,50 & 0,68 & 0,55 & 0,68 & 0,72 & 0,71 \\
\hline $\mathrm{C} 14$ & 0,17 & 0,22 & 0,23 & 0,10 & 0,26 & 0,47 & 0,46 & 0,27 & 0,46 & 0,48 & 0,40 & 0,62 & 0,49 & 0,62 & 0,55 & 0,56 \\
\hline $\mathrm{C} 15$ & 0,25 & 0,22 & 0,21 & 0,18 & 0,25 & 0,53 & 0,80 & 0,36 & 0,55 & 0,48 & 0,58 & 0,97 & 0,81 & 0,79 & 0,74 & 0,61 \\
\hline R1 & $-0,37$ & $-0,33$ & $-0,34$ & $-0,42$ & $-0,33$ & $-0,18$ & $-0,14$ & $-0,01$ & $-0,26$ & $-0,15$ & $-0,23$ & $-0,30$ & $-0,21$ & $-0,19$ & $-0,13$ & $-0,21$ \\
\hline R2 & $-0,22$ & $-0,21$ & $-0,17$ & $-0,27$ & $-0,20$ & $-0,39$ & $-0,22$ & $-0,11$ & $-0,22$ & $-0,23$ & $-0,21$ & $-0,24$ & $-0,26$ & $-0,27$ & $-0,07$ & $-0,23$ \\
\hline R3 & $-0,37$ & $-0,36$ & $-0,43$ & $-0,60$ & $-0,44$ & $-0,15$ & $-0,18$ & 0,16 & $-0,24$ & $-0,32$ & $-0,43$ & $-0,36$ & $-0,22$ & $-0,19$ & $-0,19$ & $-0,08$ \\
\hline Q1 & $-0,44$ & $-0,22$ & $-0,25$ & $-0,38$ & $-0,26$ & $-0,24$ & $-0,22$ & $-0,02$ & $-0,25$ & 0,08 & $-0,15$ & $-0,37$ & $-0,32$ & $-0,09$ & $-0,05$ & $-0,02$ \\
\hline Q2 & $-0,38$ & $-0,39$ & $-0,37$ & $-0,31$ & $-0,46$ & 0,01 & 0,03 & $-0,08$ & $-0,20$ & $-0,22$ & $-0,01$ & $-0,22$ & $-0,26$ & $-0,31$ & $-0,06$ & $-0,20$ \\
\hline Q3 & $-0,50$ & $-0,30$ & $-0,26$ & $-0,21$ & $-0,40$ & $-0,37$ & $-0,19$ & $-0,08$ & $-0,42$ & $-0,25$ & $-0,28$ & $-0,46$ & $-0,49$ & $-0,38$ & $-0,35$ & $-0,32$ \\
\hline Q4 & $-0,28$ & $-0,35$ & $-0,16$ & $-0,31$ & $-0,48$ & $-0,40$ & $-0,22$ & $-0,13$ & $-0,41$ & $-0,18$ & $-0,26$ & $-0,45$ & $-0,18$ & $-0,22$ & $-0,16$ & $-0,18$ \\
\hline Q5 & $-0,25$ & $-0,13$ & $-0,34$ & $-0,18$ & $-0,27$ & $-0,19$ & 0,05 & 0,12 & $-0,11$ & $-0,06$ & $-0,28$ & $-0,15$ & $-0,05$ & 0,15 & 0,08 & $-0,03$ \\
\hline Q6 & $-0,35$ & $-0,27$ & $-0,21$ & $-0,23$ & $-0,32$ & $-0,30$ & $-0,12$ & 0,13 & $-0,13$ & $-0,01$ & $-0,15$ & $-0,36$ & $-0,31$ & $-0,21$ & $-0,10$ & $-0,11$ \\
\hline Q7 & $-0,15$ & $-0,28$ & $-0,23$ & $-0,30$ & $-0,45$ & $-0,56$ & $-0,26$ & $-0,22$ & $-0,51$ & $-0,16$ & $-0,22$ & $-0,18$ & $-0,10$ & $-0,06$ & $-0,06$ & $-0,21$ \\
\hline Q8 & $-0,21$ & $-0,27$ & $-0,27$ & $-0,33$ & $-0,35$ & $-0,42$ & $-0,29$ & $-0,13$ & $-0,60$ & $-0,35$ & $-0,59$ & $-0,53$ & $-0,52$ & $-0,45$ & $-0,43$ & $-0,15$ \\
\hline Q9 & $-0,18$ & $-0,22$ & $-0,13$ & $-0,12$ & $-0,38$ & $-0,48$ & $-0,10$ & 0,02 & $-0,40$ & 0,02 & $-0,18$ & $-0,24$ & $-0,11$ & $-0,12$ & $-0,07$ & $-0,01$ \\
\hline
\end{tabular}




\section{Anexo C}

Matriz de Variância-Covariância da Amostra - Matriz S (continuação)

$\begin{array}{llllllllllllllll}\mathrm{C} 12 & \mathrm{C} 13 & \mathrm{C} 14 & \mathrm{C} 15 & \mathrm{R} 1 & \mathrm{R} 2 & \mathrm{R} 3 & \mathrm{Q} 1 & \mathrm{Q} 2 & \mathrm{Q} 3 & \mathrm{Q} 4 & \mathrm{Q} 5 & \mathrm{Q} 6 & \mathrm{Q} 7 & \mathrm{Q} 8 & \mathrm{Q} 9\end{array}$

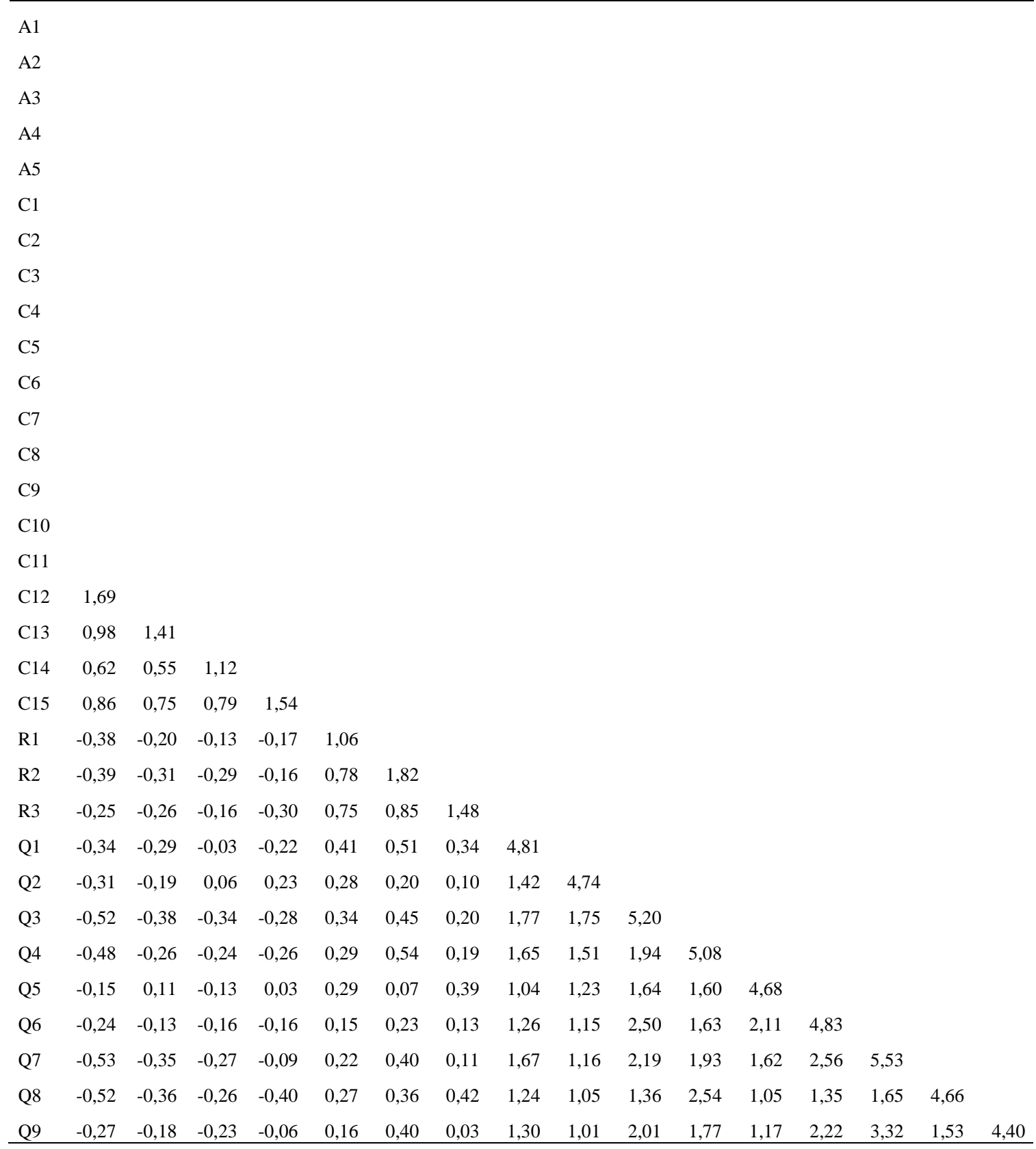




\section{Anexo D}

Tamanho da Amostra por Pares de Variáveis

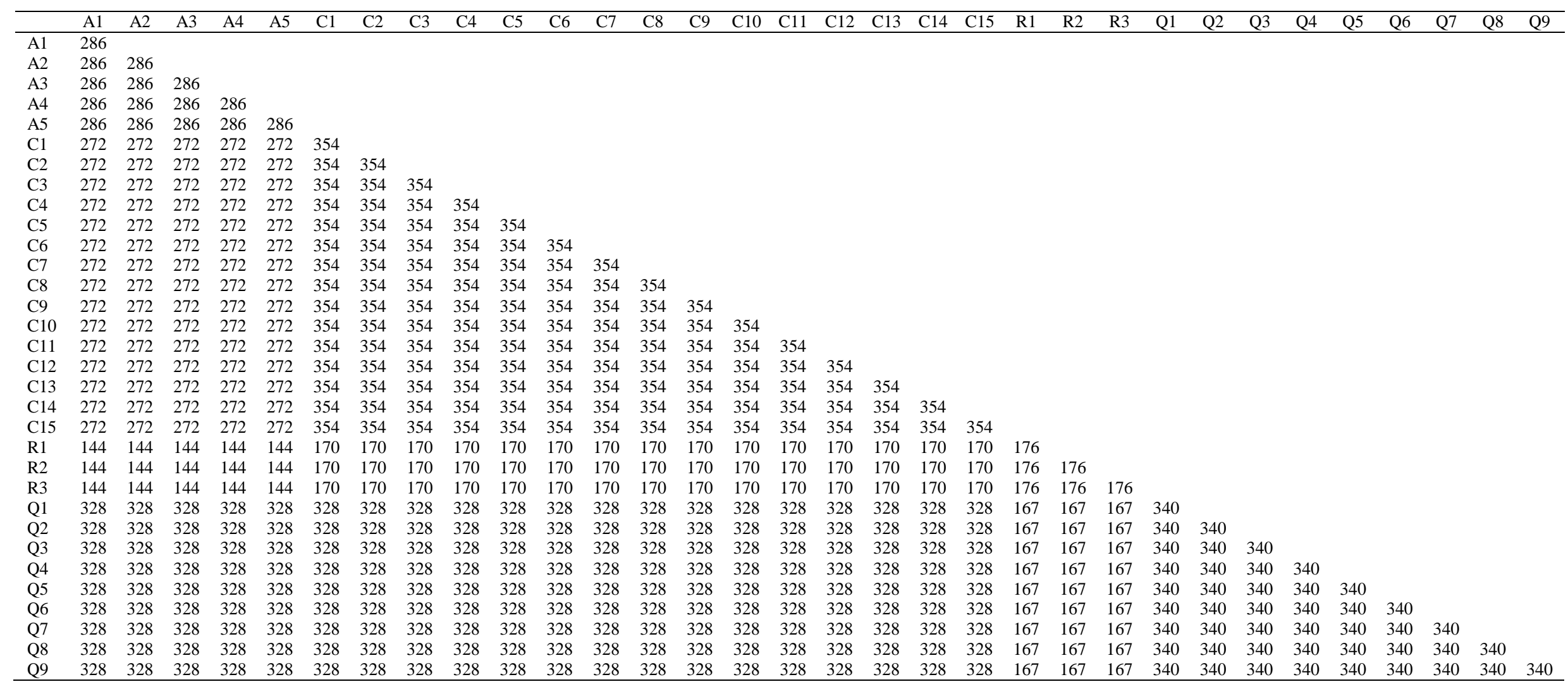




\section{Anexo E}

Estatísticas Descritivas das Variáveis Observáveis

\begin{tabular}{|c|c|c|c|c|c|c|}
\hline Item & $n$ & Dados excluídos (\%) & $M$ & $D P$ & Assimetria & Curtose \\
\hline A1 & 286 & 22,91 & 3,05 & 1,18 & $-0,12$ & $-0,77$ \\
\hline $\mathrm{A} 2$ & 286 & 22,91 & 2,94 & 0,10 & 0,00 & $-0,44$ \\
\hline A3 & 286 & 22,91 & 2,75 & 1,08 & 0,10 & $-0,63$ \\
\hline A4 & 286 & 22,91 & 3,52 & 1,06 & $-0,45$ & $-0,56$ \\
\hline A5 & 286 & 22,91 & 2,91 & 1,10 & $-0,02$ & $-0,77$ \\
\hline $\mathrm{C} 1$ & 354 & 4,58 & 2,76 & 1,34 & 0,19 & $-1,22$ \\
\hline $\mathrm{C} 2$ & 354 & 4,58 & 2,92 & 1,34 & $-0,02$ & $-1,29$ \\
\hline $\mathrm{C} 3$ & 354 & 4,58 & 3,42 & 1,26 & $-0,55$ & $-0,81$ \\
\hline $\mathrm{C} 4$ & 354 & 4,58 & 2,56 & 1,21 & 0,42 & $-0,81$ \\
\hline $\mathrm{C} 5$ & 354 & 4,58 & 2,70 & 1,25 & 0,27 & $-0,99$ \\
\hline C6 & 354 & 4,58 & 2,86 & 1,17 & 0,17 & $-0,96$ \\
\hline $\mathrm{C} 7$ & 354 & 4,58 & 2,72 & 1,31 & 0,37 & $-1,09$ \\
\hline C8 & 354 & 4,58 & 2,58 & 1,21 & 0,41 & $-0,88$ \\
\hline C9 & 354 & 4,58 & 2,36 & 1,17 & 0,66 & $-0,49$ \\
\hline C10 & 354 & 4,58 & 2,36 & 1,15 & 0,61 & $-0,56$ \\
\hline $\mathrm{C} 11$ & 354 & 4,58 & 2,82 & 1,32 & 0,10 & $-1,26$ \\
\hline C12 & 354 & 4,58 & 3,14 & 1,30 & $-0,15$ & $-1,16$ \\
\hline C13 & 354 & 4,58 & 2,72 & 1,19 & 0,25 & $-0,94$ \\
\hline $\mathrm{C} 14$ & 354 & 4,58 & 2,29 & 1,06 & 0,61 & $-0,40$ \\
\hline C15 & 354 & 4,58 & 2,42 & 1,24 & 0,69 & $-0,60$ \\
\hline $\mathrm{R} 1$ & 176 & 52,56 & 2,93 & 1,03 & 0,09 & $-0,35$ \\
\hline $\mathrm{R} 2$ & 176 & 52,56 & 3,11 & 1,35 & $-0,13$ & $-1,22$ \\
\hline R3 & 176 & 52,56 & 2,84 & 1,22 & 0,19 & $-0,81$ \\
\hline Q1 & 340 & 8,36 & 3,06 & 2,19 & 0,59 & $-1,15$ \\
\hline $\mathrm{Q} 2$ & 340 & 8,36 & 2,82 & 2,18 & 0,83 & $-0,83$ \\
\hline Q3 & 340 & 8,36 & 4,58 & 2,28 & $-0,44$ & $-1,35$ \\
\hline Q4 & 340 & 8,36 & 3,64 & 2,25 & 0,18 & $-1,46$ \\
\hline Q5 & 340 & 8,36 & 3,79 & 2,16 & 0,07 & $-1,40$ \\
\hline Q6 & 340 & 8,36 & 4,26 & 2,20 & $-0,22$ & $-1,38$ \\
\hline Q7 & 340 & 8,36 & 4,42 & 2,35 & $-0,26$ & $-1,50$ \\
\hline Q8 & 340 & 8,36 & 3,68 & 2,16 & 0,18 & $-1,36$ \\
\hline Q9 & 340 & 8,36 & 4,64 & 2,10 & $-0,44$ & $-1,09$ \\
\hline
\end{tabular}




\section{Anexo F}

Matriz de Variância-Covariância do Modelo - Matriz $\Sigma$

\begin{tabular}{|c|c|c|c|c|c|c|c|c|c|c|c|c|c|c|}
\hline & A1 & $\mathrm{A} 2$ & A3 & $\mathrm{A} 4$ & A5 & $\mathrm{C} 1$ & $\mathrm{C} 2$ & $\mathrm{C} 3$ & $\mathrm{C} 4$ & C5 & C6 & C7 & C8 & C9 \\
\hline A1 & 1,39 & & & & & & & & & & & & & \\
\hline A2 & 0,62 & 0,93 & & & & & & & & & & & & \\
\hline A3 & 0,72 & 0,69 & 1,16 & & & & & & & & & & & \\
\hline A4 & 0,53 & 0,51 & 0,59 & 1,11 & & & & & & & & & & \\
\hline A5 & 0,75 & 0,72 & 0,83 & 0,62 & 1,21 & & & & & & & & & \\
\hline $\mathrm{C} 1$ & 0,20 & 0,20 & 0,23 & 0,17 & 0,24 & 1,79 & & & & & & & & \\
\hline $\mathrm{C} 2$ & 0,22 & 0,21 & 0,24 & 0,18 & 0,25 & 0,56 & 1,79 & & & & & & & \\
\hline C3 & 0,15 & 0,14 & 0,16 & 0,12 & 0,17 & 0,38 & 0,40 & 1,58 & & & & & & \\
\hline $\mathrm{C} 4$ & 0,21 & 0,21 & 0,24 & 0,18 & 0,25 & 0,55 & 0,58 & 0,43 & 1,46 & & & & & \\
\hline C5 & 0,17 & 0,16 & 0,19 & 0,14 & 0,20 & 0,44 & 0,46 & 0,34 & 0,49 & 1,55 & & & & \\
\hline C6 & 0,20 & 0,19 & 0,22 & 0,16 & 0,23 & 0,51 & 0,54 & 0,39 & 0,57 & 0,45 & 1,38 & & & \\
\hline C7 & 0,27 & 0,26 & 0,30 & 0,22 & 0,31 & 0,69 & 0,98 & 0,50 & 0,72 & 0,57 & 0,66 & 1,71 & & \\
\hline C8 & 0,23 & 0,22 & 0,26 & 0,19 & 0,27 & 0,60 & 0,85 & 0,43 & 0,62 & 0,49 & 0,58 & 1,05 & 1,46 & \\
\hline C9 & 0,23 & 0,23 & 0,26 & 0,19 & 0,27 & 0,60 & 0,64 & 0,43 & 0,63 & 0,50 & 0,58 & 0,79 & 0,68 & 1,37 \\
\hline $\mathrm{C} 10$ & 0,21 & 0,20 & 0,23 & 0,17 & 0,24 & 0,54 & 0,57 & 0,39 & 0,57 & 0,45 & 0,52 & 0,71 & 0,61 & 0,68 \\
\hline C11 & 0,21 & 0,20 & 0,23 & 0,17 & 0,24 & 0,70 & 0,56 & 0,38 & 0,56 & 0,44 & 0,51 & 0,70 & 0,61 & 0,61 \\
\hline $\mathrm{C} 12$ & 0,28 & 0,27 & 0,31 & 0,23 & 0,33 & 0,95 & 0,76 & 0,52 & 0,76 & 0,60 & 0,70 & 0,95 & 0,82 & 0,83 \\
\hline $\mathrm{C} 13$ & 0,23 & 0,22 & 0,25 & 0,19 & 0,26 & 0,58 & 0,62 & 0,42 & 0,61 & 0,48 & 0,56 & 0,76 & 0,66 & 0,74 \\
\hline $\mathrm{C} 14$ & 0,19 & 0,18 & 0,21 & 0,16 & 0,22 & 0,49 & 0,52 & 0,35 & 0,51 & 0,40 & 0,47 & 0,64 & 0,55 & 0,62 \\
\hline C15 & 0,25 & 0,24 & 0,28 & 0,21 & 0,29 & 0,64 & 0,68 & 0,46 & 0,67 & 0,53 & 0,62 & 0,84 & 0,73 & 0,81 \\
\hline R1 & $-0,31$ & $-0,30$ & $-0,35$ & $-0,26$ & $-0,36$ & $-0,23$ & $-0,22$ & $-0,16$ & $-0,23$ & $-0,18$ & $-0,21$ & $-0,27$ & $-0,24$ & $-0,20$ \\
\hline R2 & $-0,33$ & $-0,32$ & $-0,37$ & $-0,28$ & $-0,39$ & $-0,24$ & $-0,24$ & $-0,17$ & $-0,24$ & $-0,19$ & $-0,23$ & $-0,29$ & $-0,25$ & $-0,21$ \\
\hline R3 & $-0,34$ & $-0,32$ & $-0,37$ & $-0,28$ & $-0,39$ & $-0,24$ & $-0,24$ & $-0,17$ & $-0,25$ & $-0,20$ & $-0,23$ & $-0,30$ & $-0,26$ & $-0,21$ \\
\hline Q1 & $-0,06$ & $-0,06$ & $-0,06$ & $-0,05$ & $-0,07$ & $-0,15$ & $-0,15$ & $-0,11$ & $-0,15$ & $-0,12$ & $-0,14$ & $-0,19$ & $-0,17$ & $-0,17$ \\
\hline Q2 & $-0,06$ & $-0,06$ & $-0,06$ & $-0,05$ & $-0,07$ & $-0,15$ & $-0,15$ & $-0,11$ & $-0,15$ & $-0,12$ & $-0,14$ & $-0,19$ & $-0,17$ & $-0,17$ \\
\hline Q3 & $-0,08$ & $-0,08$ & $-0,09$ & $-0,07$ & $-0,10$ & $-0,21$ & $-0,22$ & $-0,15$ & $-0,22$ & $-0,17$ & $-0,20$ & $-0,28$ & $-0,24$ & $-0,24$ \\
\hline Q4 & $-0,12$ & $-0,12$ & $-0,14$ & $-0,10$ & $-0,14$ & $-0,32$ & $-0,33$ & $-0,23$ & $-0,33$ & $-0,26$ & $-0,30$ & $-0,41$ & $-0,36$ & $-0,36$ \\
\hline Q5 & $-0,06$ & $-0,06$ & $-0,07$ & $-0,05$ & $-0,07$ & $-0,16$ & $-0,16$ & $-0,11$ & $-0,16$ & $-0,13$ & $-0,15$ & $-0,20$ & $-0,18$ & $-0,18$ \\
\hline Q6 & $-0,09$ & $-0,08$ & $-0,10$ & $-0,07$ & $-0,10$ & $-0,22$ & $-0,24$ & $-0,16$ & $-0,23$ & $-0,19$ & $-0,22$ & $-0,29$ & $-0,25$ & $-0,26$ \\
\hline Q7 & $-0,12$ & $-0,11$ & $-0,13$ & $-0,10$ & $-0,14$ & $-0,30$ & $-0,32$ & $-0,21$ & $-0,31$ & $-0,25$ & $-0,29$ & $-0,39$ & $-0,34$ & $-0,34$ \\
\hline Q8 & $-0,10$ & $-0,09$ & $-0,11$ & $-0,08$ & $-0,11$ & $-0,25$ & $-0,26$ & $-0,18$ & $-0,26$ & $-0,20$ & $-0,24$ & $-0,32$ & $-0,28$ & $-0,28$ \\
\hline Q9 & $-0,10$ & $-0,10$ & $-0,11$ & $-0,08$ & $-0,12$ & $-0,26$ & $-0,28$ & $-0,19$ & $-0,27$ & $-0,22$ & $-0,25$ & $-0,34$ & $-0,30$ & $-0,30$ \\
\hline SQPN & $-0,06$ & $-0,06$ & $-0,06$ & $-0,05$ & $-0,07$ & $-0,15$ & $-0,15$ & $-0,11$ & $-0,15$ & $-0,12$ & $-0,14$ & $-0,19$ & $-0,17$ & $-0,17$ \\
\hline SQPE & $-0,06$ & $-0,06$ & $-0,06$ & $-0,05$ & $-0,07$ & $-0,15$ & $-0,15$ & $-0,11$ & $-0,15$ & $-0,12$ & $-0,14$ & $-0,19$ & $-0,17$ & $-0,17$ \\
\hline SQPG & 0,28 & 0,27 & 0,31 & 0,23 & 0,33 & 0,73 & 0,77 & 0,52 & 0,76 & 0,60 & 0,70 & 0,95 & 0,82 & 0,83 \\
\hline $\mathrm{COA}$ & 0,64 & 0,62 & 0,72 & 0,53 & 0,75 & 0,20 & 0,22 & 0,15 & 0,21 & 0,17 & 0,20 & 0,27 & 0,23 & 0,23 \\
\hline COCS & 0,15 & 0,14 & 0,16 & 0,12 & 0,17 & 0,38 & 0,40 & 0,29 & 0,43 & 0,34 & 0,39 & 0,50 & 0,43 & 0,43 \\
\hline COCI & 0,22 & 0,21 & 0,24 & 0,18 & 0,25 & 0,56 & 0,79 & 0,40 & 0,58 & 0,46 & 0,54 & 0,98 & 0,85 & 0,64 \\
\hline COCR & 0,20 & 0,20 & 0,23 & 0,17 & 0,24 & 0,69 & 0,56 & 0,38 & 0,55 & 0,44 & 0,51 & 0,69 & 0,60 & 0,60 \\
\hline СOCP & 0,23 & 0,23 & 0,26 & 0,19 & 0,27 & 0,60 & 0,64 & 0,43 & 0,63 & 0,50 & 0,58 & 0,79 & 0,68 & 0,76 \\
\hline IS & $-0,31$ & $-0,30$ & $-0,35$ & $-0,26$ & $-0,36$ & $-0,23$ & $-0,22$ & $-0,16$ & $-0,23$ & $-0,18$ & $-0,21$ & $-0,27$ & $-0,24$ & $-0,20$ \\
\hline
\end{tabular}




\section{Anexo F}

Matriz de Variância-Covariância do Modelo - Matriz $\Sigma$ (continuação)

\begin{tabular}{|c|c|c|c|c|c|c|c|c|c|c|c|c|c|c|}
\hline & $\mathrm{C} 10$ & C11 & $\mathrm{C} 12$ & $\mathrm{C} 13$ & $\mathrm{C} 14$ & $\mathrm{C} 15$ & $\mathrm{R} 1$ & $\mathrm{R} 2$ & R3 & Q1 & Q2 & Q3 & Q4 & Q5 \\
\hline \multicolumn{15}{|l|}{$\mathrm{A} 1$} \\
\hline \multicolumn{15}{|l|}{$\mathrm{A} 2$} \\
\hline \multicolumn{15}{|l|}{ A3 } \\
\hline \multicolumn{15}{|l|}{ A4 } \\
\hline \multicolumn{15}{|l|}{ A5 } \\
\hline \multicolumn{15}{|l|}{$\mathrm{C} 1$} \\
\hline \multicolumn{15}{|l|}{$\mathrm{C} 2$} \\
\hline \multicolumn{15}{|l|}{ C3 } \\
\hline \multicolumn{15}{|l|}{$\mathrm{C} 4$} \\
\hline \multicolumn{15}{|l|}{ C5 } \\
\hline \multicolumn{15}{|l|}{ C6 } \\
\hline \multicolumn{15}{|l|}{ C7 } \\
\hline \multicolumn{15}{|l|}{$\mathrm{C} 8$} \\
\hline \multicolumn{15}{|l|}{ C9 } \\
\hline $\mathrm{C} 10$ & 1,31 & & & & & & & & & & & & & \\
\hline C11 & 0,55 & 1,74 & & & & & & & & & & & & \\
\hline $\mathrm{C} 12$ & 0,74 & 0,96 & 1,69 & & & & & & & & & & & \\
\hline $\mathrm{C} 13$ & 0,66 & 0,59 & 0,80 & 1,41 & & & & & & & & & & \\
\hline C14 & 0,55 & 0,49 & 0,67 & 0,60 & 1,12 & & & & & & & & & \\
\hline $\mathrm{C} 15$ & 0,73 & 0,65 & 0,88 & 0,79 & 0,66 & 1,54 & & & & & & & & \\
\hline R1 & $-0,18$ & $-0,23$ & $-0,31$ & $-0,19$ & $-0,16$ & $-0,21$ & 1,06 & & & & & & & \\
\hline R2 & $-0,19$ & $-0,25$ & $-0,33$ & $-0,21$ & $-0,17$ & $-0,23$ & 0,76 & 1,82 & & & & & & \\
\hline R3 & $-0,19$ & $-0,25$ & $-0,34$ & $-0,21$ & $-0,17$ & $-0,23$ & 0,77 & 0,82 & 1,48 & & & & & \\
\hline Q1 & $-0,15$ & $-0,15$ & $-0,20$ & $-0,16$ & $-0,14$ & $-0,18$ & 0,08 & 0,09 & 0,09 & 4,85 & & & & \\
\hline Q2 & $-0,15$ & $-0,15$ & $-0,20$ & $-0,16$ & $-0,14$ & $-0,18$ & 0,08 & 0,09 & 0,09 & 0,04 & 4,70 & & & \\
\hline Q3 & $-0,22$ & $-0,21$ & $-0,29$ & $-0,23$ & $-0,19$ & $-0,26$ & 0,12 & 0,13 & 0,13 & 1,24 & 0,06 & 5,21 & & \\
\hline Q4 & $-0,32$ & $-0,32$ & $-0,43$ & $-0,35$ & $-0,29$ & $-0,39$ & 0,18 & 0,19 & 0,19 & 0,09 & 1,48 & 0,13 & 5,06 & \\
\hline Q5 & $-0,16$ & $-0,16$ & $-0,21$ & $-0,17$ & $-0,14$ & $-0,19$ & 0,09 & 0,09 & 0,09 & 0,04 & 0,73 & 0,06 & 1,57 & 4,67 \\
\hline Q6 & $-0,23$ & $-0,23$ & $-0,31$ & $-0,25$ & $-0,21$ & $-0,27$ & 0,13 & 0,13 & 0,14 & 1,32 & 0,06 & 1,90 & 0,13 & 0,07 \\
\hline Q7 & $-0,31$ & $-0,30$ & $-0,41$ & $-0,33$ & $-0,28$ & $-0,36$ & 0,17 & 0,18 & 0,18 & 1,76 & 0,08 & 2,53 & 0,18 & 0,09 \\
\hline Q8 & $-0,25$ & $-0,25$ & $-0,34$ & $-0,27$ & $-0,23$ & $-0,30$ & 0,14 & 0,15 & 0,15 & 0,07 & 1,16 & 0,10 & 2,49 & 1,23 \\
\hline Q9 & $-0,27$ & $-0,26$ & $-0,36$ & $-0,29$ & $-0,24$ & $-0,32$ & 0,15 & 0,16 & 0,16 & 1,54 & 0,07 & 2,21 & 0,16 & 0,08 \\
\hline SQPN & $-0,15$ & $-0,15$ & $-0,20$ & $-0,16$ & $-0,14$ & $-0,18$ & 0,08 & 0,09 & 0,09 & 0,04 & 0,68 & 0,06 & 1,48 & 0,73 \\
\hline SQPE & $-0,15$ & $-0,15$ & $-0,20$ & $-0,16$ & $-0,14$ & $-0,18$ & 0,08 & 0,09 & 0,09 & 0,87 & 0,04 & 1,24 & 0,09 & 0,04 \\
\hline SQPG & 0,74 & 0,74 & 1,00 & 0,80 & 0,67 & 0,89 & $-0,41$ & $-0,43$ & $-0,44$ & $-0,20$ & $-0,20$ & $-0,29$ & $-0,43$ & $-0,21$ \\
\hline $\mathrm{COA}$ & 0,21 & 0,21 & 0,28 & 0,23 & 0,19 & 0,25 & $-0,31$ & $-0,33$ & $-0,34$ & $-0,06$ & $-0,06$ & $-0,08$ & $-0,12$ & $-0,06$ \\
\hline COCS & 0,39 & 0,38 & 0,52 & 0,42 & 0,35 & 0,46 & $-0,16$ & $-0,17$ & $-0,17$ & $-0,11$ & $-0,11$ & $-0,15$ & $-0,23$ & $-0,11$ \\
\hline COCI & 0,57 & 0,56 & 0,76 & 0,62 & 0,52 & 0,68 & $-0,22$ & $-0,24$ & $-0,24$ & $-0,15$ & $-0,15$ & $-0,22$ & $-0,33$ & $-0,16$ \\
\hline COCR & 0,54 & 0,70 & 0,95 & 0,58 & 0,49 & 0,64 & $-0,23$ & $-0,24$ & $-0,24$ & $-0,15$ & $-0,15$ & $-0,21$ & $-0,32$ & $-0,16$ \\
\hline COCP & 0,68 & 0,61 & 0,83 & 0,74 & 0,62 & 0,81 & $-0,20$ & $-0,21$ & $-0,21$ & $-0,17$ & $-0,17$ & $-0,24$ & $-0,36$ & $-0,18$ \\
\hline IS & $-0,18$ & $-0,23$ & $-0,31$ & $-0,19$ & $-0,16$ & $-0,21$ & 0,71 & 0,76 & 0,77 & 0,08 & 0,08 & 0,12 & 0,18 & 0,09 \\
\hline
\end{tabular}




\section{Anexo F}

Matriz de Variância-Covariância do Modelo - Matriz $\Sigma$ (continuação)

\begin{tabular}{|c|c|c|c|c|c|c|c|c|c|c|c|c|c|}
\hline & Q6 & Q7 & Q8 & Q9 & SQPN & SQPE & SQPG & $\mathrm{COA}$ & COCS & COCI & COCR & $\mathrm{COCP}$ & IS \\
\hline \multicolumn{14}{|l|}{$\mathrm{A} 1$} \\
\hline \multicolumn{14}{|l|}{ A2 } \\
\hline \multicolumn{14}{|l|}{ A3 } \\
\hline \multicolumn{14}{|l|}{ A4 } \\
\hline \multicolumn{14}{|l|}{ A5 } \\
\hline \multicolumn{14}{|l|}{$\mathrm{C} 1$} \\
\hline \multicolumn{14}{|l|}{$\mathrm{C} 2$} \\
\hline \multicolumn{14}{|l|}{$\mathrm{C} 3$} \\
\hline \multicolumn{14}{|l|}{$\mathrm{C} 4$} \\
\hline \multicolumn{14}{|l|}{ C5 } \\
\hline \multicolumn{14}{|l|}{ C6 } \\
\hline \multicolumn{14}{|l|}{$\mathrm{C} 7$} \\
\hline \multicolumn{14}{|l|}{$\mathrm{C} 8$} \\
\hline \multicolumn{14}{|l|}{ C9 } \\
\hline \multicolumn{14}{|l|}{$\mathrm{C} 10$} \\
\hline \multicolumn{14}{|l|}{ C11 } \\
\hline \multicolumn{14}{|l|}{$\mathrm{C} 12$} \\
\hline \multicolumn{14}{|l|}{$\mathrm{C} 13$} \\
\hline \multicolumn{14}{|l|}{$\mathrm{C} 14$} \\
\hline \multicolumn{14}{|l|}{$\mathrm{C} 15$} \\
\hline \multicolumn{14}{|l|}{$\mathrm{R} 1$} \\
\hline $\mathrm{R} 2$ & & & & & & & & & & & & & \\
\hline R3 & & & & & & & & & & & & & \\
\hline Q1 & & & & & & & & & & & & & \\
\hline Q2 & & & & & & & & & & & & & \\
\hline Q3 & & & & & & & & & & & & & \\
\hline Q4 & & & & & & & & & & & & & \\
\hline Q5 & & & & & & & & & & & & & \\
\hline Q6 & 4,85 & & & & & & & & & & & & \\
\hline Q7 & 2,70 & 5,55 & & & & & & & & & & & \\
\hline Q8 & 0,11 & 0,14 & 4,65 & & & & & & & & & & \\
\hline Q9 & 2,36 & 3,14 & 0,12 & 4,42 & & & & & & & & & \\
\hline SQPN & 0,06 & 0,08 & 1,16 & 0,07 & 0,68 & & & & & & & & \\
\hline SQPE & 1,32 & 1,76 & 0,07 & 1,54 & 0,04 & 0,87 & & & & & & & \\
\hline SQPG & $-0,31$ & $-0,41$ & $-0,34$ & $-0,36$ & $-0,20$ & $-0,20$ & 1,00 & & & & & & \\
\hline $\mathrm{COA}$ & $-0,09$ & $-0,12$ & $-0,10$ & $-0,10$ & $-0,06$ & $-0,06$ & 0,28 & 0,64 & & & & & \\
\hline COCS & $-0,16$ & $-0,21$ & $-0,18$ & $-0,19$ & $-0,11$ & $-0,11$ & 0,52 & 0,15 & 0,29 & & & & \\
\hline COCI & $-0,24$ & $-0,32$ & $-0,26$ & $-0,28$ & $-0,15$ & $-0,15$ & 0,77 & 0,22 & 0,40 & 0,79 & & & \\
\hline COCR & $-0,22$ & $-0,30$ & $-0,25$ & $-0,26$ & $-0,15$ & $-0,15$ & 0,73 & 0,20 & 0,38 & 0,56 & 0,69 & & \\
\hline СОCP & $-0,26$ & $-0,34$ & $-0,28$ & $-0,30$ & $-0,17$ & $-0,17$ & 0,83 & 0,23 & 0,43 & 0,64 & 0,60 & 0,76 & \\
\hline IS & 0,13 & 0,17 & 0,14 & 0,15 & 0,08 & 0,08 & $-0,41$ & $-0,31$ & $-0,16$ & $-0,22$ & $-0,23$ & $-0,20$ & 0,71 \\
\hline
\end{tabular}




\section{Anexo G}

Matriz de Resíduos de Variância-Covariância

\begin{tabular}{|c|c|c|c|c|c|c|c|c|c|c|c|c|c|c|c|c|}
\hline & $\mathrm{A} 1$ & $\mathrm{~A} 2$ & $\mathrm{~A} 3$ & A4 & A5 & $\mathrm{C} 1$ & $\mathrm{C} 2$ & $\mathrm{C} 3$ & $\mathrm{C} 4$ & C5 & C6 & C7 & $\mathrm{C} 8$ & $\mathrm{C} 9$ & $\mathrm{C} 10$ & $\mathrm{C} 11$ \\
\hline A1 & 0,00 & & & & & & & & & & & & & & & \\
\hline A2 & 0,05 & 0,00 & & & & & & & & & & & & & & \\
\hline A3 & $-0,01$ & 0,02 & 0,00 & & & & & & & & & & & & & \\
\hline A4 & $-0,10$ & $-0,07$ & 0,01 & 0,00 & & & & & & & & & & & & \\
\hline A5 & 0,00 & $-0,01$ & $-0,01$ & 0,06 & 0,00 & & & & & & & & & & & \\
\hline $\mathrm{C} 1$ & 0,07 & 0,09 & 0,02 & 0,03 & 0,05 & 0,00 & & & & & & & & & & \\
\hline $\mathrm{C} 2$ & 0,04 & 0,11 & 0,00 & $-0,02$ & $-0,02$ & 0,14 & 0,00 & & & & & & & & & \\
\hline $\mathrm{C} 3$ & $-0,22$ & $-0,07$ & $-0,09$ & $-0,05$ & $-0,06$ & 0,03 & 0,33 & 0,00 & & & & & & & & \\
\hline $\mathrm{C} 4$ & $-0,10$ & $-0,01$ & $-0,04$ & $-0,04$ & 0,00 & 0,30 & 0,10 & 0,02 & 0,00 & & & & & & & \\
\hline C5 & $-0,07$ & $-0,02$ & 0,01 & 0,02 & 0,11 & $-0,03$ & $-0,07$ & $-0,11$ & $-0,07$ & 0,00 & & & & & & \\
\hline C6 & $-0,04$ & 0,02 & $-0,02$ & 0,07 & 0,08 & $-0,07$ & 0,01 & $-0,02$ & $-0,03$ & 0,18 & 0,00 & & & & & \\
\hline C7 & $-0,13$ & $-0,05$ & $-0,10$ & 0,07 & $-0,03$ & $-0,17$ & $-0,08$ & $-0,03$ & $-0,03$ & $-0,02$ & 0,08 & 0,00 & & & & \\
\hline $\mathrm{C} 8$ & 0,01 & 0,05 & $-0,07$ & $-0,03$ & 0,09 & $-0,06$ & 0,01 & $-0,08$ & 0,00 & $-0,02$ & 0,06 & 0,04 & 0,00 & & & \\
\hline C9 & 0,07 & 0,09 & 0,01 & $-0,01$ & 0,04 & 0,00 & 0,10 & 0,09 & 0,00 & 0,05 & $-0,04$ & 0,05 & 0,06 & 0,00 & & \\
\hline $\mathrm{C} 10$ & 0,05 & 0,07 & $-0,01$ & $-0,02$ & 0,01 & $-0,06$ & 0,05 & $-0,11$ & 0,03 & 0,06 & 0,05 & $-0,05$ & $-0,04$ & $-0,01$ & 0,00 & \\
\hline C11 & 0,05 & 0,08 & 0,05 & $-0,08$ & 0,08 & 0,05 & $-0,06$ & 0,12 & 0,05 & $-0,06$ & $-0,06$ & $-0,08$ & $-0,18$ & 0,05 & $-0,01$ & 0,00 \\
\hline $\mathrm{C} 12$ & $-0,06$ & 0,03 & $-0,07$ & 0,02 & $-0,05$ & $-0,01$ & 0,11 & 0,19 & 0,00 & $-0,10$ & $-0,07$ & 0,04 & $-0,15$ & 0,03 & $-0,06$ & 0,00 \\
\hline C13 & 0,01 & $-0,03$ & $-0,07$ & $-0,05$ & $-0,03$ & 0,11 & 0,07 & 0,11 & 0,09 & 0,05 & $-0,06$ & $-0,09$ & $-0,11$ & $-0,06$ & 0,05 & 0,12 \\
\hline C14 & $-0,02$ & 0,04 & 0,02 & $-0,05$ & 0,04 & $-0,01$ & $-0,06$ & $-0,09$ & $-0,05$ & 0,08 & $-0,07$ & $-0,02$ & $-0,06$ & 0,01 & 0,00 & 0,07 \\
\hline $\mathrm{C} 15$ & 0,00 & $-0,02$ & $-0,07$ & $-0,03$ & $-0,04$ & $-0,12$ & 0,12 & $-0,11$ & $-0,13$ & $-0,05$ & $-0,04$ & 0,13 & 0,08 & $-0,03$ & 0,01 & $-0,04$ \\
\hline R1 & $-0,06$ & $-0,03$ & 0,01 & $-0,16$ & 0,03 & 0,05 & 0,08 & 0,15 & $-0,03$ & 0,03 & $-0,02$ & $-0,02$ & 0,03 & 0,01 & 0,05 & 0,02 \\
\hline R2 & 010 & 0,12 & & 0,01 & 0,19 & $-0,15$ & 0,01 & 0,06 & 0,03 & $-0,04$ & 0,01 & 0,06 & $-0,01$ & $-0,06$ & 0,12 & 0,01 \\
\hline R3 & $-0,04$ & $-0,04$ & $-0,06$ & $-0,32$ & $-0,05$ & 0,10 & 0,06 & 0,33 & 0,01 & $-0,12$ & $-0,21$ & $-0,06$ & 0,04 & 0,02 & 0,00 & 0,17 \\
\hline Q1 & $-0,38$ & $-0,17$ & $-0,19$ & $-0,34$ & -0 & $-0,10$ & $-0,06$ & 0,09 & $-0,09$ & 0,20 & $-0,01$ & $-0,18$ & $-0,15$ & 0,08 & 0,10 & 0,13 \\
\hline Q2 & $-0,33$ & $-0,34$ & $-0,31$ & $-0,26$ & $-0,39$ & 0,16 & 0,19 & 0,02 & $-0,05$ & $-0,10$ & 0,13 & $-0,03$ & $-0,09$ & $-0,15$ & 0,09 & $-0,05$ \\
\hline Q3 & $-0,42$ & $-0,22$ & $-0,17$ & $-0,14$ & $-0,31$ & $-0,16$ & 0,04 & 0,07 & $-0,20$ & $-0,08$ & $-0,08$ & $-0,18$ & $-0,25$ & $-0,14$ & $-0,14$ & $-0,11$ \\
\hline Q4 & $-0,16$ & $-0,24$ & $-0,03$ & $-0,21$ & $-0,34$ & $-0,08$ & 0,11 & 0,10 & $-0,08$ & 0,08 & 0,05 & $-0,03$ & 0,18 & 0,14 & 0,16 & 0,14 \\
\hline Q5 & $-0,19$ & $-0,08$ & $-0,28$ & $-0,13$ & $-0,20$ & $-0,04$ & 0,21 & 0,23 & 0,05 & 0,07 & $-0,13$ & 0,05 & 0,13 & 0,33 & 0,23 & 0,13 \\
\hline Q6 & $-0,26$ & $-0,18$ & $-0,11$ & $-0,15$ & $-0,21$ & $-0,08$ & 0,11 & 0,29 & 0,10 & 0,18 & 0,06 & $-0,07$ & $-0,05$ & 0,05 & 0,13 & 0,12 \\
\hline Q7 & $-0,03$ & $-0,17$ & $-0,10$ & $-0,20$ & $-0,32$ & $-0,26$ & 0,06 & $-0,01$ & $-0,20$ & 0,08 & 0,06 & 0,21 & 0,23 & 0,28 & 0,24 & 0,10 \\
\hline Q8 & $-0,11$ & $-0,17$ & $-0,16$ & $-0,26$ & $-0,24$ & $-0,17$ & $-0,03$ & 0,05 & $-0,34$ & $-0,15$ & $-0,35$ & $-0,21$ & $-0,24$ & $-0,17$ & $-0,18$ & 0,10 \\
\hline Q9 & $-0,08$ & $-0,12$ & $-0,01$ & $-0,04$ & $-0,26$ & $-0,22$ & 0,18 & 0,21 & $-0,12$ & 0,23 & 0,08 & 0,10 & 0,18 & 0,18 & 0,20 & 0,26 \\
\hline
\end{tabular}




\section{Anexo G}

Matriz de Variância-Covariância Residual (continuação)

\begin{tabular}{|c|c|c|c|c|c|c|c|c|c|c|c|c|c|c|c|c|}
\hline & $\mathrm{C} 12$ & $\mathrm{C} 13$ & $\mathrm{C} 14$ & $\mathrm{C} 15$ & $\mathrm{R} 1$ & $\mathrm{R} 2$ & $\mathrm{R} 3$ & $\mathrm{Q} 1$ & $\mathrm{Q} 2$ & Q3 & Q4 & Q5 & Q6 & Q7 & Q8 & Q9 \\
\hline \multicolumn{17}{|l|}{$\mathrm{A} 1$} \\
\hline \multicolumn{17}{|l|}{ A2 } \\
\hline \multicolumn{17}{|l|}{ A3 } \\
\hline \multicolumn{17}{|l|}{ A4 } \\
\hline \multicolumn{17}{|l|}{ A5 } \\
\hline \multicolumn{17}{|l|}{$\mathrm{C} 1$} \\
\hline \multicolumn{17}{|l|}{$\mathrm{C} 2$} \\
\hline \multicolumn{17}{|l|}{$\mathrm{C} 3$} \\
\hline \multicolumn{17}{|l|}{$\mathrm{C} 4$} \\
\hline \multicolumn{17}{|l|}{ C5 } \\
\hline \multicolumn{17}{|l|}{ C6 } \\
\hline \multicolumn{17}{|l|}{ C7 } \\
\hline \multicolumn{17}{|l|}{$\mathrm{C} 8$} \\
\hline \multicolumn{17}{|l|}{$\mathrm{C} 9$} \\
\hline \multicolumn{17}{|l|}{$\mathrm{C} 10$} \\
\hline \multicolumn{17}{|l|}{$\mathrm{C} 11$} \\
\hline $\mathrm{C} 12$ & 0,00 & & & & & & & & & & & & & & & \\
\hline $\mathrm{C} 13$ & 0,18 & 0,00 & & & & & & & & & & & & & & \\
\hline $\mathrm{C} 14$ & $-0,05$ & $-0,05$ & 0,00 & & & & & & & & & & & & & \\
\hline $\mathrm{C} 15$ & $-0,03$ & $-0,04$ & 0,13 & 0,00 & & & & & & & & & & & & \\
\hline R1 & $-0,07$ & $-0,01$ & 0,03 & 0,04 & 0,01 & & & & & & & & & & & \\
\hline $\mathrm{R} 2$ & $-0,06$ & $-0,10$ & $-0,12$ & 0,06 & 0,02 & 0,01 & & & & & & & & & & \\
\hline R3 & 0,09 & $-0,05$ & 0,01 & $-0,07$ & $-0,01$ & 0,03 & 0,01 & & & & & & & & & \\
\hline Q1 & $-0,14$ & $-0,13$ & 0,11 & $-0,04$ & 0,32 & 0,42 & 0,25 & $-0,04$ & & & & & & & & \\
\hline Q2 & $-0,11$ & $-0,03$ & 0,19 & 0,41 & 0,20 & 0,11 & 0,01 & 1,38 & 0,04 & & & & & & & \\
\hline Q3 & $-0,23$ & $-0,14$ & $-0,15$ & $-0,02$ & 0,22 & 0,33 & 0,08 & 0,53 & 1,69 & $-0,01$ & & & & & & \\
\hline Q4 & $-0,05$ & 0,09 & 0,05 & 0,13 & 0,11 & 0,35 & $-0,01$ & 1,56 & 0,03 & 1,81 & 0,02 & & & & & \\
\hline Q5 & 0,06 & 0,28 & 0,02 & 0,22 & 0,20 & $-0,03$ & 0,29 & 0,99 & 0,50 & 1,57 & 0,04 & 0,01 & & & & \\
\hline Q6 & 0,07 & 0,12 & 0,05 & 0,12 & 0,03 & 0,10 & 0,00 & $-0,06$ & 1,09 & 0,61 & 1,50 & 2,04 & $-0,02$ & & & \\
\hline Q7 & $-0,12$ & $-0,02$ & 0,00 & 0,28 & 0,05 & 0,23 & $-0,07$ & $-0,09$ & 1,07 & $-0,34$ & 1,75 & 1,54 & $-0,13$ & $-0,03$ & & \\
\hline Q8 & $-0,18$ & $-0,09$ & $-0,03$ & $-0,10$ & 0,13 & 0,21 & 0,27 & 1,17 & $-0,11$ & 1,27 & 0,04 & $-0,18$ & 1,25 & 1,51 & 0,01 & \\
\hline Q9 & 0,09 & 0,11 & 0,01 & 0,26 & 0,01 & 0,24 & $-0,12$ & $-0,24$ & 0,93 & $-0,20$ & 1,62 & 1,09 & $-0,14$ & 0,18 & 1,41 & $-0,02$ \\
\hline
\end{tabular}




\section{Anexo H}

Equações de Mensuração

Equação

$E P$

Teste- $z$

\begin{tabular}{|c|c|c|}
\hline $\mathrm{A} 1=1,00 \mathrm{COA}+1,00 \mathrm{E} 6$ & - & - \\
\hline $\mathrm{A} 2=0,96 \mathrm{COA}+1,00 \mathrm{E} 7$ & 0,08 & $12,37 *$ \\
\hline $\mathrm{A} 3=1,11 \mathrm{COA}+1,00 \mathrm{E} 8$ & 0,09 & $12,27 *$ \\
\hline $\mathrm{A} 4=0,83 \mathrm{COA}+1,00 \mathrm{E} 9$ & 0,10 & $8,33 *$ \\
\hline $\mathrm{A} 5=1,17 \mathrm{COA}+1,00 \mathrm{E} 10$ & 0,10 & $11,95^{*}$ \\
\hline $\mathrm{C} 3=1,00 \mathrm{COCS}+1,00 \mathrm{E} 13$ & - & - \\
\hline $\mathrm{C} 4=1,45 \mathrm{COCS}+1,00 \mathrm{E} 14$ & 0,21 & $7,05^{*}$ \\
\hline $\mathrm{C} 5=1,15 \mathrm{COCS}+1,00 \mathrm{E} 15$ & 0,20 & $5,74 *$ \\
\hline $\mathrm{C} 6=1,34 \mathrm{COCS}+1,00 \mathrm{E} 16$ & 0,21 & $6,45^{*}$ \\
\hline $\mathrm{C} 2=1,00 \mathrm{COCI}+1,00 \mathrm{E} 12$ & - & - \\
\hline $\mathrm{C} 7=1,24 \mathrm{COCI}+1,00 \mathrm{E} 17$ & 0,11 & $11,46^{*}$ \\
\hline $\mathrm{C} 8=1,07 \mathrm{COCI}+1,00 \mathrm{E} 18$ & 0,09 & $11,82 *$ \\
\hline $\mathrm{C} 1=1,00 \mathrm{COCR}+1,00 \mathrm{E} 11$ & - & - \\
\hline $\mathrm{C} 11=1,01 \mathrm{COCR}+1,00 \mathrm{E} 21$ & 0,10 & $10,49 *$ \\
\hline $\mathrm{C} 12=1,37 \mathrm{COCR}+1,00 \mathrm{E} 22$ & 0,12 & $11,29 *$ \\
\hline $\mathrm{C} 9=1,00 \mathrm{COCP}+1,00 \mathrm{E} 19$ & - & - \\
\hline $\mathrm{C} 10=0,90 \mathrm{COCP}+1,00 \mathrm{E} 20$ & 0,07 & $13,29 *$ \\
\hline $\mathrm{C} 13=0,97 \mathrm{COCP}+1,00 \mathrm{E} 23$ & 0,07 & $13,28^{*}$ \\
\hline $\mathrm{C} 14=0,81 \mathrm{COCP}+1,00 \mathrm{E} 24$ & 0,07 & $12,10^{*}$ \\
\hline $\mathrm{C} 15=1,07 \mathrm{COCP}+1,00 \mathrm{E} 25$ & 0,08 & $14,07 *$ \\
\hline $\mathrm{R} 1=1,00 \mathrm{IS}+1,00 \mathrm{E} 26$ & - & - \\
\hline $\mathrm{R} 2=1,07 \mathrm{IS}+1,00 \mathrm{E} 27$ & 0,15 & $7,26 *$ \\
\hline $\mathrm{R} 3=1,08 \mathrm{IS}+1,00 \mathrm{E} 28$ & 0,15 & $7,03 *$ \\
\hline $\mathrm{SQPN}=-0,20 \mathrm{SQP}+1,00 \mathrm{D} 1$ & 0,07 & $-3,07 *$ \\
\hline $\mathrm{SQPE}=-0,20 \mathrm{SQP}+1,00 \mathrm{D} 2$ & 0,07 & $-3,07 *$ \\
\hline $\mathrm{Q} 2=1,00 \mathrm{SQPN}+1,00 \mathrm{E} 30$ & - & - \\
\hline $\mathrm{Q} 4=2,16 \mathrm{SQPN}+1,00 \mathrm{E} 32$ & 0,40 & $5,35^{*}$ \\
\hline $\mathrm{Q} 5=1,06 \mathrm{SQPN}+1,00 \mathrm{E} 33$ & 0,21 & $5,12 *$ \\
\hline $\mathrm{Q} 8=1,69 \mathrm{SQPN}+1,00 \mathrm{E} 36$ & 0,34 & $4,92 *$ \\
\hline $\mathrm{Q} 1=1,00 \mathrm{SQPE}+1,00 \mathrm{E} 29$ & - & - \\
\hline $\mathrm{Q} 3=1,44 \mathrm{SQPE}+1,00 \mathrm{E} 31$ & 0,20 & $7,19 *$ \\
\hline $\mathrm{Q} 6=1,53 \mathrm{SQPE}+1,00 \mathrm{E} 34$ & 0,23 & $6,74 *$ \\
\hline $\mathrm{Q} 7=2,04 \mathrm{SQPE}+1,00 \mathrm{E} 35$ & 0,30 & $6,86^{*}$ \\
\hline $\mathrm{Q} 9=1,78 \mathrm{SQPE}+1,00 \mathrm{E} 37$ & 0,26 & $6,85^{*}$ \\
\hline
\end{tabular}

Nota: Significância testada por meio do teste- $z$ (quociente entre parâmetro e $E P$ ).

(*) $p<0,05$.

(-) Parâmetro fixo no modelo identificado. 


\section{Anexo I}

Equações Estruturais do Modelo Estimado

Equação $\quad E P \quad$ Teste- $z$

\begin{tabular}{lcc}
\hline COA $=\mathbf{0 , 2 8 S Q P}+1,00 D 4$ & 0,06 & $5,07^{*}$ \\
COCS = 0,52SQP + 1,00D5 & 0,07 & $7,16^{*}$ \\
COCI = 0,77SQP + 1,00D6 & 0,07 & $10,96^{*}$ \\
COCR = 0,73SQP + 1,00D7 & 0,07 & $10,84^{*}$ \\
COCP = 0,83SQP + 1,00D8 & 0,06 & $14,94^{*}$ \\
IS = -0,35COA + 2,58COCS + 0,45COCI + 0,41COCR + & 0,14 & $-2,48^{*}$ \\
1,92 COCP - 3,90SQP + 1,00D9 & 4,65 & 0,56 \\
& 0,57 & 0,80 \\
& 0,62 & 0,67 \\
& 1,69 & 1,14 \\
\hline
\end{tabular}

Nota: Significância testada por meio do teste- $z$ (quociente entre parâmetro e $E P$ ).

Parâmetros significativos em negrito.

$* p<0,05$. 


\section{Anexo J}

Efeito Total com Valores dos Parâmetros Não-padronizados

\begin{tabular}{|c|c|c|}
\hline Equações & $E P$ & Teste- $z$ \\
\hline $\mathrm{A} 1=1,00 \mathrm{COA}+0,28 \mathrm{SQP}+1,00 \mathrm{E} 6+1,00 \mathrm{D} 4$ & 0,06 & $5,07 *$ \\
\hline \multirow[t]{3}{*}{$\mathrm{A} 2=0,96 \mathrm{COA}+0,27 \mathrm{SQP}+1,00 \mathrm{E} 7+0,96 \mathrm{D} 4$} & 0,08 & $12,37 *$ \\
\hline & 0,06 & $4,57 *$ \\
\hline & 0,08 & $12,37 *$ \\
\hline \multirow[t]{3}{*}{$\mathrm{A} 3=1,11 \mathrm{COA}+0,31 \mathrm{SQP}+1,00 \mathrm{E} 8+1,11 \mathrm{D} 4$} & 0,09 & $12,27 *$ \\
\hline & 0,07 & $4,36^{*}$ \\
\hline & 0,09 & $12,27 *$ \\
\hline \multirow[t]{3}{*}{$\mathrm{A} 4=0,83 \mathrm{COA}+0,23 \mathrm{SQP}+1,00 \mathrm{E} 9+0,83 \mathrm{D} 4$} & 0,10 & $8,33 *$ \\
\hline & 0,06 & $4,05^{*}$ \\
\hline & 0,10 & $8,33^{*}$ \\
\hline \multirow[t]{3}{*}{$\mathrm{A} 5=1,17 \mathrm{COA}+0,33 \mathrm{SQP}+1,00 \mathrm{E} 10+1,17 \mathrm{D} 4$} & 0,10 & $11,95^{*}$ \\
\hline & 0,07 & $4,41 *$ \\
\hline & 0,10 & $11,95^{*}$ \\
\hline $\mathrm{C} 1=1,00 \mathrm{COCR}+0,73 \mathrm{SQP}+1,00 \mathrm{E} 11+1,00 \mathrm{D} 7$ & 0,07 & $10,84 *$ \\
\hline $\mathrm{C} 2=1,00 \mathrm{COCI}+0,77 \mathrm{SQP}+1,00 \mathrm{E} 12+1,00 \mathrm{D} 6$ & 0,07 & $10,96^{*}$ \\
\hline $\mathrm{C} 3=1,00 \mathrm{COCS}+0,52 \mathrm{SQP}+1,00 \mathrm{E} 13+1,00 \mathrm{D} 5$ & 0,07 & $7,16^{*}$ \\
\hline \multirow[t]{3}{*}{$\mathrm{C} 4=1,45 \mathrm{COCS}+0,76 \mathrm{SQP}+1,00 \mathrm{E} 14+1,45 \mathrm{D} 5$} & 0,21 & $7,05^{*}$ \\
\hline & 0,20 & $3,72 *$ \\
\hline & 0,21 & $7,05^{*}$ \\
\hline \multirow[t]{3}{*}{$\mathrm{C} 5=1,15 \mathrm{COCS}+0,60 \mathrm{SQP}+1,00 \mathrm{E} 15+1,15 \mathrm{D} 5$} & 0,20 & $5,74 *$ \\
\hline & 0,18 & $3,36^{*}$ \\
\hline & 0,20 & $5,74 *$ \\
\hline \multirow[t]{3}{*}{$\mathrm{C} 6=1,34 \mathrm{COCS}+0,70 \mathrm{SQP}+1,00 \mathrm{E} 16+1,34 \mathrm{D} 5$} & 0,21 & $6,45^{*}$ \\
\hline & 0,20 & $3,52 *$ \\
\hline & 0,21 & $6,45^{*}$ \\
\hline \multirow[t]{3}{*}{$\mathrm{C} 7=1,24 \mathrm{COCI}+0,95 \mathrm{SQP}+1,00 \mathrm{E} 17+1,24 \mathrm{D} 6$} & 0,11 & $11,46^{*}$ \\
\hline & 0,16 & $5,86^{*}$ \\
\hline & 0,11 & $11,46^{*}$ \\
\hline \multirow{3}{*}{$\mathrm{C} 8=1,07 \mathrm{COCI}+0,82 \mathrm{SQP}+1,00 \mathrm{E} 18+1,07 \mathrm{D} 6$} & 0,09 & $11,82 *$ \\
\hline & 0,14 & $6,01 *$ \\
\hline & 0,09 & $11,82 *$ \\
\hline $\mathrm{C} 9=1,00 \mathrm{COCP}+0,83 \mathrm{SQP}+1,00 \mathrm{E} 19+1,00 \mathrm{D} 8$ & 0,06 & $14,94 *$ \\
\hline \multirow{3}{*}{$\mathrm{C} 10=0,90 \mathrm{COCP}+0,74 \mathrm{SQP}+1,00 \mathrm{E} 20+0,90 \mathrm{D} 8$} & 0,07 & $13,29 *$ \\
\hline & 0,09 & $8,22 *$ \\
\hline & 0,07 & $13,29 *$ \\
\hline \multirow[t]{3}{*}{$\mathrm{C} 11=1,01 \mathrm{COCR}+0,74 \mathrm{SQP}+1,00 \mathrm{E} 21+1,01 \mathrm{D} 7$} & 0,10 & $10,49 *$ \\
\hline & 0,12 & $5,93 *$ \\
\hline & 0,10 & $10,49 *$ \\
\hline \multirow[t]{3}{*}{$\mathrm{C} 12=1,37 \mathrm{COCR}+1,00 \mathrm{SQP}+1,00 \mathrm{E} 22+1,37 \mathrm{D} 7$} & 0,12 & $11,29 *$ \\
\hline & 0,17 & $5,73 *$ \\
\hline & 0,12 & $11,29 *$ \\
\hline \multirow[t]{3}{*}{$\mathrm{C} 13=0,97 \mathrm{COCP}+0,80 \mathrm{SQP}+1,00 \mathrm{E} 23+0,97 \mathrm{D} 8$} & 0,07 & $13,28 *$ \\
\hline & 0,10 & $8,16^{*}$ \\
\hline & 0,07 & $13,28 *$ \\
\hline
\end{tabular}




\section{Anexo J}

Efeito Total com Valores dos Parâmetros Não-padronizados (continuação)

\begin{tabular}{|c|c|c|}
\hline Equações & $E P$ & Teste- $z$ \\
\hline \multirow[t]{3}{*}{$\mathrm{C} 14=0,81 \mathrm{COCP}+0,67 \mathrm{SQP}+1,00 \mathrm{E} 24+0,81 \mathrm{D} 8$} & 0,07 & $12,10^{*}$ \\
\hline & 0,09 & $7,87 *$ \\
\hline & 0,07 & $12,10^{*}$ \\
\hline \multirow[t]{3}{*}{$\mathrm{C} 15=1,07 \mathrm{COCP}+0,89 \mathrm{SQP}+1,00 \mathrm{E} 25+1,07 \mathrm{D} 8$} & 0,08 & $14,07 *$ \\
\hline & 0,11 & $8,22 *$ \\
\hline & 0,08 & $14,07 *$ \\
\hline $\mathrm{R} 1=-0,35 \mathrm{COA}+2,58 \mathrm{COCS}+0,45 \mathrm{COCI}+0,41 \mathrm{COCR}+$ & 0,14 & $-2,48 *$ \\
\hline $1,92 \mathrm{COCP}+1,00 \mathrm{IS}-0,41 \mathrm{SQP}+1,00 \mathrm{E} 26-, 35 \mathrm{D} 4+$ & 4,65 & 0,56 \\
\hline \multirow[t]{9}{*}{$2,58 \mathrm{D} 5+0,45 \mathrm{D} 6+0,41 \mathrm{D} 7+1,92 \mathrm{D} 8+1,00 \mathrm{D} 9$} & 0,57 & 0,80 \\
\hline & 0,62 & 0,67 \\
\hline & 1,69 & 1,14 \\
\hline & 8,03 & $-0,05$ \\
\hline & 0,14 & $-2,48 *$ \\
\hline & 4,65 & 0,56 \\
\hline & 0,57 & 0,80 \\
\hline & 0,62 & 0,67 \\
\hline & 1,69 & 1,14 \\
\hline $\mathrm{R} 2=-0,37 \mathrm{COA}+2,76 \mathrm{COCS}+0,49 \mathrm{COCI}+0,44 \mathrm{COCR}+$ & 0,13 & $-2,78 *$ \\
\hline $2,05 \mathrm{COCP}+1,07 \mathrm{IS}-0,43 \mathrm{SQP}+1,00 \mathrm{E} 27-0,37 \mathrm{D} 4+$ & 5,00 & 0,55 \\
\hline \multirow[t]{11}{*}{$2,76 \mathrm{D} 5+0,49 \mathrm{D} 6+0,44 \mathrm{D} 7+2,05 \mathrm{D} 8+1,07 \mathrm{D} 9$} & 0,61 & 0,79 \\
\hline & 0,68 & 0,66 \\
\hline & 1,82 & 1,13 \\
\hline & 0,15 & $7,26^{*}$ \\
\hline & 8,58 & $-0,05$ \\
\hline & 0,13 & $-2,78 *$ \\
\hline & 5,00 & 0,55 \\
\hline & 0,61 & 0,79 \\
\hline & 0,68 & 0,66 \\
\hline & 1,82 & 1,13 \\
\hline & 0,15 & $7,26^{*}$ \\
\hline $\mathrm{R} 3=-0,38 \mathrm{COA}+2,79 \mathrm{COCS}+0,49 \mathrm{COCI}+0,45 \mathrm{COCR}+$ & 0,16 & $-2,40 *$ \\
\hline $2,07 \mathrm{COCP}+1,08 \mathrm{IS}-0,44 \mathrm{SQP}+1,00 \mathrm{E} 28-0,38 \mathrm{D} 4+$ & 4,99 & 0,56 \\
\hline \multirow[t]{11}{*}{$2,79 \mathrm{D} 5+0,49 \mathrm{D} 6+0,45 \mathrm{D} 7+2,07 \mathrm{D} 8+1,08 \mathrm{D} 9$} & 0,61 & 0,80 \\
\hline & 0,68 & 0,66 \\
\hline & 1,82 & 1,14 \\
\hline & 0,15 & $7,03 *$ \\
\hline & 8,68 & $-0,05$ \\
\hline & 0,16 & $-2,40 *$ \\
\hline & 4,99 & 0,56 \\
\hline & 0,61 & 0,80 \\
\hline & 0,68 & 0,66 \\
\hline & 1,82 & 1,14 \\
\hline & 0,15 & $7,03 *$ \\
\hline $\mathrm{Q} 1=1,00 \mathrm{SQPE}-0,20 \mathrm{SQP}+1,00 \mathrm{E} 29+1,00 \mathrm{D} 2$ & 0,07 & $-3,07 *$ \\
\hline
\end{tabular}




\section{Anexo J}

Efeito Total com Valores dos Parâmetros Não-padronizados (continuação)

\begin{tabular}{|c|c|c|}
\hline Equações & $E P$ & Teste- $z$ \\
\hline $\mathrm{Q} 2=1,00 \mathrm{SQPN}-0,20 \mathrm{SQP}+1,00 \mathrm{E} 30+1,00 \mathrm{D} 1$ & 0,07 & $-3,07 *$ \\
\hline \multirow[t]{3}{*}{$\mathrm{Q} 3=1,44 \mathrm{SQPE}-0,29 \mathrm{SQP}+1,00 \mathrm{E} 31+1,44 \mathrm{D} 2$} & 0,20 & $7,19 *$ \\
\hline & 0,11 & $-2,60 *$ \\
\hline & 0,20 & $7,19 *$ \\
\hline \multirow[t]{3}{*}{$\mathrm{Q} 4=2,16 \mathrm{SQPN}-0,43 \mathrm{SQP}+1,00 \mathrm{E} 32+2,16 \mathrm{D} 1$} & 0,40 & $5,35 *$ \\
\hline & 0,19 & $-2,29 *$ \\
\hline & 0,40 & $5,35^{*}$ \\
\hline \multirow[t]{3}{*}{$\mathrm{Q} 5=1,06 \mathrm{SQPN}-0,21 \mathrm{SQP}+1,00 \mathrm{E} 33+1,06 \mathrm{D} 1$} & 0,21 & $5,12 *$ \\
\hline & 0,09 & $-2,35^{*}$ \\
\hline & 0,21 & $5,12 *$ \\
\hline \multirow[t]{3}{*}{$\mathrm{Q} 6=1,53 \mathrm{SQPE}-0,31 \mathrm{SQP}+1,00 \mathrm{E} 34+1,53 \mathrm{D} 2$} & 0,23 & $6,74 *$ \\
\hline & 0,12 & $-2,50 *$ \\
\hline & 0,23 & $6,74^{*}$ \\
\hline \multirow[t]{3}{*}{$\mathrm{Q} 7=2,04 \mathrm{SQPE}-0,41 \mathrm{SQP}+1,00 \mathrm{E} 35+2,04 \mathrm{D} 2$} & 0,30 & $6,86^{*}$ \\
\hline & 0,17 & $-2,45^{*}$ \\
\hline & 0,30 & $6,86^{*}$ \\
\hline \multirow{3}{*}{$\mathrm{Q} 8=1,69 \mathrm{SQPN}-0,34 \mathrm{SQP}+1,00 \mathrm{E} 36+1,69 \mathrm{D} 1$} & 0,34 & $4,92 *$ \\
\hline & 0,14 & $-2,44^{*}$ \\
\hline & 0,34 & $4,92 *$ \\
\hline \multirow[t]{3}{*}{$\mathrm{Q} 9=1,78 \mathrm{SQPE}-0,36 \mathrm{SQP}+1,00 \mathrm{E} 37+1,78 \mathrm{D} 2$} & 0,26 & $6,85^{*}$ \\
\hline & 0,15 & $-2,45^{*}$ \\
\hline & 0,26 & $6,85^{*}$ \\
\hline $\mathrm{SQPN}=-0,20 \mathrm{SQP}+1,00 \mathrm{D} 1$ & - & - \\
\hline $\mathrm{SQPE}=-0,20 \mathrm{SQP}+1,00 \mathrm{D} 2$ & - & - \\
\hline $\mathrm{COA}=0,28 \mathrm{SQP}+1,00 \mathrm{D} 4$ & - & - \\
\hline $\mathrm{COCS}=0,52 \mathrm{SQP}+1,00 \mathrm{D} 5$ & - & - \\
\hline $\mathrm{COCI}=0,77 \mathrm{SQP}+1,00 \mathrm{D} 6$ & - & - \\
\hline $\mathrm{COCR}=0,73 \mathrm{SQP}+1,00 \mathrm{D} 7$ & - & - \\
\hline $\mathrm{COCP}=0,83 \mathrm{SQP}+1,00 \mathrm{D} 8$ & - & - \\
\hline $\mathrm{IS}=\mathbf{- 0 , 3 5 C O A}+2,58 \mathrm{COCS}+0,45 \mathrm{COCI}+0,41 \mathrm{COCR}+$ & 0,14 & $-2,48^{*}$ \\
\hline 1,92COCP - 0,41SQP -0,35D4 + 2,58D5 + 0,45D6 + & 4,65 & 0,56 \\
\hline \multirow[t]{9}{*}{$0,41 \mathrm{D} 7+1,92 \mathrm{D} 8+1,00 \mathrm{D} 9$} & 0,57 & 0,80 \\
\hline & 0,62 & 0,67 \\
\hline & 1,69 & 1,14 \\
\hline & 8,03 & $-0,05$ \\
\hline & 0,14 & $-2,48^{*}$ \\
\hline & 4,65 & 0,56 \\
\hline & 0,57 & 0,80 \\
\hline & 0,62 & 0,67 \\
\hline & 1,69 & 1,14 \\
\hline
\end{tabular}

Nota: Significância testada por meio do teste- $z$ (quociente entre parâmetro e $E P$ ). Parâmetros significativos para os construtos em negrito. $* p<0,05$. 


\section{Anexo K}

Efeito Total com Valores dos Parâmetros Padronizados

\section{Equações}

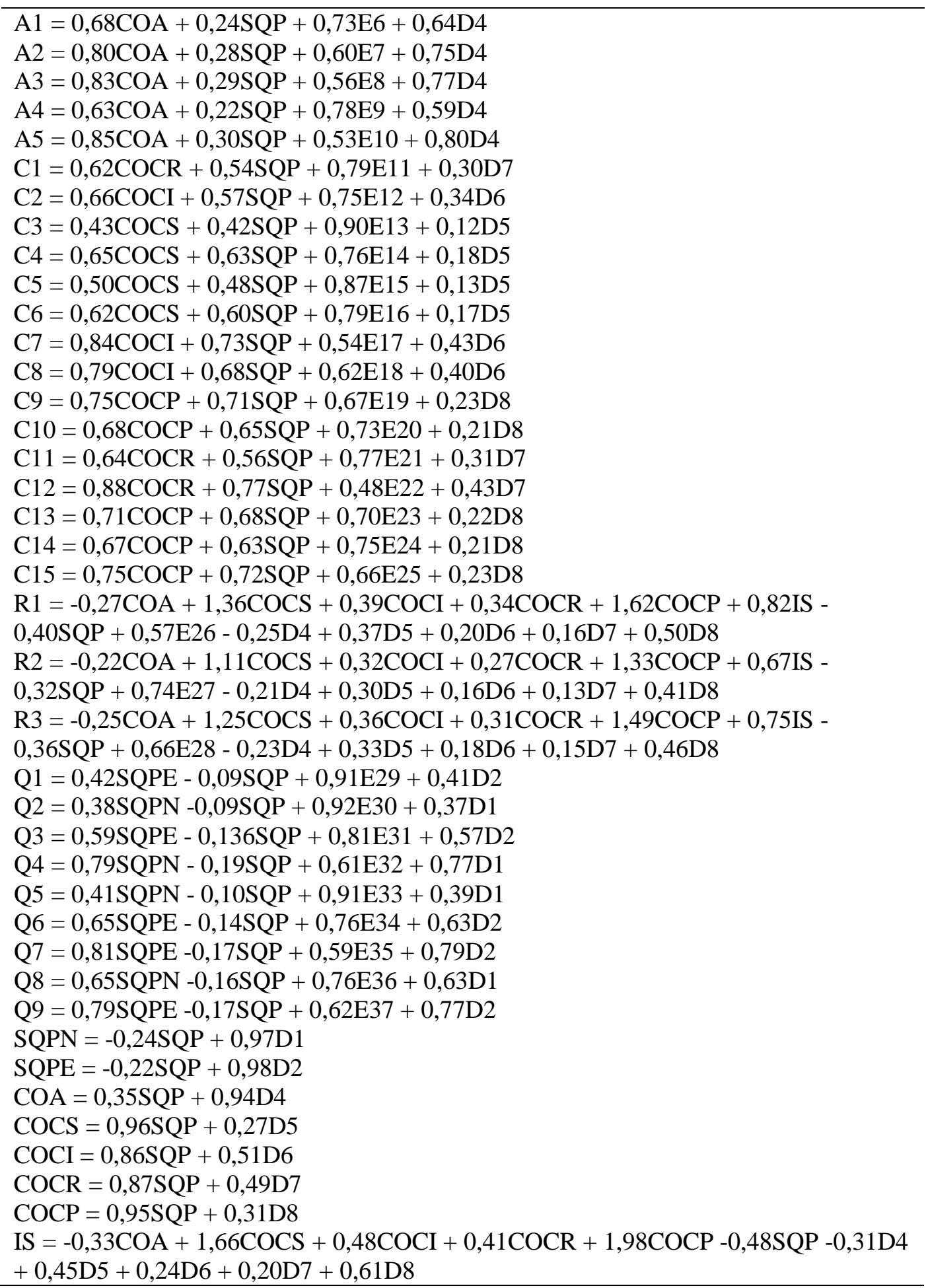




\section{Anexo L}

Efeito Indireto com Valores dos Parâmetros Não-padronizados

\begin{tabular}{|c|c|c|}
\hline Equações & $E P$ & Teste- $z$ \\
\hline $\mathrm{A} 1=0,28 \mathrm{SQP}+1,00 \mathrm{D} 4$ & 0,06 & $5,07 *$ \\
\hline \multirow[t]{2}{*}{$\mathrm{A} 2=0,27 \mathrm{SQP}+0,96 \mathrm{D} 4$} & 0,06 & $4,57 *$ \\
\hline & 0,08 & $12,37^{*}$ \\
\hline \multirow[t]{2}{*}{$\mathrm{A} 3=0,31 \mathrm{SQP}+1,11 \mathrm{D} 4$} & 0,07 & $4,36^{*}$ \\
\hline & 0,09 & $12,27^{*}$ \\
\hline \multirow[t]{2}{*}{$\mathrm{A} 4=0,23 \mathrm{SQP}+0,83 \mathrm{D} 4$} & 0,06 & $4,05^{*}$ \\
\hline & 0,10 & $8,33^{*}$ \\
\hline \multirow[t]{2}{*}{$\mathrm{A} 5=0,33 \mathrm{SQP}+1,17 \mathrm{D} 4$} & 0,07 & $4,41 *$ \\
\hline & 0,10 & $11,95^{*}$ \\
\hline $\mathrm{C} 1=0,73 \mathrm{SQP}+1,00 \mathrm{D} 7$ & 0,07 & $10,84 *$ \\
\hline $\mathrm{C} 2=0,77 \mathrm{SQP}+1,00 \mathrm{D} 6$ & 0,07 & $10,96^{*}$ \\
\hline $\mathrm{C} 3=0,52 \mathrm{SQP}+1,00 \mathrm{D} 5$ & 0,07 & $7,16^{*}$ \\
\hline \multirow[t]{2}{*}{$\mathrm{C} 4=0,76 \mathrm{SQP}+1,45 \mathrm{D} 5$} & 0,20 & $3,72 *$ \\
\hline & 0,21 & $7,05^{*}$ \\
\hline \multirow[t]{2}{*}{$\mathrm{C} 5=0,60 \mathrm{SQP}+1,15 \mathrm{D} 5$} & 0,18 & $3,36^{*}$ \\
\hline & 0,20 & $5,74 *$ \\
\hline \multirow[t]{2}{*}{$\mathrm{C} 6=0,70 \mathrm{SQP}+1,34 \mathrm{D} 5$} & 0,20 & $3,52 *$ \\
\hline & 0,21 & $6,45^{*}$ \\
\hline \multirow[t]{2}{*}{$\mathrm{C} 7=0,95 \mathrm{SQP}+1,24 \mathrm{D} 6$} & 0,16 & $5,86^{*}$ \\
\hline & 0,11 & $11,46^{*}$ \\
\hline \multirow[t]{2}{*}{$\mathrm{C} 8=0,82 \mathrm{SQP}+1,07 \mathrm{D} 6$} & 0,14 & $6,01 *$ \\
\hline & 0,09 & $11,82^{*}$ \\
\hline $\mathrm{C} 9=0,83 \mathrm{SQP}+1,00 \mathrm{D} 8$ & 0,06 & $14,94 *$ \\
\hline \multirow[t]{2}{*}{$\mathrm{C} 10=0,74 \mathrm{SQP}+0,90 \mathrm{D} 8$} & 0,09 & $8,22 *$ \\
\hline & 0,07 & $13,29 *$ \\
\hline \multirow[t]{2}{*}{$\mathrm{C} 11=0,74 \mathrm{SQP}+1,01 \mathrm{D} 7$} & 0,12 & $5,93 *$ \\
\hline & 0,10 & $10,49 *$ \\
\hline \multirow[t]{2}{*}{$\mathrm{C} 12=1,00 \mathrm{SQP}+1,37 \mathrm{D} 7$} & 0,17 & $5,73 *$ \\
\hline & 0,12 & $11,29 *$ \\
\hline \multirow[t]{2}{*}{$\mathrm{C} 13=0,80 \mathrm{SQP}+0,97 \mathrm{D} 8$} & 0,10 & $8,16^{*}$ \\
\hline & 0,07 & $13,28 *$ \\
\hline \multirow[t]{2}{*}{$\mathrm{C} 14=0,671 \mathrm{SQP}+0,81 \mathrm{D} 8$} & 0,09 & $7,87 *$ \\
\hline & 0,07 & $12,10^{*}$ \\
\hline \multirow[t]{2}{*}{$\mathrm{C} 15=0,89 \mathrm{SQP}+1,07 \mathrm{D} 8$} & 0,11 & $8,22 *$ \\
\hline & 0,08 & $14,07 *$ \\
\hline $\mathrm{R} 1=-0,35 \mathrm{COA}+2,58 \mathrm{COCS}+0,45 \mathrm{COCI}+0,41 \mathrm{COCR}+1,92 \mathrm{COCP}$ & 0,14 & $-2,48 *$ \\
\hline \multirow[t]{10}{*}{$-0,41 \mathrm{SQP}-0,35 \mathrm{D} 4+2,58 \mathrm{D} 5+0,45 \mathrm{D} 6+0,41 \mathrm{D} 7+1,92 \mathrm{D} 8+1,00 \mathrm{D} 9$} & 4,61 & 0,56 \\
\hline & 0,57 & 0,80 \\
\hline & 0,62 & 0,67 \\
\hline & 1,69 & 1,14 \\
\hline & 8,03 & $-0,05$ \\
\hline & 0,14 & $-2,48 *$ \\
\hline & 4,65 & 0,56 \\
\hline & 0,57 & 0,80 \\
\hline & 0,62 & 0,67 \\
\hline & 1,69 & 1,14 \\
\hline
\end{tabular}




\section{Anexo L}

Efeito Indireto dos Parâmetros com Valores Não-padronizados (continuação)

\begin{tabular}{|c|c|c|}
\hline Equações & $E P$ & Teste- $z$ \\
\hline $\mathrm{R} 2=-0,37 \mathrm{COA}+2,76 \mathrm{COCS}+0,49 \mathrm{COCI}+0,44 \mathrm{COCR}+2,05 \mathrm{COCP}$ & 0,13 & $-2,78^{*}$ \\
\hline \multirow{11}{*}{$-0,43 \mathrm{SQP}-0,37 \mathrm{D} 4+2,76 \mathrm{D} 5+0,49 \mathrm{D} 6+0,44 \mathrm{D} 7+2,05 \mathrm{D} 8+1,07 \mathrm{D} 9$} & 5,00 & 0,55 \\
\hline & 0,61 & 0,79 \\
\hline & 0,68 & 0,66 \\
\hline & 1,82 & 1,13 \\
\hline & 8,58 & $-0,05$ \\
\hline & 0,13 & $-2,78^{*}$ \\
\hline & 5,00 & 0,55 \\
\hline & 0,61 & 0,79 \\
\hline & 0,68 & 0,66 \\
\hline & 1,82 & 1,13 \\
\hline & 0,15 & $7,26 *$ \\
\hline $\mathrm{R} 3=-0,38 \mathrm{COA}+2,79 \mathrm{COCS}+0,49 \mathrm{COCI}+045 \mathrm{COCR}+2,07 \mathrm{COCP}-$ & 0,16 & $-2,40 *$ \\
\hline \multirow[t]{11}{*}{$0,44 \mathrm{SQP}-0,38 \mathrm{D} 4+2,79 \mathrm{D} 5+0,49 \mathrm{D} 6+0,45 \mathrm{D} 7+2,07 \mathrm{D} 8+1,08 \mathrm{D} 9$} & 4,99 & 0,56 \\
\hline & 0,61 & 0,80 \\
\hline & 0,68 & 0,66 \\
\hline & 1,82 & 1,14 \\
\hline & 8,68 & $-0,05$ \\
\hline & 0,16 & $-2,40 *$ \\
\hline & 4,99 & 0,56 \\
\hline & 0,61 & 0,80 \\
\hline & 0,68 & 0,66 \\
\hline & 1,82 & 1,14 \\
\hline & 0,15 & $7,03 *$ \\
\hline $\mathrm{Q} 1=-0,20 \mathrm{SQP}+1,00 \mathrm{D} 2$ & 0,07 & $-3,07 *$ \\
\hline $\mathrm{Q} 2=-0,20 \mathrm{SQP}+1,00 \mathrm{D} 1$ & 0,07 & $-3,07 *$ \\
\hline \multirow[t]{2}{*}{$\mathrm{Q} 3=-0,29 \mathrm{SQP}+1,44 \mathrm{D} 2$} & 0,11 & $-2,60 *$ \\
\hline & 0,20 & $7,19 *$ \\
\hline \multirow[t]{2}{*}{$\mathrm{Q} 4=-0,43 \mathrm{SQP}+2,16 \mathrm{D} 1$} & 0,19 & $-2,29 *$ \\
\hline & 0,40 & $5,35^{*}$ \\
\hline \multirow[t]{2}{*}{$\mathrm{Q} 5=-0,21 \mathrm{SQP}+1,06 \mathrm{D} 1$} & 0,09 & $-2,35^{*}$ \\
\hline & 0,21 & $5,12 *$ \\
\hline \multirow[t]{2}{*}{$\mathrm{Q} 6=-0,31 \mathrm{SQP}+1,53 \mathrm{D} 2$} & 0,12 & $-2,50 *$ \\
\hline & 0,23 & $6,74 *$ \\
\hline \multirow[t]{2}{*}{$\mathrm{Q} 7=-0,41 \mathrm{SQP}+2,04 \mathrm{D} 2$} & 0,17 & $-2,45^{*}$ \\
\hline & 0,30 & $6,86^{*}$ \\
\hline \multirow[t]{2}{*}{$\mathrm{Q} 8=-0,34 \mathrm{SQP}+1,69 \mathrm{D} 1$} & 0,14 & $-2,44 *$ \\
\hline & 0,34 & $4,92 *$ \\
\hline \multirow[t]{2}{*}{$\mathrm{Q} 9=-0,36 \mathrm{SQP}+1,78 \mathrm{D} 2$} & 0,15 & $-2,45^{*}$ \\
\hline & 0,26 & $6,85^{*}$ \\
\hline \multirow[t]{6}{*}{$\mathrm{IS}=3,49 \mathrm{SQP}-0,35 \mathrm{D} 4+2,58 \mathrm{D} 5+0,45 \mathrm{D} 6+0,41 \mathrm{D} 7+1,92 \mathrm{D} 8$} & 3,90 & 0,89 \\
\hline & 0,14 & $-2,48 *$ \\
\hline & 4,65 & 0,56 \\
\hline & 0,57 & 0,80 \\
\hline & 0,62 & 0,67 \\
\hline & 1,69 & 1,14 \\
\hline
\end{tabular}




\section{Anexo M}

Efeito Indireto com Valores dos Parâmetros Padronizados

\section{Equações}

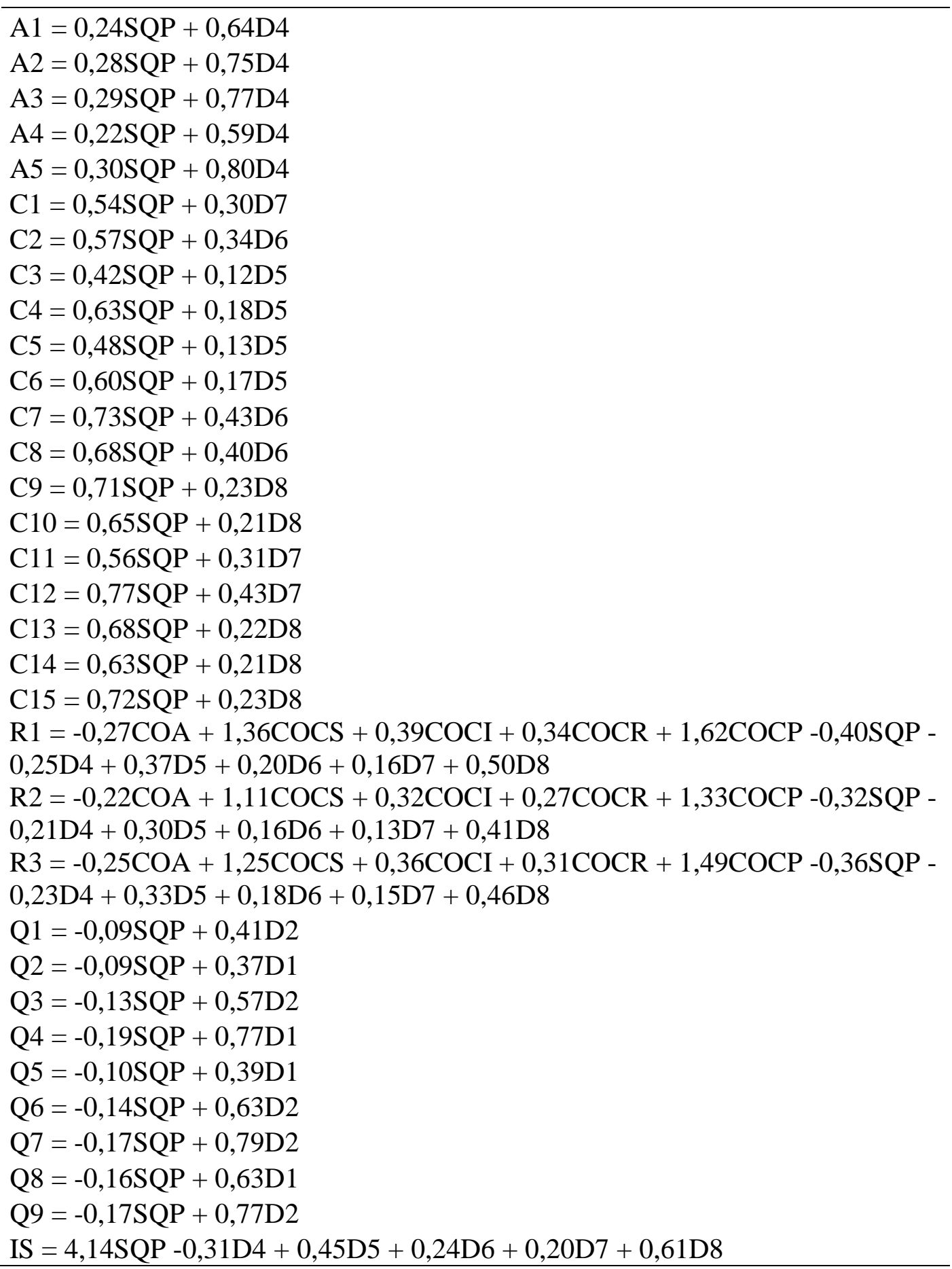




\section{Anexo N}

Solução Padronizada para Variáveis Observáveis e Latentes

Equações

$R^{2}$

\begin{tabular}{|c|c|}
\hline $\mathrm{A} 1=0,68 \mathrm{COA}+0,73 \mathrm{E} 6$ & 0,46 \\
\hline $\mathrm{A} 2=0,80 \mathrm{COA}+0,60 \mathrm{E} 7$ & 0,64 \\
\hline $\mathrm{A} 3=0,83 \mathrm{COA}+0,56 \mathrm{E} 8$ & 0,68 \\
\hline $\mathrm{A} 4=0,63 \mathrm{COA}+0,78 \mathrm{E} 9$ & 0,40 \\
\hline $\mathrm{A} 5=0,85 \mathrm{COA}+0,53 \mathrm{E} 10$ & 0,72 \\
\hline $\mathrm{C} 1=0,62 \mathrm{COCR}+0,78 \mathrm{E} 11$ & 0,39 \\
\hline $\mathrm{C} 2=0,66 \mathrm{COCI}+0,75 \mathrm{E} 12$ & 0,44 \\
\hline $\mathrm{C} 3=0,43 \mathrm{COCS}+0,90 \mathrm{E} 13$ & 0,19 \\
\hline $\mathrm{C} 4=0,65 \mathrm{COCS}+0,76 \mathrm{E} 14$ & 0,43 \\
\hline $\mathrm{C} 5=0,50 \mathrm{COCS}+0,87 \mathrm{E} 15$ & 0,25 \\
\hline $\mathrm{C} 6=0,62 \mathrm{COCS}+0,79 \mathrm{E} 16$ & 0,38 \\
\hline $\mathrm{C} 7=0,84 \mathrm{COCI}+0,54 \mathrm{E} 17$ & 0,71 \\
\hline $\mathrm{C} 8=0,79 \mathrm{COCI}+0,62 \mathrm{E} 18$ & 0,62 \\
\hline $\mathrm{C} 9=0,75 \mathrm{COCP}+0,67 \mathrm{E} 19$ & 0,56 \\
\hline $\mathrm{C} 10=0,68 \mathrm{COCP}+0,73 \mathrm{E} 20$ & 0,47 \\
\hline $\mathrm{C} 11=0,64 \mathrm{COCR}+0,77 \mathrm{E} 21$ & 0,41 \\
\hline $\mathrm{C} 12=0,88 \mathrm{COCR}+0,48 \mathrm{E} 22$ & 0,77 \\
\hline $\mathrm{C} 13=0,71 \mathrm{COCP}+0,70 \mathrm{E} 23$ & 0,51 \\
\hline $\mathrm{C} 14=0,67 \mathrm{COCP}+0,75 \mathrm{E} 24$ & 0,44 \\
\hline $\mathrm{C} 15=0,75 \mathrm{COCP}+0,66 \mathrm{E} 25$ & 0,57 \\
\hline $\mathrm{R} 1=0,82 \mathrm{IS}+0,58 \mathrm{E} 26$ & 0,67 \\
\hline $\mathrm{R} 2=0,67 \mathrm{IS}+0,74 \mathrm{E} 27$ & 0,45 \\
\hline $\mathrm{R} 3=0,75 \mathrm{IS}+0,66 \mathrm{E} 28$ & 0,56 \\
\hline $\mathrm{SQPN}=-0,24 \mathrm{SQP}+0,97 \mathrm{D} 1$ & 0,06 \\
\hline $\mathrm{SQPE}=-0,22 \mathrm{SQP}+0,98 \mathrm{D} 2$ & 0,05 \\
\hline $\mathrm{Q} 1=0,42 \mathrm{SQPE}+0,91 \mathrm{E} 29$ & 0,18 \\
\hline $\mathrm{Q} 2=0,38 \mathrm{SQPN}+0,92 \mathrm{E} 30$ & 0,15 \\
\hline $\mathrm{Q} 3=0,59 \mathrm{SQPE}+0,81 \mathrm{E} 31$ & 0,34 \\
\hline $\mathrm{Q} 4=0,79 \mathrm{SQPN}+0,61 \mathrm{E} 32$ & 0,63 \\
\hline $\mathrm{Q} 5=0,41 \mathrm{SQPN}+0,91 \mathrm{E} 33$ & 0,17 \\
\hline $\mathrm{Q} 6=0,65 \mathrm{SQPE}+0,76 \mathrm{E} 34$ & 0,42 \\
\hline $\mathrm{Q} 7=0,81 \mathrm{SQPE}+0,59 \mathrm{E} 35$ & 0,65 \\
\hline $\mathrm{Q} 8=0,65 \mathrm{SQPN}+0,76 \mathrm{E} 36$ & 0,42 \\
\hline $\mathrm{Q} 9=0,79 \mathrm{SQPE}+0,62 \mathrm{E} 37$ & 0,62 \\
\hline $\mathrm{COA}=0,35 \mathrm{SQP}+0,94 \mathrm{D} 4$ & 0,12 \\
\hline $\mathrm{COCS}=0,96 \mathrm{SQP}+0,27 \mathrm{D} 5$ & 0,93 \\
\hline $\mathrm{COCI}=0,86 \mathrm{SQP}+0,51 \mathrm{D} 6$ & 0,75 \\
\hline $\mathrm{COCR}=0,87 \mathrm{SQP}+0,49 \mathrm{D} 7$ & 0,76 \\
\hline $\mathrm{COCP}=0,95 \mathrm{SQP}+0,31 \mathrm{D} 8$ & 0,91 \\
\hline $\begin{array}{l}\mathrm{IS}=-0,33 \mathrm{COA}+1,66 \mathrm{COCS}+0,48 \mathrm{COCI}+0,41 \mathrm{COCR}+1,98 \mathrm{COCP}- \\
4,62 \mathrm{SQP}+0,00 \mathrm{D} 9\end{array}$ & 1,00 \\
\hline
\end{tabular}

